\title{
3. Freiwilliges Engagement und öffentliche gemeinschaftliche Aktivität
}

\author{
Claudia Vogel, Christine Hagen, Julia Simonson \& Clemens Tesch-Römer
}

\section{Kernaussagen}

Heute sind 43,6 Prozent der Wohnbevölkerung Deutschlands im Alter ab 14 Jahren freiwillig engagiert - dies entspricht 30,9 Millionen Menschen. Öffentlich aktiv sind mehr als zwei Drittel der Wohnbevölkerung Deutschlands (70,2 Prozent), diese Personen machen in mindestens einem von vierzehn Engagementbereichen mit.

In den letzten fünfzehn Jahren ist die Engagementquote stetig angestiegen - um insgesamt knapp zehn Prozentpunkte. Insbesondere zwischen 2009 und 2014 hat sich dieser Anstieg dynamisiert: Die Quote ist in einem stärkeren Maße als zuvor angestiegen. Die Zunahme des Engagements ist auf gesellschaftliche Veränderungen zurückzuführen.

Durch das methodische Vorgehen in früheren Wellen ist der Anstieg der Engagementquote bislang nicht in vollem Umfang sichtbar geworden. Als, freiwillig engagiert' wird gezählt, wer in der Befragung angibt, freiwillige oder ehrenamtliche Arbeiten oder Aufgaben außerhalb von Beruf und Familie auszuüben. Alle Selbstangaben werden zweimal überprüft (während und nach der Befragung). Von 1999 über 2004 bis 2009 wurden im Rahmen der Prüfung der Selbstangaben zunehmend mehr Personen als nicht-engagiert eingestuft: Während die geprüften Quoten nur moderat stiegen (34,0 Prozent, 35,7 Prozent und 35,9 Prozent), zeigen die ungeprüften Quoten einen deutlichen Anstieg des Engagements (35,3 Prozent, 37,6 Prozent und 39,8 Prozent). Dieser Anstieg setzt sich 2014 noch einmal dynamisiert fort: Nun beträgt die Quote 43,6 Prozent (geprüft) beziehungsweise 44,3 Prozent (ungeprüft).

Die Beteiligung am Engagement unterscheidet sich zwischen Bevölkerungsgruppen deutlich. Frauen engagieren sich mit 41,5 Prozent seltener freiwillig als Männer mit 45,7 Prozent. In den Altersgruppen 14 bis 29 Jahre und 30 bis 49 Jahre liegen die Anteile Engagierter am höchsten. Den geringsten Anteil von freiwillig Engagierten weisen Personen im Alter von 65 und mehr Jahren auf. Personen mit hohem Schulabschluss engagieren sich zu einem deutlich höheren Anteil als Personen mit mittlerer und niedriger Schulbildung.

In allen Bevölkerungsgruppen ist ein Anstieg des freiwilligen Engagements zu beobachten, dieser ist jedoch unterschiedlich stark. Frauen haben ihr Engagement zwischen 1999 und 2014 deutlicher ausgeweitet als Männer. Somit nähern sich die Quoten der Frauen und der Männer etwas an. Das Engagement der jüngeren sowie der älteren Personen hat im Vergleich zum Engagement der mittleren Altersgruppen in den letzten fünfzehn Jahren stärker zugenommen. Die Unterschiede zwischen den Bildungsgruppen haben sich vergrößert, da das Engagement bei Personen mit hoher Bildung zwischen 1999 und 2014 deutlich stärker gestiegen ist als das niedriggebildeter Personen. 
Zwischen den Engagementbereichen finden sich deutliche Unterschiede. Sport und Bewegung ist der gesellschaftliche Bereich, in dem sich die meisten Menschen freiwillig engagieren. Danach folgen die Bereiche Schule oder Kindergarten, Kultur und Musik, Soziales sowie Kirche oder Religion.

\subsection{Einleitung}

Ein Hauptziel des Freiwilligensurveys war und ist es, einen umfassenden Überblick über das Feld des freiwilligen Engagements der Menschen zu geben, die in Deutschland leben (von Rosenbladt 2001: 17). Hierbei sollen die Vielzahl von mehr oder weniger regelmäßigen Tätigkeiten in ganz unterschiedlichen Kontexten in ihrer Differenziertheit umrissen und Aussagen über Veränderungen und Wandel der Engagierten, ihrer Aufgaben und Tätigkeiten sowie der gesellschaftlichen Bereiche ermöglicht werden, in denen Engagement stattfindet. Freiwilliges Engagement hat unterschiedliche Namen: Ehrenamt, bürgerschaftliches Engagement, Freiwilligenarbeit. So unterschiedlich diese Bezeichnungen und die Tätigkeiten im freiwilligen Engagement auch sind: Freiwilliges Engagement ist der Einsatz für andere, es bietet Gelegenheiten zur gesellschaftlichen Teilhabe und gilt als Gradmesser für die Solidarität in der Gesellschaft. Für viele Akteure im Bereich des freiwilligen Engagements sind aktueller Zustand und Veränderungen des Engagements in den unterschiedlichen gesellschaftlichen Bereichen von hohem Interesse, also beispielsweise in den Bereichen Sport, Kultur, Kirche, Schule, Gesundheit und Soziales. Zudem berichten wir auf Basis des Freiwilligensurveys über den Anteil von Personen, die gemeinschaftlich und öffentlich aktiv sind, indem sie in einem der gesellschaftlichen Engagementbereiche mitmachen, ohne dort jedoch unbedingt freiwillige Aufgaben oder Arbeiten zu übernehmen. Das Ausmaß zivilgesellschaftlicher Aktivität kann ebenso wie der Anteil freiwillig Engagierter als Indikator für den Zusammenhalt in unserer Gesellschaft betrachtet werden.

Der Freiwilligensurvey 2014 ist die vierte Welle einer Studie, die im Jahr 1999 zum ersten
Mal durchgeführt und danach in den Jahren 2004 und 2009 wiederholt wurde. Zentrale Fragen an den Freiwilligensurvey 2014 lauten: Wie hoch ist der Anteil engagierter Menschen heute? Ist dieser Anteil im Vergleich zu früheren Erhebungen gleich groß geblieben, zurückgegangen oder gestiegen? Betrachtet man gesellschaftliche Veränderungen und Trends, so ist ein Anstieg der Engagementquote zu erwarten. Freiwilliges Engagement ist in den letzten Jahren und Jahrzehnten im gesellschaftlichen Diskurs zunehmend thematisiert und durch politische Maßnahmen gefördert worden. Freiwillig und unentgeltlich ausgeübte Tätigkeiten wurden als gesellschaftliche Ressource entdeckt und verstärkt durch politische Maßnahmen gefördert. Beginnend mit der Einsetzung der Enquete-Kommission ,Zukunft des Bürgerschaftlichen Engagements im Jahr 1999 (Enquete-Kommission ,Zukunft des Bürgerschaftlichen Engagements' 2002) hat sich die Engagementpolitik nach und nach als eigenes Politikfeld herausgebildet (vgl. Hartnuß, Olk \& Klein 2011). Darüber hinaus haben sich die zivilgesellschaftlichen Rahmenbedingungen für Engagement verbessert. So ist die Zahl der Vereine und Stiftungen in den letzten Jahren stark angestiegen (Krimmer \& Priemer 2013). Zugleich hat die Zahl von Einrichtungen wie Freiwilligenagenturen oder Mehrgenerationenhäuser zugenommen, die Engagement fördern und unterstützen.

Aber auch gesellschaftliche Veränderungen wie die Bildungsexpansion können auf das freiwillige Engagement wirken. Heute verfügen mehr Menschen als früher über die Voraussetzungen, sich engagieren $\mathrm{zu}$ können. Höhergebildete haben eher die materiellen und immateriellen Ressourcen, die für freiwilliges Engagement benötigt 
werden und verfügen häufig über bessere Informationen, wo und wie sie sich engagieren können. Auch die zunehmende Erwerbspartizipation von Frauen (Brenke 2015) und von Älteren (Naumann \& Romeu Gordo 2010) könnte sich positiv auf die Beteiligung im Engagement auswirken, wenn durch die Erwerbsarbeit Gelegenheitsstrukturen für Engagement entstehen, beispielsweise für ehrenamtliche Tätigkeiten in Beiräten oder Aufsichtsräten. Allerdings könnte es hier zunehmend auch zu Zeitkonflikten zwischen Erwerbstätigkeit und Engagement kommen, insbesondere vor dem Hintergrund, dass auch der Leistungsdruck in unserer Gesellschaft steigt.

Nicht zuletzt treten in Deutschland neue Potenziale sowie Bedarfe und Anforderungen für das freiwillige Engagement durch den demografischen Wandel zu Tage. Diesen Herausforderungen widmet sich auch der von der Bundesregierung in Auftrag gegebene Zweite Engagementbericht „Demografischer Wandel und bürgerschaftliches Engagement: Der Beitrag des Engagements zur lokalen Entwicklung“. Die Bevölkerungszusammensetzung in unserer Gesellschaft, die als Gesellschaft des langen Lebens charakterisiert werden kann, wird zum einen durch einen steigenden Anteil Älterer und einen sinkenden Anteil Jüngerer geprägt und zum anderen durch internationale Zuwanderung beeinflusst. Ältere Menschen sind dabei häufig Empfängerinnen und Empfänger von freiwilliger Hilfe; sie sind aber ebenso wichtig als Personen, die sich für andere engagieren. Tendenziell ist hierdurch eher ein Anstieg des Engagements zu erwarten, auch vor dem Hintergrund der deutlich verbesserten gesundheitlichen Situation und der gestiegenen Bildungsressourcen Älterer. Hinsichtlich der Entwicklung des Engagements Jüngerer lassen sich ebenfalls unterschiedliche Erwartungen formulieren: Aufgrund der Konkurrenz zu schulischen Leistungsanforderungen, aber auch zu Freizeitaktivitäten wie Computerund Mediennutzung könnte sich das freiwillige Engagement Jüngerer rückläufig entwickeln. Andererseits sind das freiwillige Engagement und seine Bedeutung heute weithin anerkannt und in schulischen oder universitären Curricula festgeschrieben. Zudem ist vor dem Hintergrund des demografischen Wandels zu erwarten, dass sich zivilgesellschaftliche Akteure besondere Mühe geben, um jüngere freiwillig Engagierte zu werben.

Internationale Zuwanderung führt $\mathrm{zu}$ einer Zunahme der Bevölkerung mit Migrationshintergrund in Deutschland. Bisherige Untersuchungen zeigen, dass Personen mit Migrationshintergrund im Durchschnitt weniger häufig freiwillig engagiert sind als Personen ohne Migrationshintergrund (siehe Kapitel 23). Die sich insbesondere in der jüngsten Vergangenheit verändernde Zuwanderung scheint jedoch auch die Engagementbereitschaft in der Bevölkerung zu verändern. Hier ist zurzeit ein großes Engagement für Flüchtlinge und deren Integration zu beobachten (Karakayali \& Kleist 2015; Mutz, Costa-Schott, Hammer, Layritz, Lexhaller, Mayer, Poryadina, Ragus \& Wolff 2015). Erst zukünftige Untersuchungen werden zeigen, welche konkreten Auswirkungen diese Entwicklungen auf das Engagement in Deutschland insgesamt haben werden.

Wie bereits angedeutet, haben nicht alle Menschen dieselben Möglichkeiten, sich zu beteiligen. In diesem Kapitel wird deshalb nicht nur berichtet, wie hoch die Anteile freiwillig engagierter Menschen in Deutschland sind und wie sie sich in den letzten fünfzehn Jahren entwickelt haben, sondern es wird auch untersucht, ob es Unterschiede im freiwilligen Engagement zwischen verschiedenen gesellschaftlichen Gruppen gibt. Zudem wird danach gefragt, ob diese Unterschiede zwischen diesen Gruppen ähnlich stark ausgeprägt sind wie in den Jahren zuvor oder es - vor dem Hintergrund gesellschaftlicher Veränderungen - zu einer Angleichung des Engagements und der Aktivitäten gekommen ist. Betrachtet werden Unterschiede und Ähnlichkeiten im Engagement von Frauen und Männern, von Menschen unterschiedlichen Alters und mit unterschiedlicher Bildung sowie von Menschen, die in unterschiedlichen Haushaltszusammensetzungen leben. 
Im Einzelnen werden in diesem Kapitel die folgenden Fragen beantwortet:

1. Wie haben sich die Anteile freiwillig Engagierter im Fünfzehn-Jahres-Zeitraum seit dem Jahr 1999 entwickelt, in dem der Freiwilligensurvey zum ersten Mal durchgeführt wurde?

2. $\mathrm{Zu}$ welchen Anteilen sind Menschen in Deutschland freiwillig engagiert und wie unterscheiden sich Bevölkerungsgruppen bezüglich der Anteile Engagierter? Welche Unterschiede lassen sich zwischen Frauen und Männern und zwischen Alters- und Bildungsgruppen finden? Da Anstöße zum Engagement häufig auch über Familienangehörige vermittelt werden, untersuchen wir auch die Unterschiede zwischen Personen, die in
Haushalten mit eigenen Kindern und ohne eigene Kinder leben, sowie zwischen Personen, die in Haushalten mit oder ohne Partnerin beziehungsweise Partner leben.

3. $\mathrm{Zu}$ welchen Anteilen sind Menschen in Deutschland gemeinschaftlich und öffentlich aktiv, wie unterscheiden sich Bevölkerungsgruppen bezüglich der Anteile Aktiver, und wie hat sich der Anteil Aktiver seit 1999 entwickelt?

4. Gibt es Unterschiede zwischen gesellschaftlichen Bereichen im Anteil freiwillig Engagierter und öffentlich gemeinschaftlich Aktiver? Wie haben sich die Anteile freiwillig engagierter und öffentlich gemeinschaftlich aktiver Menschen in den gesellschaftlichen Bereichen seit dem Jahr 1999 entwickelt?

\subsection{Datengrundlage}

Die in diesem Kapitel berichteten Befunde basieren auf gewichteten Analysen. Für die Gewichtung wurden in allen Erhebungsjahren dieselben Gewichtungsmerkmale berücksichtigt. Dabei handelt es sich um die Designgewichtung, die sich auf die Auswahlwahrscheinlichkeit einer Person bezieht (Haushaltsgröße, Zahl der Festnetznummern und, nur für das Jahr 2014, auch die Zahl der Mobilfunknummern) und Gewichtungsmerkmale, die Abweichungen der Stichprobenverteilung von der Grundgesamtheit in bestimmten Dimensionen ausgleichen (Bundesland, Gemeindegrößenklassen, Geschlecht, Altersgruppen). Von einer Hinzunahme weiterer Gewichtungsmerkmale wie etwa des Bildungsstandes haben wir abgesehen, um die Vergleichbarkeit mit den bisher veröffentlichten Berichten zu erhalten.

Die Erfassung freiwilligen Engagements erfolgt im Freiwilligensurvey 2014 wie in den Er- hebungswellen zuvor in einem zweistufigen Verfahren: Erstens werden die Befragten nach dem Mitmachen in gesellschaftlichen Bereichen befragt (öffentliche Aktivität), zweitens nach konkreten Aufgaben und Arbeiten in den entsprechenden Bereichen (freiwilliges Engagement). Empirische Aussagen zu der Entwicklung des Engagements sowie Vergleiche unterschiedlicher Gruppen von Engagierten sind nur auf der Basis einer klaren Unterscheidung zwischen Engagierten und Nicht-Engagierten möglich. Daher wurden die Tätigkeitsangaben jener Personen anhand eines hierfür entwickelten Kriterienkataloges geprüft, die im Interview des Deutschen Freiwilligensurveys angegeben hatten, einem freiwilligen Engagement nachzugehen (siehe Kapitel 2). Die Erhebung und die Prüfschritte werden im Folgenden erläutert. 


\subsubsection{Zweistufige Erhebung des freiwilligen Engagements}

Für die Ermittlung der gemeinschaftlich öffentlichen Aktivitäten werden in der Befragung vierzehn Gesellschaftsbereiche benannt, in denen man mitmachen oder sich aktiv beteiligen kann (Kasten 1).

Das freiwillige Engagement wird im Freiwilligensurvey im zweiten Schritt dieses Verfahrens ermittelt (Kasten 2).

\section{Kasten 1: Frage zur Aktivität in vierzehn gesellschaftlichen Bereichen}

Es gibt vielfältige Möglichkeiten, außerhalb von Beruf und Familie irgendwo mitzumachen, beispielsweise in einem Verein, einer Initiative, einem Projekt oder einer Selbsthilfegruppe. Ich nenne Ihnen verschiedene Bereiche, die dafür infrage kommen. Wenn Sie an die letzten 12 Monate denken: Haben Sie sich in einem oder mehreren dieser Bereiche aktiv beteiligt? Sind Sie oder waren Sie irgendwo aktiv...

(1) ... im Bereich Sport und Bewegung

z. B. in einem Sportverein oder in einer Bewegungsgruppe?

(2) ... im Bereich Kultur und Musik

z. B. einer Theater- oder Musikgruppe, einem Chor, einer kulturellen Vereinigung oder einem Förderverein?

(3) ... im Bereich Freizeit und Geselligkeit

z. B. in einem Kleingartenverein oder einem Spieletreff?

(4) ... im sozialen Bereich

z. B. in einem Wohlfahrtsverband oder einer anderen Hilfsorganisation, in der Nachbarschaftshilfe oder einer Selbsthilfegruppe?

(5) ... im Gesundheitsbereich

z. B. als Helfer/in in der Krankenpflege oder bei Besuchsdiensten, in einem Verband oder einer Selbsthilfegruppe?

(6) ... im Bereich Schule oder Kindergarten
z. B. in der Elternvertretung, der Schülervertretung oder einem Förderverein?

(7) ... in der außerschulischen Jugendarbeit oder der Bildungsarbeit für Erwachsene

z. B. Kinder- oder Jugendgruppen betreuen oder Bildungsveranstaltungen durchführen?

(8) ... im Bereich Umwelt, Naturschutz oder Tierschutz

z. B. in einem entsprechenden Verband oder Projekt?

(9) ... im Bereich Politik und politische Interessenvertretung

z. B. in einer Partei, im Gemeinderat oder Stadtrat, in politischen Initiativen oder Solidaritätsprojekten?

(10) ... im Bereich der beruflichen Interessenvertretung außerhalb des Betriebes

z. B. in einer Gewerkschaft, einem Berufsverband, einer Arbeitsloseninitiative?

(11) ... im kirchlichen oder religiösen Bereich

z. B. in der Kirchengemeinde, einer religiösen Organisation oder einer religiösen Gemeinschaft?

(12) ... im Bereich der Justiz und der Kriminalitätsprobleme

z. B. als Schöffe/in oder Ehrenrichter/in, in der Betreuung von Straffälligen oder Verbrechensopfern?

(13) ... im Unfall- oder Rettungsdienst oder in der freiwilligen Feuerwehr?

(14) ... in einem bisher noch nicht genannten Bereich

z. B. in Bürgerinitiativen oder Arbeitskreisen zur Orts- und Verkehrsentwicklung, aber auch Bürgerclubs und sonstiges, das bisher nicht genannt wurde? 
In jedem der Bereiche, in denen eine Person angegeben hat, öffentlich aktiv zu sein, wird gefragt, ob die Person in den letzten zwölf Monaten dort freiwillig und unentgeltlich oder gegen geringe Aufwandsentschädigung Aufgaben oder Arbeiten übernommen hat und um welche Tätigkeiten es sich dabei konkret handelt. Pro Bereich können bis zu fünf Tätigkeiten angegeben werden. Die Informationen zur Art der Organisation, zur konkreten Tätigkeit und deren Namen werden mit Hilfe von drei offenen Fragen erhoben, das heißt, die Interviewerinnen und Interviewer protokollierten jeweils die Organisation, die Tätigkeit und den Namen der Tätigkeit. Abschließend wird bereichsübergreifend noch einmal nachgefragt, ob weitere noch nicht genannte Tätigkeiten vorliegen.

\section{Kasten 2: Fragen zum freiwilligen Engagement in vierzehn gesellschaftlichen Bereichen}

Uns interessiert nun, ob Sie in den Bereichen, in denen Sie aktiv sind, auch ehrenamtliche Tätigkeiten ausüben oder in Vereinen, Initiativen, Projekten oder Selbsthilfegruppen engagiert sind. Es geht um freiwillig übernommene Aufgaben und Arbeiten, die man unbezahlt oder gegen geringe Aufwandsentschädigung ausübt. Sie sagten, Sie sind im Bereich [Name des Bereichs] aktiv. Wenn Sie an die letzten 12 Monate denken:

- Haben Sie in diesem Bereich auch Aufgaben oder Arbeiten übernommen, die Sie freiwillig oder ehrenamtlich ausüben?

Wenn ja:

- Um welche Art von Gruppe, Organisation oder Einrichtung handelt es sich, in der Sie da tätig sind? Können Sie mir das bitte kurz beschreiben?

- Und was machen Sie dort konkret? Welche Aufgabe oder Arbeit üben Sie dort aus?

- Hat Ihre Tätigkeit einen Namen? Wenn ja, welchen?

- Haben Sie sich auch in den letzten vier Wochen freiwillig oder ehrenamtlich engagiert? Bitte berücksichtigen Sie alle Ihre ehrenamtlichen oder freiwilligen Tätigkeiten.

Neu im Deutschen Freiwilligensurvey 2014 ist, dass bei der Abfrage der Aktivitäten und des Engagements das Zeitfenster eine differenzierte Berücksichtigung findet. Statt nach der ,derzeitigen Aktivität oder dem ,derzeitigen' Engagement zu fragen wie in den Erhebungswellen zuvor, zielt die aktuelle Formulierung auf die Aktivität und das Engagement innerhalb der letzten zwölf Monate. Dieses Zeitfenster ermöglicht es, auch saisonales und unregelmäßiges Engagement zu erfassen und Studien miteinander zu vergleichen, die zu unterschiedlichen Jahreszeiten erhoben worden sind. Wir gehen davon aus, dass sich die Ergänzung des Zeitfensters nicht auf die ermittelte Engagementquote auswirkt (siehe zur methodischen Diskussion Abschnitt 2.4.4 in Kapitel 2 sowie Abschnitt 3.7 in diesem Kapitel). In einer zusätzlichen Frage wird nach dem Engagement in den letzten vier
Wochen gefragt (Kasten 2). Somit können nun mit dem Freiwilligensurvey erstmals unterschiedliche Zeitfenster des Engagements unterschieden werden. Diese Abfragen machen den Freiwilligensurvey international anschlussfähig, denn hier hat sich die Erhebung des Engagements mit klaren Zeitfenstern etabliert.

\subsubsection{Prüfung der Selbstangaben zum freiwilligen Engagement}

Die Selbstangaben zum freiwilligen Engagement bilden die Grundlage für eine inhaltliche Prüfung, in der bewertet wurde, ob die Angaben der dem Freiwilligensurvey zugrunde gelegten Definition freiwilligen Engagements entsprechen. Diese Prüfung erfolgte im Freiwilligensurvey 2014 in zwei Schritten: während des Interviews und nach 
dem Interview. Alle Personen, die Angaben zum freiwilligen Engagement gemacht hatten, wurden während des Interviews (nach der Erfassung der offenen Angaben) gefragt, ob es sich dabei um (eine) ehrenamtliche oder freiwillige, unbezahlte oder gegen geringe Aufwandsentschädigung ausgeübte Tätigkeit(en) handelt. Nur wenn die interviewte Person diese Nachfrage bejahte, wurde sie im weiteren Interviewverlauf als, engagiert' behandelt und erhielt alle Fragen zu Inhalten und Ausgestaltung des Engagements. Nach Abschluss der Interviews wurde eine Prüfung der offenen Angaben vorgenommen. Anhand eines für den Freiwilligensurvey 2014 entwickelten Kriterienkatalogs sowie einer Operationalisierung dieser Kriterien wurde geprüft, ob es sich bei den genannten Tätigkeiten um freiwilliges Engagement handelt oder nicht (siehe Kapitel 2).

Auch in den bisherigen Erhebungswellen 1999, 2004 und 2009 wurden die angegebenen Tätigkeiten während und nach der Befragung geprüft, allerdings mit unterschiedlichen Ergebnissen. Der Anteil der Personen, die im Verlauf der beiden Prüfschritten von, engagiert' zu ,nicht-engagiert' wechselten, lag im Jahr 1999 bei 3,5 Prozent $^{1}$, im Jahr 2004 bei 5,4 Prozent, im Jahr 2009 bei 10,4 Prozent und im Jahr 2014 bei 1,6 Prozent. Offensichtlich unterscheidet sich der Anteil der Personen, die nach der Prüfung als, nicht-engagiert' bewertet wurden, zwischen den Wellen deutlich. Im Jahr 2014 wurden weniger Tätigkeiten $\mathrm{zu}$ Nicht-Engagement recodiert als in den Jahren davor. Von 1999 über 2004 bis 2009 wurden zunehmend mehr Tätigkeiten recodiert (siehe Kapitel 2). Dies könnte zu einer Unterschätzung der Engagementquote insbesondere im Jahr 2009 geführt haben. Da die Entwicklung der Engagementquoten im Zeitvergleich stark beeinflusst ist von der vorgenommenen Prüfung der offenen Angaben zum Engagement, berichten wir in diesem Kapitel sowohl die Quoten vor Prüfung der Angaben als auch die Quoten nach Prüfung der Angaben, wenn es um den Zeitvergleich des Engagements geht. Das heißt, in Abschnitt 3.3 werden in den Abbildungen beide Quoten - vor und nach der Prüfung - ausgewiesen. Die Beschreibungen des Zeitvergleichs im Text beziehen sich - wenn nicht anders erwähnt - auf die Quoten nach der Prüfung. In den weiteren Abschnitten dieses Kapitels wird ausschließlich über die Quoten nach Prüfung auf Basis des Freiwilligensurveys 2014 berichtet.

\subsection{Entwicklung des Anteils freiwillig Engagierter von 1999 bis 2014}

Im Zeitvergleich nimmt das freiwillige Engagement der Wohnbevölkerung in Deutschland zwischen 1999 und 2014 stark zu (Abbildung 3-1). Betrachtet man die Quote der sich selbst als ,engagiert' einschätzenden Personen (Quote vor Prüfung), so ist seit 1999 ein stetiger Anstieg im Anteil engagierter Menschen an der Bevölkerung Deutschlands im Alter von 14 Jahren und älter zu beobachten (1999: 35,3 Prozent, 2004: 37,6 Pro- zent, 2009: 39,8 Prozent, 2014: 44,3 Prozent). Betrachtet man dagegen den Anteil der nach inhaltlicher Prüfung als, engagiert' bewerteten Personen (Quote nach Prüfung), so findet man lediglich einen moderaten Anstieg zwischen 1999 und 2009 sowie einen stark dynamisierten Anstieg im Jahr 2014 (1999: 34,0 Prozent, 2004: 35,7 Prozent, 2009: 35,9 Prozent, 2014: 43,6 Prozent). Der Anstieg zwischen 1999 und 2014 be-

1 Bei der Angabe für das Jahr 1999 handelt es sich um eine Schätzung, da nicht alle zur Berechnung notwendigen Informationen vorlagen. 
trägt 9,6 Prozentpunkte, der Anstieg zwischen 2009 und 2014 entspricht 7,7 Prozentpunkten.

Dieser Anstieg der Engagementquote ist als belastbarer Befund zu bewerten, der auf verschiedene gesellschaftliche Trends zurückzuführen ist, die auch zu einer Dynamisierung des Anstiegs in den letzten fünf Jahren beigetragen haben könnten. Beispielhaft seien hier nur die Bildungsexpansion, die gestiegene Erwerbsbetei- ligung sowie die wachsende Zahl von Vereinen, die Gelegenheiten für freiwilliges Engagement bieten, genannt (siehe für eine Diskussion der gesellschaftlichen Trends Abschnitt 3.7.1). Die Entscheidungen, die bei der Prüfung der Angaben zu freiwilligen Tätigkeiten in der Vergangenheit getroffen wurden, haben allerdings dazu geführt, dass der Anstieg in seiner Dynamik überzeichnet wird.

\section{Abbildung 3-1: Anteile freiwillig engagierter Personen vor und nach Prüfung im Zeitvergleich}

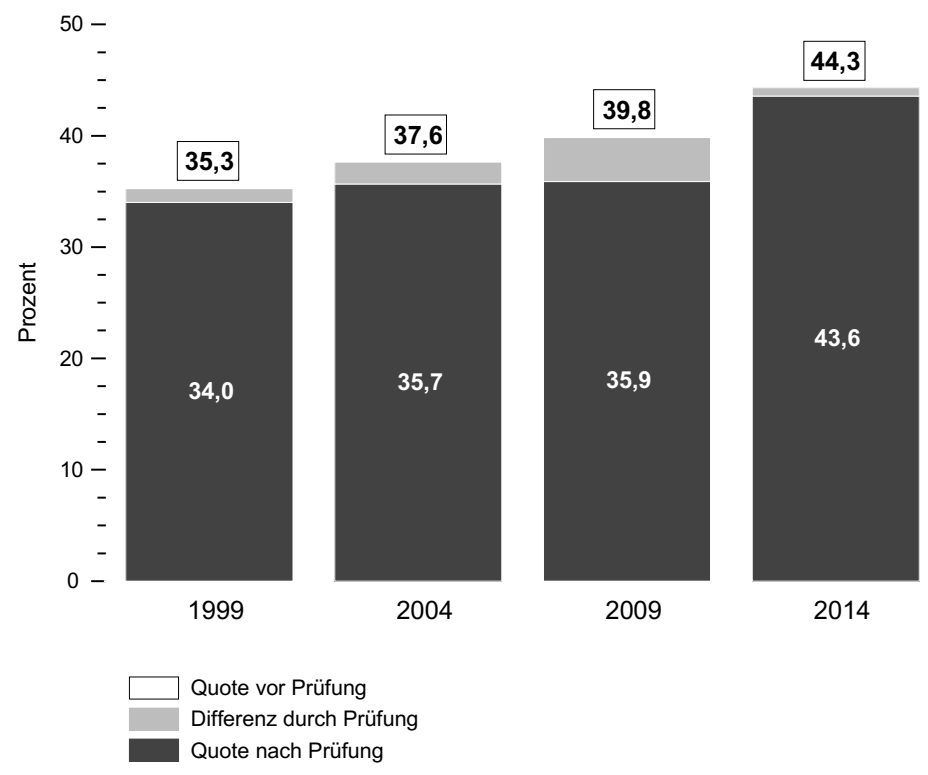

Quelle: FWS, gewichtet, eigene Berechnungen (DZA). Basis: Alle Befragten. FWS 1999 ( $n=14.922$ ), FWS 2004 ( $n=15.000)$, FWS 2009 ( $n=20.005)$, FWS 2014 ( $n=28.689$ ).

Nachrichtlich: Bei der Quote vor Prüfung im Jahr 1999 handelt es sich um eine Schätzung.

Die geschlechtsspezifischen Unterschiede im freiwilligen Engagement haben sich im Zeitverlauf etwas verringert, denn der Anstieg des Engagements fällt bei Frauen stärker aus als bei Männern (Abbildung 3-2a): Bei den Frauen ist das Engagement von 1999 zu 2014 um 11,6 Prozentpunkte gestiegen, bei den Männern im gleichen Zeitraum um 7,3 Prozentpunkte. Zwar liegt die Engagementquote der Frauen mit 41,5 Prozent noch immer unter der Quote der Männer mit 45,7
Prozent, eine Annäherung ist jedoch über die Jahre zu beobachten. Dies ist möglicherweise auf eine zunehmende Erwerbsbeteiligung von Frauen - insbesondere im Rahmen von Teilzeitbeschäftigung - zurückzuführen, wenn diese nicht nur als Begrenzung von Zeitressourcen erlebt wird, sondern durch bestehende soziale Kontakte und berufliche Tätigkeiten Gelegenheitsstrukturen für freiwilliges Engagement schafft. 
Abbildung 3-2: Anteile freiwillig engagierter Personen vor und nach Prüfung im Zeitvergleich, a) nach Geschlecht, b) nach Alter und c) nach Bildung

a) nach Geschlecht

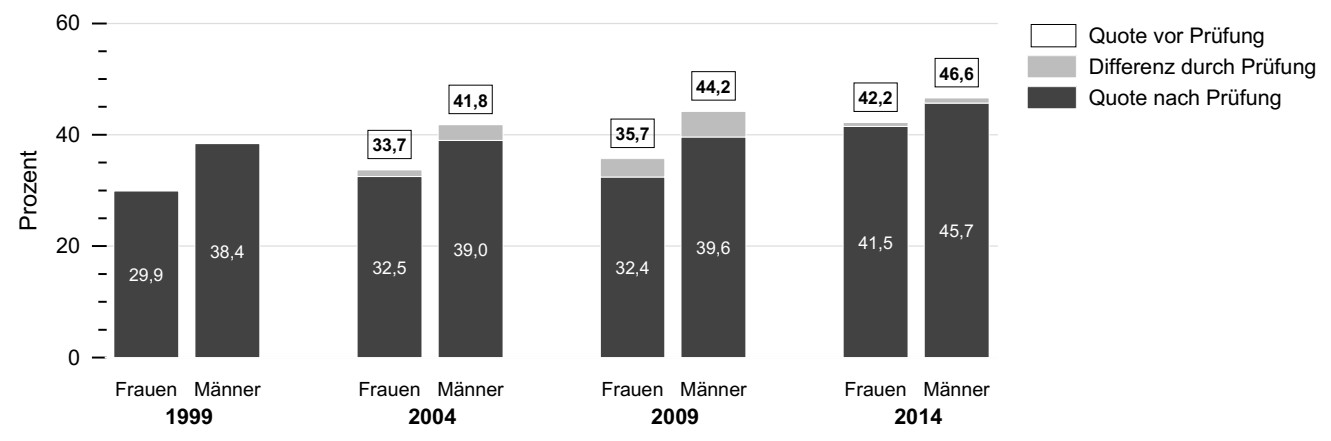

b) nach Alter

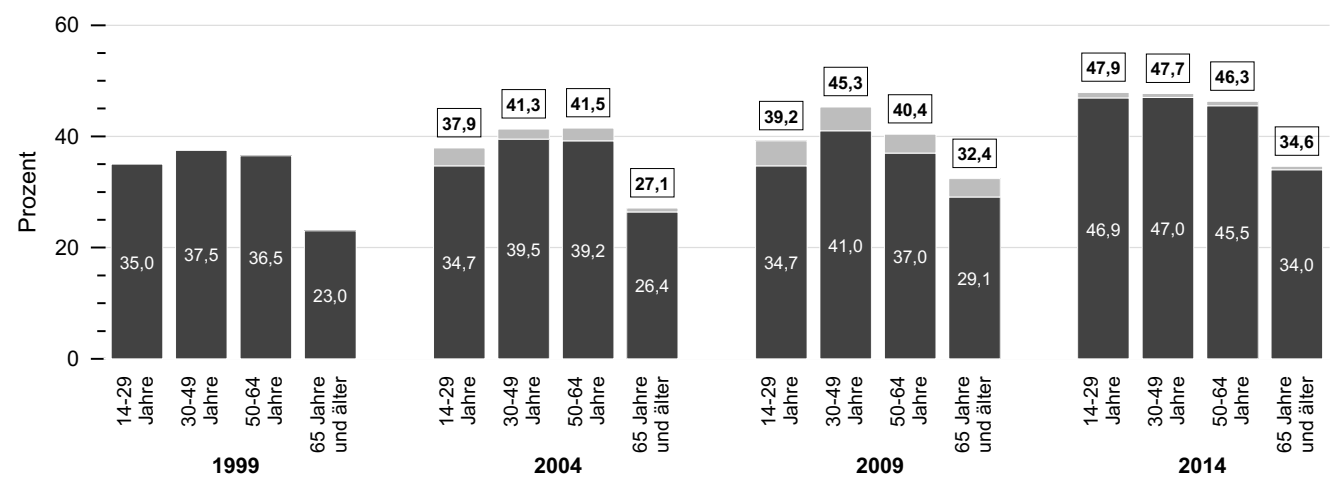

c) nach Bildung

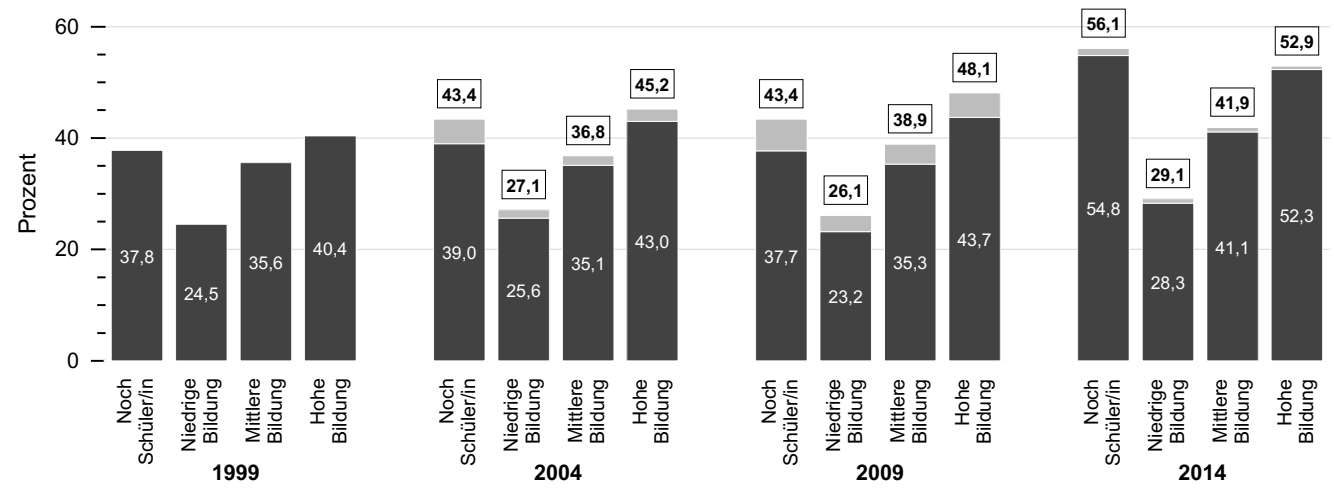

Quelle: FWS, gewichtet, eigene Berechnungen (DZA). Basis: Alle Befragten. FWS $1999(n=14.922)$, FWS 2004 $(n=15.000)$, FWS $2009(n=20.005)$, FWS $2014(n=28.689)$.

Nachrichtlich: Für 1999 werden keine Quoten vor Prüfung berichtet, da die hierfür notwendigen Individualdaten nicht vorliegen. 
Auffällig ist hierbei, dass der Anstieg des freiwilligen Engagements bei den Frauen im Vergleich $\mathrm{zu}$ den Männern insbesondere in den beiden jüngeren Altersgruppen besonders hoch ausfällt: Bei den 14- bis 29-jährigen Frauen ist ein Anstieg der Engagementquote von 29,0 Prozent im Jahr 1999 auf 45,0 Prozent im Jahr 2014, also um 16,0 Prozentpunkte, zu beobachten. Bei den gleichaltrigen Männern steigt das Engagement im gleichen Zeitraum mit 8,2 Prozentpunkten vergleichsweise mäßig an. Bei den 30 - bis 49-Jährigen fällt der Anstieg zwar etwas geringer aus, jedoch ist auch hier der Unterschied in der Entwicklung der Engagementquoten zwischen Frauen mit 12,6 Prozentpunkten und Männern mit 5,8 Prozentpunkten Anstieg in den letzten fünfzehn Jahren sehr groß (ohne Abbildung).

Bei der Differenzierung nach Alter ist im Zeitvergleich festzustellen, dass es in allen Altersgruppen einen Anstieg der Engagementquote gibt (Abbildung 3-2b). Auffällig ist dabei, dass sich die Engagementquoten 2014 bei den unteren drei Altersgruppen stark angeglichen haben, hier gibt es keine signifikanten Unterschiede mehr. Die 65-Jährigen und Älteren sind zwar mit einer Engagementquote von 34,0 Prozent am seltensten engagiert, ihr Engagement hat sich jedoch seit 1999 um 11,0 Prozentpunkte erhöht. Während die jüngste Altersgruppe in der Vergangenheit noch etwas niedrigere Engagementquoten aufwies, liegt die Engagementquote der 14- bis 29-Jährigen 2014 mit 46,9 Prozent auf ähnlich hohem Niveau wie die der 30- bis 49-Jährigen (mit 47,0 Prozent) sowie der 50- bis 64-Jährigen (mit 45,5 Prozent). Das bedeutet, dass das Engagement insbesondere bei den Jugendlichen und jungen Erwachsenen stark gestiegen ist. Dieser Anstieg könnte allerdings bereits vor 2014 eingesetzt haben: Betrachtet man die Differenzen zwischen den Engagementquoten vor und nach den Prüfungsprozeduren, so wird deutlich, dass diese Differenzen für die beiden jüngeren Altersgruppen im Jahr 2009 vergleichsweise hoch ausfallen, für die jüngste Altersgruppe auch im Jahr 2004.
Wenn nach unterschiedlichen Bildungsgruppen differenziert wird, zeigt sich in allen vier Erhebungsjahren des Freiwilligensurveys das gleiche Muster: Je höher der Bildungsabschluss, desto höher die Engagementquote. Bei Personen mit niedrigem Bildungsabschluss zeigen sich die geringste und bei denjenigen mit mittlerer Bildung eine etwas höhere und bei Personen mit einem hohen Bildungsabschluss die höchste Engagementquote (Abbildung 3-2c). Ein Anstieg der Engagementquoten ist in allen Bildungsgruppen zu verzeichnen. Allerdings ist der Anstieg, ebenfalls in Prozentpunkten ausgedrückt, über fünfzehn Jahre am deutlichsten bei Personen mit hoher Bildung, der Anstieg von 40,4 auf 52,3 Prozent beträgt 11,9 Prozentpunkte. Das freiwillige Engagement von Personen mit niedriger Bildung legte im gleichen Zeitraum lediglich um 3,8 Prozentpunkte auf 28,3 Prozent zu. Die Schere zwischen den Bildungsgruppen öffnet sich somit weiter: Die ohnehin schon beträchtlichen Unterschiede zwischen den Bildungsgruppen hinsichtlich der Beteiligung im freiwilligen Engagement nehmen weiter zu.

Zudem ist ein besonders großer Anstieg innerhalb der Gruppe der Personen zu beobachten, die noch zur Schule gehen. Hier ist die Engagementquote in den letzten fünfzehn Jahren um 17,0 Prozentpunkte gestiegen (Abbildung 3-2c). Schülerinnen und Schüler werden offensichtlich von zivilgesellschaftlichen Organisationen besonders angesprochen beziehungsweise umworben, um sich freiwillig $\mathrm{zu}$ engagieren, wie auch aus den überdurchschnittlich häufig bereitgestellten Sachzuwendungen für diese Personengruppe im Engagement deutlich wird (siehe Kapitel 14). Zudem besuchen immer mehr Schülerinnen und Schüler das Gymnasium, sodass der Anteil der Schülerinnen und Schüler, die auf einen niedrigen oder mittleren Schulabschluss zuarbeiten, geringer ist. Höhere Engagementquoten wie bei Personen mit hoher Bildung könnten hier schon bei den Schülerinnen und Schülern zu beobachten sein, die ihre Schulzeit mit einem hohen Bildungsabschluss beenden werden. 
Aber auch die Jugendlichen und jungen Erwachsenen, die bereits die Schule verlassen haben, weisen einen im Vergleich zu Älteren höheren Anstieg der Engagementquote in den letzten fünfzehn Jahren auf. Beispielsweise ist der Anteil der freiwillig Engagierten in der Altersgruppe der 14- bis 29-Jährigen mit einem mittleren Bildungsabschluss in diesem Zeitraum um 9,1 Prozentpunkte gestiegen. In den drei hier ausgewiesenen höheren Altersgruppen mit mittlerer Bildung ist ein Anstieg der Engagementquote lediglich auf wesentlich niedrigerem Niveau zu verzeichnen (ohne Abbildung). Ein weiterer auffälliger Befund ist, dass es unter den Jugendlichen und jungen Erwachsenen auch eine Gruppe gibt, die keine steigende sondern eine sinkende Engagementquote aufweist: Die 14- bis 29-jährigen Frauen mit niedriger Bildung. Dies ist bei keiner anderen Bevölkerungsgruppe zu beobachten. Waren 1999 noch 24,0 Prozent dieser Frauen engagiert, so liegt der Anteil 2014 nur noch bei 15,3 Prozent (ohne Abbildung). Bei den 14- bis 29-jährigen Männern mit niedriger
Bildung ist hingegen ein stabiler Anteil freiwillig Engagierter zu beobachten: Von ihnen waren im Jahr 1999 31,5 Prozent und im Jahr 2014 31,1 Prozent engagiert (ohne Abbildung).

Die Befunde, die einen Anstieg des freiwilligen Engagements bei Jugendlichen und jungen Erwachsenen und insbesondere bei Schülerinnen und Schülern belegen, stehen in Einklang mit Ergebnissen des Sozio-oekonomischen Panels (SOEP), die eine stark zunehmende Verbreitung ehrenamtlicher Tätigkeiten unter Jugendlichen zwischen 2001 und 2012 belegen (Hille, Arnold \& Schupp 2013). $\mathrm{Zu}$ einem anderen Ergebnis kommt dagegen die Shell Jugendstudie 2015, die bei Schülerinnen und Schülern zwischen 2002 und 2015 einen rückläufigen Anteil derer feststellt, die sich für soziale oder politische Zwecke oder für andere Menschen engagieren (Schneekloth 2015: 193). Allerdings hat laut dieser Studie im gleichen Zeitraum der Anteil der Jugendlichen zugenommen, die sich häufig in einem Projekt, einer Initiative oder einem Verein engagieren (Leven \& Schneekloth 2015: 113).

\subsection{Freiwillig Engagierte im Jahr 2014}

\subsubsection{Anteile freiwillig Engagierter}

Während im vorherigen Abschnitt die Entwicklungen des Engagements in Deutschland im Mittelpunkt standen, werden im Folgenden die Beteiligungsquoten unterschiedlicher Bevölkerungsgruppen im Engagement 2014 eingehender beschrieben. Dabei wollen wir nicht nur der Frage nachgehen, wie sich die Anteile freiwillig Engagierter zwischen Frauen und Männern sowie zwischen Alters- und Bildungsgruppen unterscheiden, sondern auch betrachten, welche Bedeutung der jeweiligen familiären Lebenssituation zukommt. Ebenso fragen wir, welche Bevölkerungsgruppen sich regelmäßiger engagieren oder mehreren freiwilligen Tätigkeiten nachgehen. Ziel ist es, wichtige Differenzierungslinien im Engagement darzustellen.

Wie bereits gezeigt, engagieren sich im Jahr 2014 insgesamt 43,6 Prozent der Wohnbevölkerung im Alter von 14 und mehr Jahren freiwillig, das heißt, sie haben in den vergangenen zwölf Monaten außerhalb von Beruf und Familie unentgeltlich Aufgaben und Arbeiten übernommen. Dies entspricht 30,9 Millionen Menschen. Frauen engagieren sich anteilig etwas seltener freiwillig als Männer, der Anteil freiwillig Engagierter beträgt 41,5 Prozent für Frauen und 45,7 Prozent für Männer (Abbildung 3-3a). Die Differenz zwischen den Geschlechtern ist mit 4,2 Prozentpunkten jedoch gering im Vergleich zu den deutlich größeren Unterschieden, die wir etwa 
zwischen Altersgruppen und Bildungsgruppen beobachten.

Am höchsten ist der Anteil der freiwillig Engagierten bei den Jüngeren: Sowohl in der Altersgruppe der 14- bis 29-Jährigen als auch bei der Gruppe der 30- bis 49-Jährigen zeigen sich mit 46,9 Prozent und 47,0 Prozent die höchsten Quoten (Abbildung 3-3a). Auch der Anteil der 50- bis 64-Jährigen liegt mit 45,5 Prozent über dem Gesamtanteil. Wesentlich niedriger ist der Anteil in der Altersgruppe der Personen im Alter von 65 und mehr Jahren mit 34,0 Prozent. Die Beteiligung im freiwilligen Engagement unterscheidet sich somit deutlich nach Altersgruppen, die auch als Ausdruck verschiedener Lebenssituationen verstanden werden können. Personen im beruflichen Ruhestand sind vergleichsweise seltener freiwillig engagiert als Personen, die noch zur Schule gehen oder in der Ausbildung sind, und als Personen in der Erwerbs- und/oder der Familienphase.

Abbildung 3-3: Anteile freiwillig engagierter Personen 2014, a) gesamt, nach Geschlecht und nach Alter, b) nach Bildung, c) nach Haushalten mit Kindern und ohne Kinder sowie nach Haushalten mit und ohne Partnerin oder Partner

a) gesamt, nach Geschlecht und nach Alter

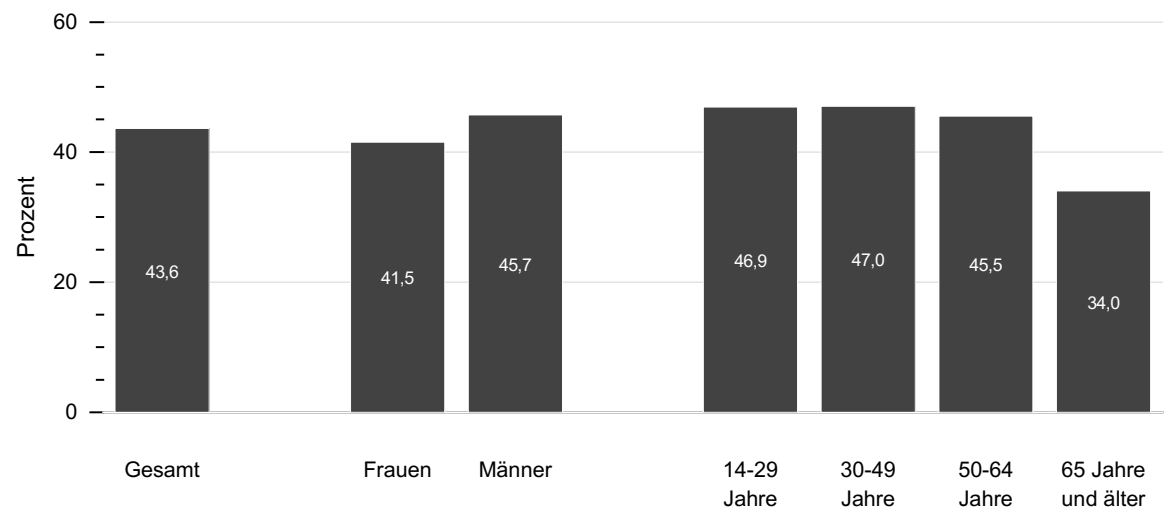

b) nach Bildung

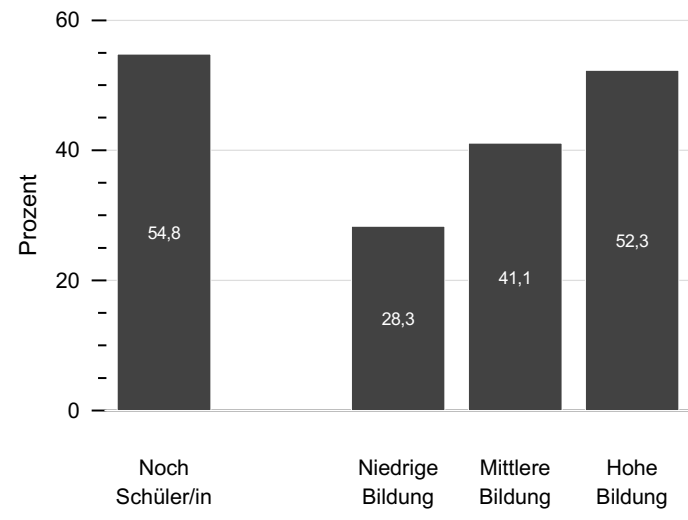


c) nach Haushalten mit Kindern und ohne Kinder sowie mit und ohne Partnerin oder Partner

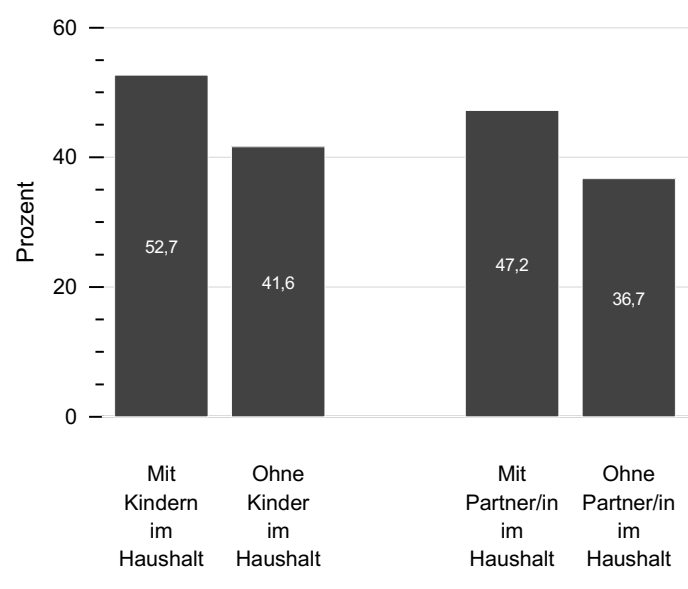

Quelle: FWS 2014, gewichtet, eigene Berechnungen (DZA). Basis: Alle Befragten ( $n=28.689$ ).

Es ist allgemein bekannt, dass Bildung eine wichtige Ressource ist, etwa um sich für das Erreichen gemeinsamer politischer Ziele einsetzen zu können. Die Ergebnisse des Deutschen Freiwilligensurveys 2014 belegen auf eindrucksvolle Weise, wie stark allein der erreichte höchste Schulabschluss die Beteiligung im freiwilligen Engagement strukturiert. Effekte der beruflichen Bildung und der Berufserfahrung sind hier also noch gar nicht berücksichtigt (zu diesen Aspekten siehe die Analysen in Kapitel 16). Am geringsten ist der Anteil freiwillig Engagierter in der Gruppe der Personen mit niedriger Bildung, also bei Personen, die keinen oder nur einen niedrigen Schulabschluss erreicht haben. Aus der Gruppe mit niedriger Bildung sind lediglich 28,3 Prozent in den letzten zwölf Monaten freiwillig engagiert (Abbildung 3-3b). Deutlich höher ist der Anteil bei Personen mit hoher Schulbildung, mehr als die Hälfte dieser Gruppe engagiert sich freiwillig in den zwölf Monaten vor der Befragung (52,3 Prozent). Am höchsten ist jedoch das Engagement in der Gruppe der Personen, die ihre Schulausbildung noch nicht abgeschlossen haben: 54,8 Prozent der Schülerinnen und Schüler engagieren sich freiwillig.
Auch nach dem Haushaltstyp zeigen sich deutliche Unterschiede. Personen, die in Haushalten mit eigenen Kindern im Alter bis zu 14 Jahren leben, engagieren sich häufiger freiwillig mit einem Anteil von 52,7 Prozent als Personen, die in anderen Haushaltskonstellationen leben (alleine, mit erwachsenen Kindern etc.) mit einem Anteil von 41,6 Prozent (Abbildung 3-3c). Darüber hinaus ist der Anteil Engagierter deutlich höher bei Personen, die mit einer Partnerin oder einem Partner im gemeinsamen Haushalt leben als bei Personen, die dies nicht tun, etwa weil sie derzeit keine Partnerin oder keinen Partner haben oder weil sie getrennte Haushalte führen (Abbildung 3-3c). Diese Unterschiede nach Haushaltstypen werden in Kapitel 16 noch differenzierter dargestellt und die Einflussgrößen auf Engagement werden dort multivariat überprüft, wobei sich ebenfalls deutliche Gruppenunterschiede zeigen (siehe Kapitel 16).

Betrachten wir die Anteile der freiwillig Engagierten etwas differenzierter nach $\mathrm{Al}$ tersgruppen (Abbildung 3-4), so finden sich insbesondere bei den Jüngeren sowie bei den Älteren heterogene Beteiligungsquoten. Es zeigt sich, dass die Gruppe mit dem höchsten Anteil freiwillig Engagierter tatsächlich die der 14- bis 
19-Jährigen ist, über die Hälfte dieser Altersgruppe engagiert sich freiwillig. Während sich auch die 20- bis 24-Jährigen mit 48,4 Prozent noch überdurchschnittlich häufig engagieren, sind es bei den darauffolgenden Altersgruppen der 25- bis 29-Jährigen (40,1 Prozent) und der 30- bis 34-Jährigen (41,2 Prozent) deutlich weniger. Möglicherweise sind hier dem freiwilligen Engagement durch beginnende Berufstätigkeit und Familiengründungsprozesse stärkere zeitliche Restriktionen gesetzt als in den vorange- henden und darauffolgenden Altersgruppen. Die Engagementquoten im mittleren und höheren Lebensalter sind vergleichsweise homogen, erst im Alter ab 70 Jahren und noch deutlicher $a b$ 75 Jahren sind die Anteile freiwillig Engagierter deutlich geringer. Dies kann mit gesundheitlichen Einschränkungen oder bestehenden Altersgrenzen im Engagement zusammenhängen, die ähnlich dem gesetzlichen Renteneintrittsalter als Höchstaltersgrenze wirken.

\section{Abbildung 3-4: Anteile freiwillig engagierter Personen 2014, nach Fünf-Jahres-Altersgruppen}

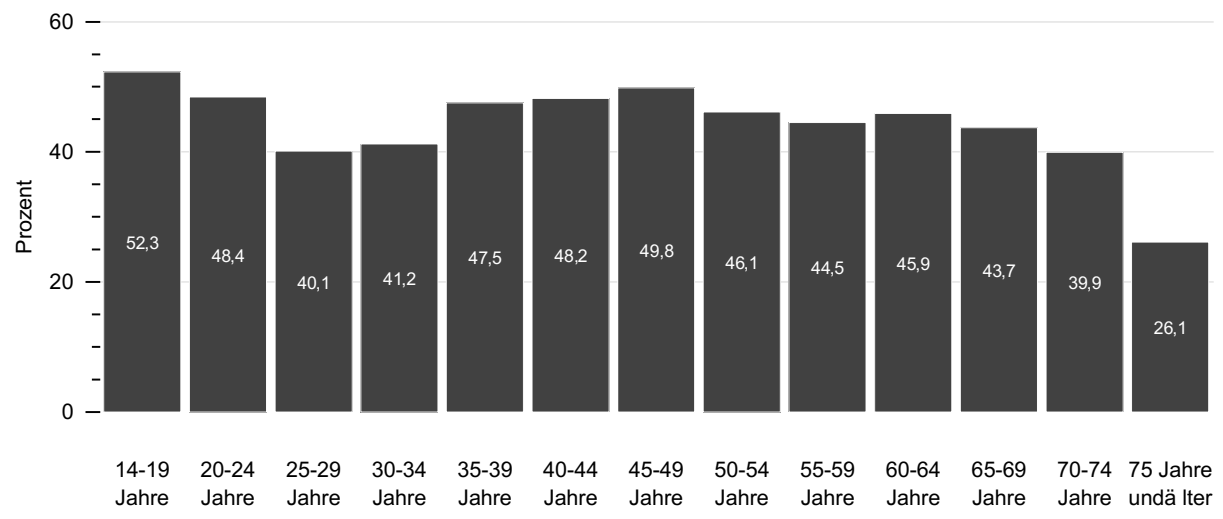

Quelle: FWS 2014, gewichtet, eigene Berechnungen (DZA). Basis: Alle Befragten ( $n=28.689$ ).

Nach Alter und Geschlecht betrachtet zeigt sich, dass sowohl bei den Frauen als auch bei den Männern der Anteil freiwillig Engagierter bei den Älteren am niedrigsten ist (Abbildung 3-5a). Die Geschlechterdifferenz ist allerdings in dieser Gruppe (65-Jährige und Ältere) am höchsten: Während der Anteil der Männer, die sich in dieser Altersgruppe in den letzten zwölf Monaten freiwillig engagiert haben, bei 39,6 Prozent liegt, beträgt der Anteil freiwillig Engagierter bei den gleichaltrigen Frauen 29,7 Prozent; sie liegt also immerhin fast zehn Prozentpunkte darunter. Die Differenz zwischen Frauen und Männern stellt sich in den jüngeren Altersgruppen nicht so stark dar. Bei den 30- bis 49-Jährigen sind sogar die Frauen $\mathrm{zu}$ einem etwas höheren Anteil als die Männer freiwillig engagiert. In diesem Alter ist der Anteil der freiwillig engagierten Frauen am höchsten, fast die Hälfte (48,1 Prozent) der 30- bis 49-jährigen Frauen ist freiwillig engagiert (Abbildung 3-5a). Das könnte daran liegen, dass vor allem der Beteiligungsgrad von Müttern mit Kindern im Kindergarten- oder Schulalter deutlich höher ist, da diese Bildungsinstitutionen auch Gelegenheiten für freiwilliges Engagement schaffen. Der Befund, dass Frauen im Bereich Schule oder Kindergarten häufig freiwillig engagiert sind, könnte für die hohe Engagementquote in dieser Lebensphase eine Erklärung bieten (siehe Bereichsprofile im Anhang dieses Kapitels). 
Abbildung 3-5: Anteile freiwillig engagierter Personen 2014, a) nach Alter und Geschlecht, b) nach Bildung und Geschlecht, c) nach Alter und Bildung

a) nach Alter und Geschlecht

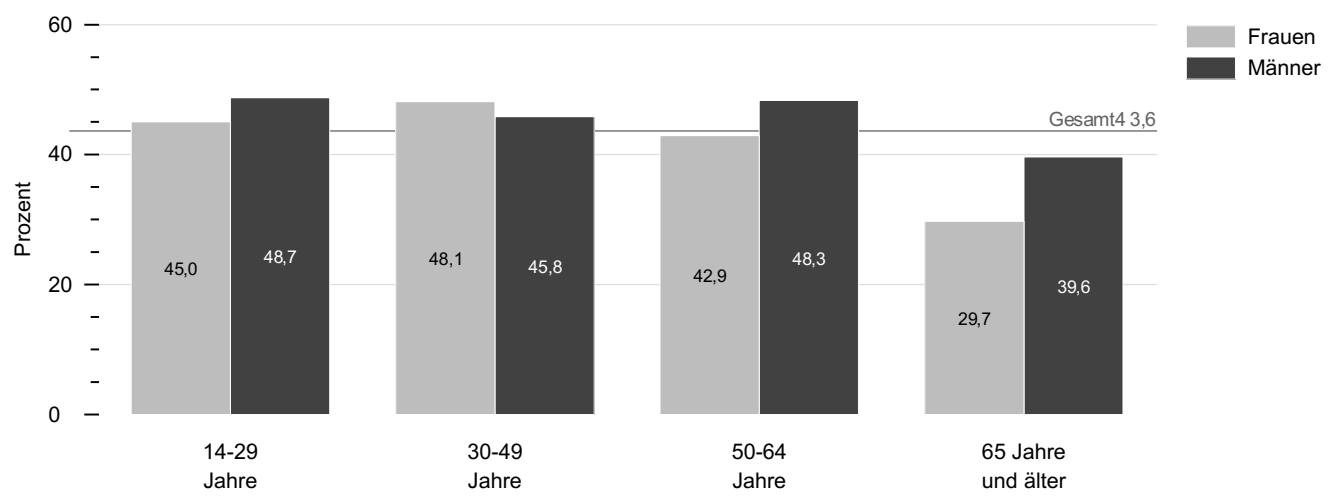

b) nach Bildung und Geschlecht

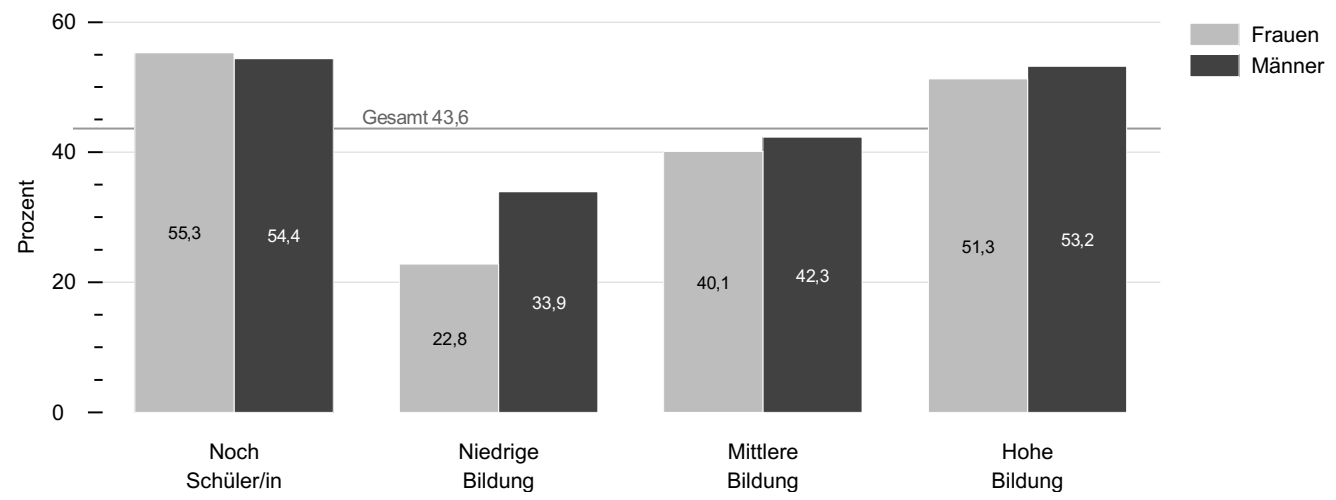

c) nach Alter und Bildung

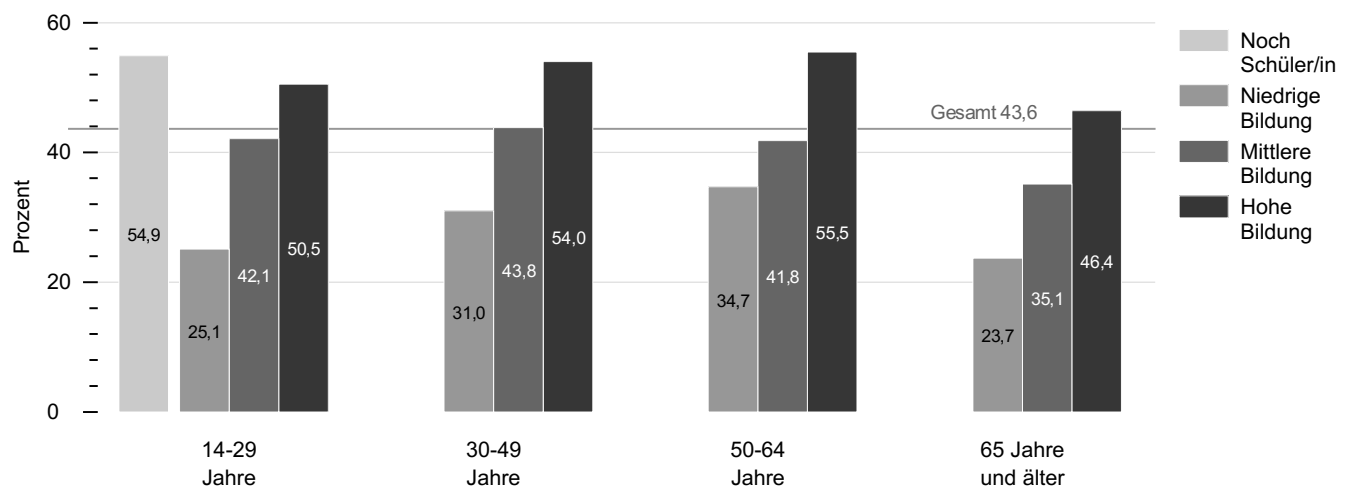

Quelle: FWS 2014, gewichtet, eigene Berechnungen (DZA). Basis: Alle Befragten ( $n=28.689$ ). 
Bei Frauen und Männern finden sich einerseits Bildungsunterschiede im Sinne eines Bildungsgradienten, insofern, dass bei beiden Geschlechtern der Anteil freiwillig Engagierter am kleinsten ist bei den Niedriggebildeten und am größten bei den Personen mit hohem Schulabschluss, wenn man ausschließlich Personen mit bereits abgeschlossener Schulbildung betrachtet. Andererseits ist festzuhalten, dass die Bildungsunterschiede bei den Frauen sogar noch deutlich ausgeprägter sind als bei den Männern. So ist die Differenz der Engagementquote zwischen niedriggebildeten und hochgebildeten Frauen mit 22,8 Prozent zu 51,3 Prozent - das entspricht 28,5 Prozentpunkten - deutlich größer als die Differenz zwischen den Quoten der niedriggebildeten und der hochgebildeten Männer mit 33,9 Prozent zu 53,2 Prozent, beziehungsweise einer Differenz von 19,3 Prozentpunkten (Abbildung 3-5b). Dies ist vor allem darauf zurückzuführen, dass sich Frauen mit niedriger Bildung wesentlich seltener freiwillig engagieren als Männer mit niedriger Bildung. Bezüglich der Gleichstellung von Frauen und Männern im freiwilligen Engagement ist also von besonderer Relevanz, den weit unterdurchschnittlichen Anteil der freiwillig engagierten Frauen mit geringer Bildung zur Kenntnis zu nehmen. Wenn zivilgesellschaftliche Organisationen Engagierte gewinnen wollen, könnte es sein, dass manche bisher vernachlässigt haben, Frauen und insbesondere Frauen mit niedriger Bildung für freiwillige Tätigkeiten zu werben. Offensichtlich gilt dies aber auch für Männer mit niedriger Bildung, was sich am deutlichsten in der jüngsten Altersgruppe zeigt. Der Bildungsgradient scheint bei den 14- bis 29-Jährigen ausgeprägter als bei den Personen im mittleren Lebensalter zu sein (Abbildung 3-5c). Zivilgesellschaftliche Akteure sollten sich überlegen, wie sie sich mit ihren Angeboten verstärkt an Personen mit niedriger Bildung wenden könnten, und zwar sowohl an Frauen als auch an Männer.

\subsubsection{Freiwilliges Engagement in den letzten vier Wochen}

Mit den Daten des Deutschen Freiwilligensurveys 2014 ist es nicht nur möglich, freiwilliges Engagement im Zeitfenster von zwölf Monaten zu betrachten, sondern auch im kürzeren Zeitfenster von den letzten vier Wochen vor der Befragung. Dieses Zeitfenster entspricht dem von der International Labour Organization (ILO) vorgeschlagenen Zeitfenster (International Labour Organization (ILO) 2011). Die Anteile der Engagierten über den kürzeren Zeitraum von vier Wochen fallen wesentlich geringer aus, weil in einem kürzeren Zeitraum hauptsächlich freiwilliges Engagement betrachtet wird, das regelmäßig und häufig ausgeübt wird. Ausschlaggebend für die nach Zeitfenster differenziellen Befunde ist, dass sich Engagierte in unterschiedlicher Häufigkeit (zum Beispiel täglich, wöchentlich oder aber nur monatlich oder seltener) und in unterschiedlicher Regelmäßigkeit (also regelmäßig jede Woche oder jeden Monat, oder nur unregelmäßig, etwa saisonabhängig in den Sommerferien oder in der Adventszeit) freiwillig betätigen (siehe Kapitel 12).

Während insgesamt 43,6 Prozent aller Männer und Frauen in Deutschland in den letzten zwölf Monaten eine freiwillige Tätigkeit ausgeübt haben, liegt der Anteil der Personen, die in den letzten vier Wochen freiwillig engagiert waren, bei 27,6 Prozent (Abbildung 3-6a). Anders ausgedrückt: Knapp zwei Drittel der Engagierten, die sich in den vergangenen zwölf Monaten engagiert haben, haben sich auch in den letzten vier Wochen engagiert. Dies ist bei engagierten Frauen und bei engagierten Männern recht ähnlich. Insofern geben insgesamt mit 25,7 Prozent auch weniger Frauen als Männer (29,5 Prozent) an, sich innerhalb der letzten vier Wochen freiwillig engagiert zu haben.

Insbesondere unter den Älteren geben verhältnismäßig viele Personen an, sich auch in den letzten vier Wochen freiwillig engagiert $\mathrm{zu}$ haben. Der Anteil liegt bei den 65-Jährigen und Älteren zwar mit 23,9 Prozent immer noch un- 
ter den Anteilen der jüngeren Altersgruppen, fällt aber dennoch verhältnismäßig hoch aus (Abbildung 3-6a). Während sich bei der ältesten Altersgruppe knapp drei Viertel der Personen, die sich in den vergangenen zwölf Monaten freiwillig engagiert haben, auch in den letzten vier Wochen engagiert haben, liegt dieser Anteil bei der jüngsten Altersgruppe lediglich bei 55,7 Prozent (in der Altersgruppe der 30- bis 49-Jährigen: 61,9 Prozent und in der Altersgruppe der 50- bis 64-Jährigen: 67,5 Prozent). Ältere scheinen somit regelmäßiger sowie möglicherweise auch dauerhafter freiwillig engagiert zu sein als Jüngere.

\section{Abbildung 3-6: Anteile freiwillig engagierter Personen 2014 in den letzten vier Wochen, a) gesamt, nach Geschlecht und nach Alter, b) nach Bildung}

a) gesamt, nach Geschlecht und nach Alter

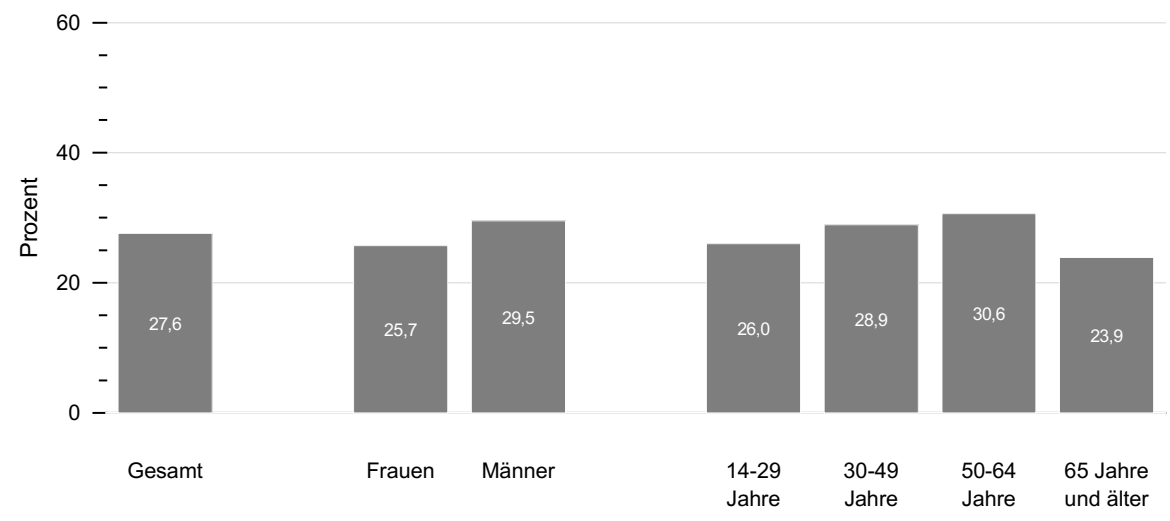

b) nach Bildung

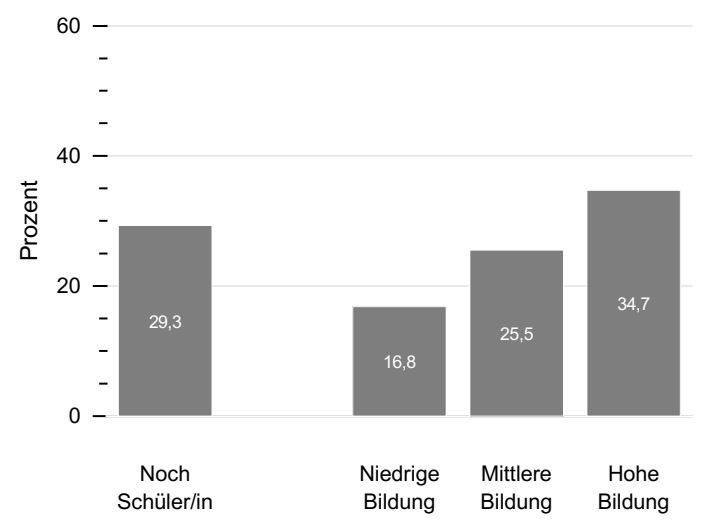

Quelle: FWS 2014, gewichtet, eigene Berechnungen (DZA). Basis: Alle Befragten $(n=28.689)$.

Deutliche Unterschiede zeigen sich auch nach Bildungsgruppen: Während von den Personen mit niedriger Bildung nur 16,8 Prozent angeben, sich in den letzten vier Wochen freiwillig betätigt 
zu haben, sind es bei den Personen mit hoher Bildung mit 34,7 Prozent etwa doppelt so viele. Der Bildungsgradient ist hier also noch etwas stärker ausgeprägt als bei der Betrachtung des freiwilligen Engagements in den letzten zwölf Monaten. Schülerinnen und Schüler nehmen bei der Betrachtung des Engagements in den letzten vier Wochen eine Sonderstellung ein: Sie sind insgesamt die Gruppe mit der höchsten
Engagementrate (54,8 Prozent der Personen, die noch zur Schule gehen, haben sich in den letzten zwölf Monaten freiwillig engagiert). Innerhalb der letzten vier Wochen haben sich aber nur 29,3 Prozent der Schülerinnen und Schüler freiwillig engagiert. Das Engagement dieser Gruppe ist anscheinend deutlich sporadischer und/oder kurzfristiger als das anderer Bevölkerungsgruppen.

Abbildung 3-7: Anteile Mehrfachengagierter 2014, a) gesamt, nach Geschlecht und nach Alter,

b) nach Bildung

a) gesamt, nach Geschlecht und nach Alter

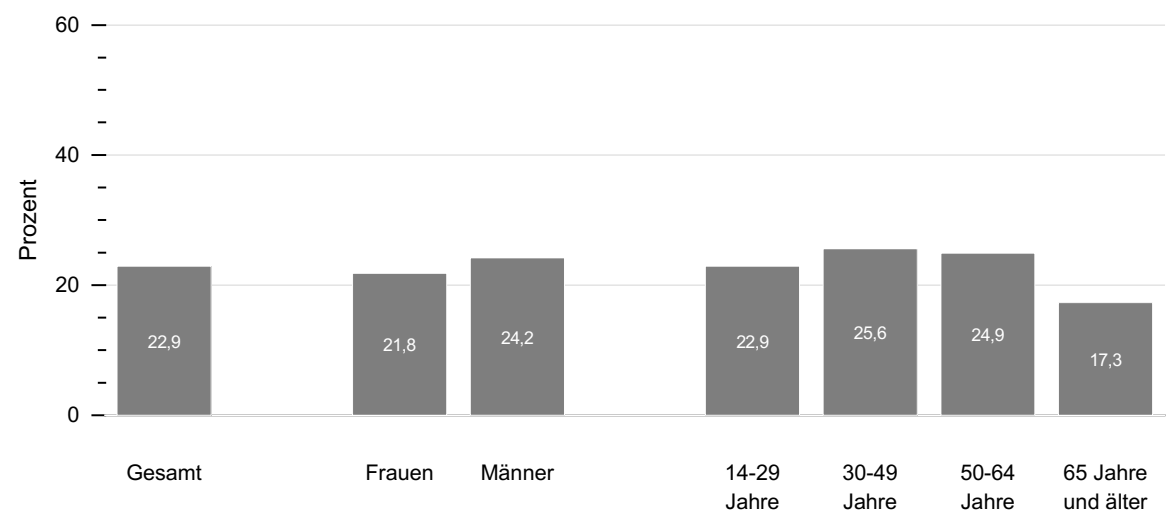

b) nach Bildung

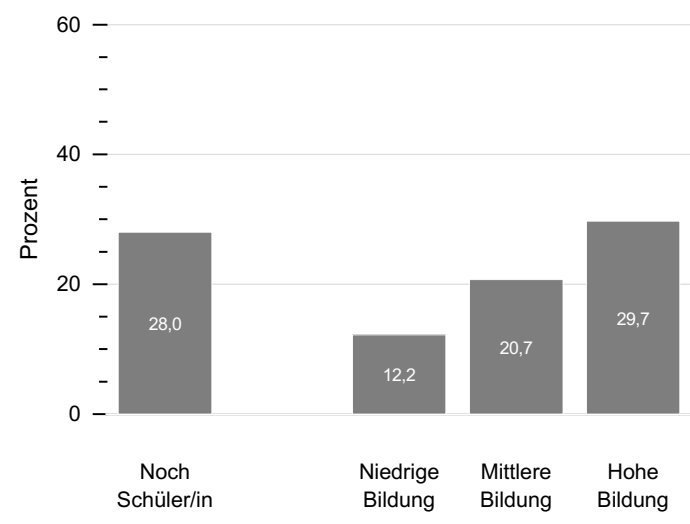

Quelle: FWS 2014, gewichtet, eigene Berechnungen (DZA). Basis: Alle Befragten ( $n=28.689$ ). 


\subsubsection{Mehrfachengagierte in den letzten zwölf Monaten}

Menschen können sich im Rahmen einer freiwilligen Tätigkeit für eine Sache oder Zielgruppe einsetzen, sie können aber auch mehreren freiwilligen Tätigkeiten in einem gesellschaftlichen Engagementbereich oder in verschiedenen Engagementbereichen nachgehen. Hierbei sind ganz unterschiedliche Kombinationen von Tätigkeiten denkbar. So kann ein und dieselbe Person beispielsweise sowohl in der Suppenküche der Kirchengemeinde helfen als auch ehrenamtliches Mitglied in der Stadtverordnetenversammlung sein. Möglich ist aber auch, dass Personen sehr ähnliche Tätigkeiten in unterschiedlichen Kontexten ausüben, wenn Ärztinnen oder Ärzte sich etwa freiwillig für die medizinische Versorgung von Flüchtlingen engagieren und auch Sprechstunden für Wohnungslose anbieten.

Die Engagierten, die zwei oder mehr verschiedene freiwillige Tätigkeiten ausüben, bezeich- nen wir im Folgenden als Mehrfachengagierte. 2014 haben 22,9 Prozent der Wohnbevölkerung Deutschlands im Alter ab 14 Jahren zwei oder mehr freiwillige Tätigkeiten ausgeübt (Abbildung 3-7a). Frauen sind etwas seltener mehrfach freiwillig engagiert als Männer, und Personen im Alter ab 65 Jahren etwas seltener als der Bevölkerungsdurchschnitt (Abbildung 3-7a). Der Anteil Mehrfachengagierter ist zudem bei Personen mit hohem Schulabschluss sowie bei Schülerinnen und Schülern wesentlich höher als bei Personen mit niedrigem Schulabschluss (Abbildung 3-7b).

Der große Anteil Mehrfachengagierter bedeutet, dass mehr als die Hälfte aller Engagierten zwei oder mehr freiwillige Tätigkeiten ausübt. Es ist davon auszugehen, dass die Personen, die sich engagieren, zunehmend mehrere verschiedene Tätigkeiten übernehmen, da sie auch innerhalb einer freiwilligen Tätigkeit mehr verschiedene Aufgaben übernehmen (siehe Kapitel 11).

\section{5 Öffentliche gemeinschaftliche Aktivität}

\subsubsection{Anteil öffentlich gemein- schaftlich Aktiver 2014}

In den vorangegangenen Abschnitten dieses Kapitels wurde die Beteiligung unterschiedlicher Personengruppen im freiwilligen Engagement betrachtet. Im Folgenden soll der Blick auf alle diejenigen Personen ausgeweitet werden, die in mindestens einem von vierzehn im Freiwilligensurvey berücksichtigten gesellschaftlichen Bereichen aktiv sind. Diese öffentlichen gemeinschaftlichen Aktivitäten können eine Vorform des freiwilligen Engagements darstellen - zum Beispiel wenn Personen, die im Sportverein aktiv sind, gefragt werden, ob sie eine Tätigkeit als Trainerin oder Trainer übernehmen wollen - sie können aber auch für sich genommen eine wichtige Funktion für den gesellschaftlichen
Zusammenhalt sowie die soziale Integration der Individuen haben.

Die große Mehrheit der Wohnbevölkerung Deutschlands im Alter ab 14 Jahren ist öffentlich und gemeinschaftlich aktiv: 70,2 Prozent geben an, dass sie außerhalb von Beruf und Familie in den letzten zwölf Monaten irgendwo mitgemacht haben beziehungsweise mitmachen (Abbildung 3-8-a). Die gemeinschaftlich aktiven Personen sind in einem oder in mehreren der vierzehn Bereiche, also zum Beispiel im Bereich Sport und Bewegung oder im kirchlichen oder sozialen Bereich aktiv (vergleiche die Bereichsprofile im Anhang). Der Anteil von öffentlich und gemeinschaftlich aktiven Personen ist bei Frauen mit 69,6 Prozent fast ebenso hoch wie bei Männern mit 70,9 Prozent (Abbildung 3-8a). Das Interesse von Frauen und Männern, sich öf- 
fentlich einzubringen und in gesellschaftlichen Bereichen in ihrer Freizeit aktiv zu sein, ist also demnach vergleichbar stark ausgeprägt.

Kleine Unterschiede zeigen sich jedoch zwischen Frauen und Männern, wenn ihr Alter berücksichtigt wird: Während in der jüngsten Altersgruppe Frauen etwas seltener öffentlich gemeinschaftlich aktiv sind als Männer (72,1 Prozent der 14- bis 29-jährigen Frauen und 77,1 Prozent der gleichaltrigen Männer), ist es bei den 30- bis 49-Jährigen umgekehrt: 71,6 Prozent der Frauen und 69,1 Prozent der Männer dieser Altersgruppe sind in ihrer Freizeit öffentlich aktiv. In der ältesten hier betrachteten Altersgruppe der 65-Jährigen und Älteren ist der Anteil öffentlich Aktiver wiederum bei Frauen niedriger $(63,4$ Prozent) als bei Männern (67,6 Prozent) (ohne Abbildung). Festzuhalten gilt, dass Frauen etwas stärker als Männer insbesondere im mittleren Lebensalter, außerhalb ihrer beruflichen und ihrer familialen Tätigkeiten, öffentlich gemeinschaftlich aktiv sind, in den jüngeren Jahren sowie im höheren Alter sind es hingegen die Männer, die sich häufiger aktiv beteiligen. Der Anteil von öffentlich und gemeinschaftlich Aktiven ist aber insgesamt - bei beiden Geschlechtern - bei der jüngsten Altersgruppe am höchsten und in der Altersgruppe der 65-Jährigen und Älteren am geringsten (ohne Abbildung).

Die Anteile öffentlich gemeinschaftlich Aktiver unterscheiden sich sehr stark nach Bildungsgruppen, die wiederum bezüglich des erreichten Schulabschlusses dargestellt sind. Die Bildungsunterschiede stellen sich deutlich stärker dar als etwa die Unterschiede zwischen den Altersgruppen. Der kleinste Anteil von öffentlich gemeinschaftlich aktiven Personen liegt mit 58,6 Prozent in der Gruppe von Personen mit niedriger Bildung vor (Abbildung 3-8b). In der Gruppe von Personen mit mittlerer Bildung beträgt der vergleichbare Anteil 68,1 Prozent und mit hoher Bildung sogar 76,0 Prozent. Der allerhöchste Anteil gemeinschaftlich Aktiver findet sich jedoch in der Gruppe derjenigen, die noch zur Schule gehen: 87,3 Prozent der Schülerinnen und Schüler sind öffentlich aktiv. In Schulen und
Jugendeinrichtungen können Schülerinnen und Schüler sich ausprobieren und herausfinden, welche Aktivitäten ihnen Freude machen und wo sie sich am besten einbringen können, beispielsweise in Vereinen. In Bildungsinstitutionen sind Schülerinnen und Schüler flächendeckend $\mathrm{zu}$ erreichen, um sie an freiwilliges politisches oder soziales Engagement heranzuführen. Allerdings zeigt sich hier auch eine Unschärfe des im Freiwilligensurvey seit 1999 verwendeten Aktivitätskonzepts: Da in der Abfrage zu öffentlichen gemeinschaftlichen Aktivitäten im Freiwilligensurvey explizit nach dem Mitmachen, außerhalb von Beruf und Familie' gefragt wird, jedoch nicht nach dem Mitmachen ,außerhalb der Schule', ist es möglich, dass Schülerinnen und Schüler mitunter auch Aktivitäten nennen, die im Rahmen des Schulbesuchs ausgeübt werden. Die Quote öffentlich gemeinschaftlich Aktiver bei den Schülerinnen und Schülern könnte insofern in allen Wellen des Freiwilligensurveys leicht überschätzt sein. Dennoch ist davon auszugehen, dass ein Großteil der Schülerinnen und Schüler auch außerhalb der Schule aktiv ist, beispielsweise in einem Verein. So gibt gut die Hälfte der Schülerinnen und Schüler im Freiwilligensurvey an, Mitglied in einem Verein zu sein (Kapitel 8). Auf Grundlage der Studie ,Aufwachsen in Deutschland heute: Alltagswelten' (AID:A) sind 2014/15 nahezu zwei Drittel der 13- bis 32-Jährigen in einem Verein aktiv, bei den 13- bis 17-Jährigen (die zum großen Teil Schüler und Schülerinnen sein dürften), ist der Anteil sogar noch höher (Gille 2015).

Die starken Bildungsgruppenunterschiede sind insofern relevant, da die öffentliche Aktivität durchaus als Vorstufe des freiwilligen Engagements betrachtet werden kann, weil hier Kontakte geknüpft werden und Austausch stattfindet, sodass auch die Übernahme von konkreten freiwilligen Aufgaben oder Arbeiten vereinbart werden kann. Ohne öffentlich und gemeinschaftlich aktiv zu sein, sind die Chancen für die Aufnahme eines freiwilligen Engagements sicherlich deutlich geringer. 
Abbildung 3-8: Anteile öffentlich gemeinschaftlich aktiver Personen 2014, a) gesamt, nach Geschlecht und nach Alter, b) nach Bildung

a) gesamt, nach Geschlecht und nach Alter

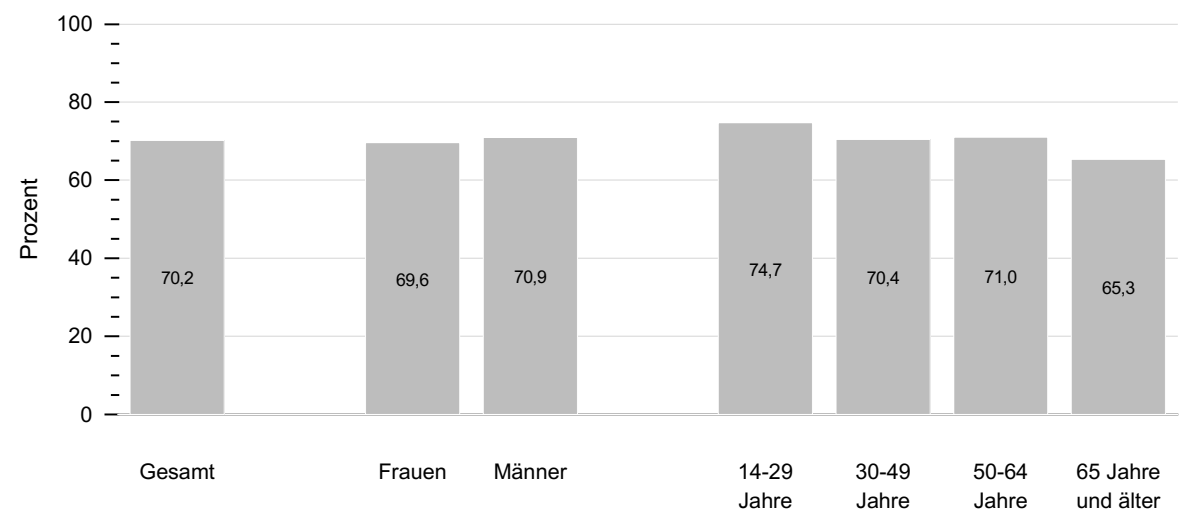

b) nach Bildung

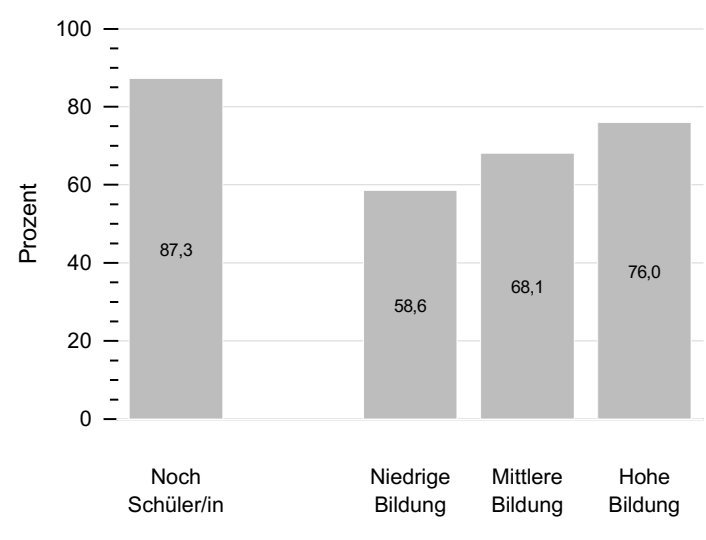

Quelle: FWS 2014, gewichtet, eigene Berechnungen (DZA). Basis: Alle Befragten $(n=28.689)$. 


\subsubsection{Entwicklung des Anteils öffentlich gemeinschaftlich Aktiver im Zeitvergleich von 1999 bis 2014}

Vergleichen wir den Anteil öffentlich Aktiver im Jahr 2014 mit dem Anteil öffentlich Aktiver im Jahr 2009, so ist eine Stagnation zu beobachten: Im Jahr 2009 waren 71,3 Prozent der Wohnbevölkerung ab 14 Jahren in Deutschland außerhalb von Beruf und Familie aktiv, im Jahr 2014 sind es 70,2 Prozent (Abbildung 3-9). Über einen längeren Zeitraum von fünfzehn Jahren betrachtet kann hingegen ein leichter Anstieg des Anteils öffentlich Aktiver konstatiert werden: Im Jahr 1999 waren 65,7 Prozent der Wohnbevölkerung ab 14 Jahren aktiv, der Anstieg zu 2014 beträgt damit 4,5 Prozentpunkte, wobei der Anteil öffentlich gemeinschaftlich Aktiver insbesondere zwischen 1999 und 2004 gestiegen ist.

Die geschlechtsspezifischen Unterschiede in den öffentlichen Aktivitäten haben sich im Zeitvergleich etwas verringert: Waren 1999 63,9 Prozent der Frauen und 67,7 Prozent der Männer gemeinschaftlich aktiv, so liegen die Quoten öffentlicher gemeinschaftlicher Aktivität von Frauen und Männern im Jahr 2014 mit 69,6 Prozent und 70,9 Prozent fast auf gleichem Niveau. Der Anstieg der Quote öffentlicher gemeinschaftlicher Aktivität fiel bei den Frauen von 1999 zu 2014 mit 5,7 Prozentpunkten also etwas höher als bei den Männern mit 3,2 Prozentpunkten aus (ohne Abbildung).

Auch die Abstände in den Quoten öffentlicher gemeinschaftlicher Aktivität zwischen den verschiedenen Altersgruppen haben sich im Zeitverlauf verringert, insbesondere bedingt durch ein Aufholen bei den Personen im Alter von 65 und mehr Jahren. 1999 waren in dieser Altersgruppe lediglich 52,4 Prozent öffentlich ak- tiv, 2009 waren es bereits 66,7 Prozent und 2014 sind es 65,3 Prozent. Der Anteil der öffentlich gemeinschaftlich Aktiven ist sowohl bei den Frauen als auch bei den Männern in dieser Altersgruppe deutlich gestiegen (ohne Abbildung). Die Unterschiede zwischen den Bildungsgruppen fallen im Jahr 2014 größer aus als 1999, zum einen, weil die Personen mit hohem Bildungsabschluss beim Anteil öffentlich Aktiver deutlicher zugelegt haben als die Personen mit niedriger Schulbildung, zum anderen weil die Schülerinnen und Schüler einen deutlich höheren Anteil öffentlich Aktiver aufweisen (ohne Abbildung).

Diese Veränderungen bezüglich der öffentlichen gemeinschaftlichen Aktivität in den verschiedenen Bildungs- und Altersgruppen sind wichtig für die Erklärung der divergierenden Engagementquoten in den verschiedenen Bevölkerungsgruppen. Personen mit niedriger Bildung etwa sind nicht nur anteilig seltener freiwillig engagiert, sondern auch anteilig seltener öffentlich aktiv. Zivilgesellschaftliche Akteure könnten darauf achten, sich insgesamt stärker für Personen mit niedriger Bildung zu öffnen. Bezüglich des Engagements von Frauen und Männern lässt sich festhalten, dass Frauen und Männer sich heute ungefähr gleich häufig öffentlich betätigen, indem sie in mindestens einem gesellschaftlichen Bereich mitmachen. Sie hätten also diesbezüglich die Voraussetzungen, auch gleich häufig freiwillige Aufgaben oder Arbeiten zu übernehmen, das tun sie aber nicht. Die vergleichsweise geringere Engagementbeteiligung von Frauen muss also auf andere Erklärungsfaktoren zurückzuführen sein, etwa eine traditionelle geschlechtsspezifische Arbeitsteilung, die sich in der Beteiligung im freiwilligen Engagement ebenso widerspiegelt wie in der Erwerbsarbeit. Zudem sind Frauen und Männer in unterschiedlichen gesellschaftlichen Bereichen öffentlich aktiv und freiwillig engagiert. 


\section{Abbildung 3-9: Anteile öffentlich gemeinschaftlich aktiver Personen im Zeitvergleich}

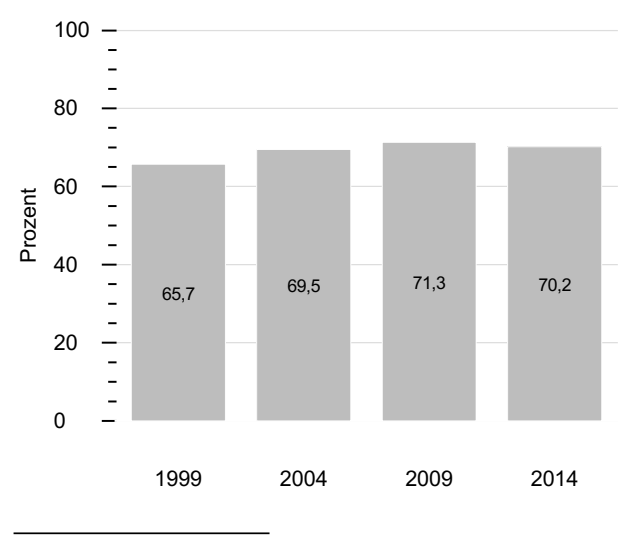

Quelle: FWS, gewichtet, eigene Berechnungen (DZA). Basis: Alle Befragten. FWS 1999 ( $n=14.922$ ), FWS 2004 $(n=15.000)$, FWS $2009(n=20.005)$, FWS $2014(n=28.689)$.

\subsection{Gesellschaftliche Bereiche des Engagements und der Aktivität}

Die im Folgenden berichteten bereichsspezifischen Engagement- und Aktivitätsquoten geben an, welcher Anteil der Wohnbevölkerung im Alter ab 14 Jahren sich jeweils in einem der vierzehn gesellschaftlichen Engagementbereiche in den letzten zwölf Monaten freiwillig engagiert hat beziehungsweise öffentlich aktiv beteiligt hat (siehe auch die Profile der gesellschaftlichen Bereiche im Anhang dieses Kapitels).

Die höchste bereichsspezifische Engagementquote liegt für den Bereich Sport und Bewegung vor: 16,3 Prozent der in Deutschland lebenden Personen ab 14 Jahren engagieren sich freiwillig im Bereich Sport und Bewegung (Abbildung 3-10). Sport und Bewegung ist auch der gesellschaftliche Bereich, in dem der mit Abstand größte Anteil von Menschen mitmacht. Insgesamt 43,7 Prozent der Wohnbevölkerung ab 14 Jahren sind in diesem Bereich gemeinschaftlich aktiv (Abbildung 3-10). Hierbei kann es sich zumeist um eine öffentliche gemeinschaftliche Aktivität im Rahmen der in allen Regionen
Deutschlands zahlreich vorhandenen Sportvereine handeln, aber zum Beispiel auch um Gesundheitsinitiativen für mehr Bewegung oder um spezielle Angebote für spezielle Zielgruppen wie die Teilnahme an einem Seniorensportkurs. Sport und Bewegung ist der größte Engagementund Aktivitätsbereich.

Weitere größere Engagementbereiche sind Schule und Kindergarten (z. B. Elternvertretung, Schülervertretung, Förderkreis) mit einer bereichsspezifischen Quote von 9,1 Prozent, Kultur und Musik (z. B. Theater- oder Musikgruppe, Chor, kulturelle Vereinigung, Förderkreis) mit einer Engagementquote von 9,0 Prozent, der soziale Bereich (z. B. Wohlfahrtsverband, Hilfsorganisation, Nachbarschaftshilfe) mit einer Quote von 8,5 Prozent, und der kirchliche oder religiöse Bereich (z. B. Kirchengemeinde, religiöse Organisation oder religiöse Gemeinschaft) mit einer Engagementquote von 7,6 Prozent. Während im Bereich Kindergarten und Schule jedoch die meisten dort öffentlich gemeinschaftlich Aktiven 
auch gleichzeitig freiwillig engagiert sind, das heißt konkrete Arbeiten oder Aufgaben übernommen haben, steht der Bereich Kultur und Musik nach dem Anteil öffentlich Aktiver mit
19,2 Prozent an zweiter Stelle. Somit ist fast jede beziehungsweise jeder Fünfte in der Wohnbevölkerung im Alter ab 14 Jahren in diesem Bereich öffentlich gemeinschaftlich aktiv.

\section{Abbildung 3-10: Anteile freiwillig engagierter und öffentlich gemeinschaftlich aktiver Personen in vierzehn Bereichen 2014}

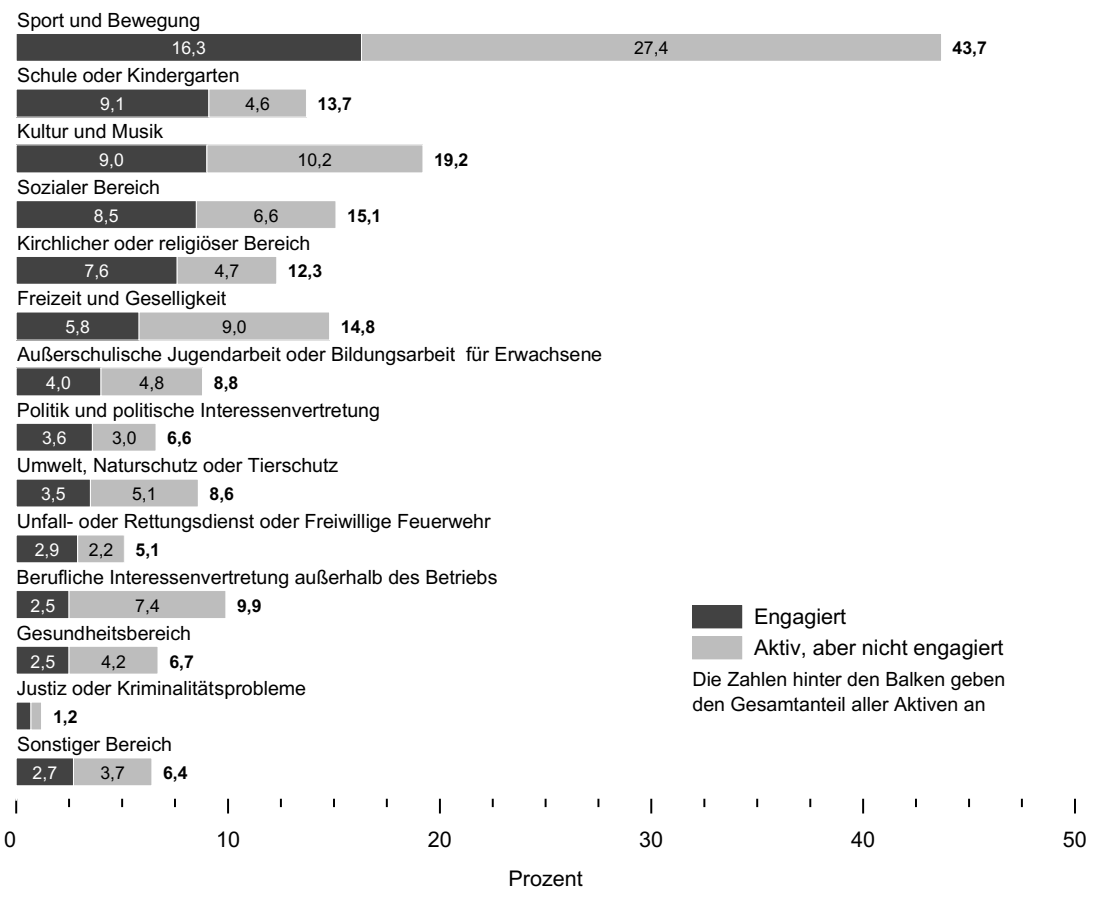

Quelle: FWS 2014, gewichtet, eigene Berechnungen (DZA). Basis: Alle Befragten ( $n=28.689$ ).

$\mathrm{Zu}$ den kleinsten Engagementbereichen zählen mit 0,5 Prozent der Bereich Justiz oder Kriminalitätsprobleme (z. B. als Schöffin oder Schöffe, Betreuung von Straffälligen oder Verbrechensopfern), mit 2,5 Prozent der Gesundheitsbereich (z. B. als Helfer oder Helferin in der Krankenpflege, Besuchsdienste, Verband, Selbsthilfegruppe) sowie der Bereich der beruflichen Interessenvertretung (z. B. Gewerkschaft, Berufsverband, Arbeitsloseninitiative) mit ebenfalls 2,5 Prozent Engagierter an der Wohnbevölkerung im Alter ab 14 Jahren (Abbildung 3-10). In einem sonstigen Bereich sind weitere 2,7 Prozent der Wohnbevölkerung freiwillig engagiert.
Stellen sich die Quoten in den Engagementbereichen anders dar, wenn man nicht nach den letzten zwölf Monaten, sondern nach den letzten vier Wochen fragt? Man könnte annehmen, dass mit Blick auf den Zeitraum der letzten zwölf Monate sowohl häufig ausgeübtes Engagement als auch selten ausgeübtes Engagment berichtet wird. Dagegen könnte mit Blick auf den Zeitraum der letzten vier Wochen vor allem häufig ausgeübtes Engagement berichtet werden. Allerdings zeigt der Vergleich der Quoten in den Engagementbereichen nach zwölf Monaten beziehungsweise nach vier Wochen ein ganz ähnliches Muster: Die stark besetzten Engagementbereiche 
in der Abfrage nach den letzten zwölf Monaten (Sport und Bewegung, Schule oder Kindergarten, Kultur und Musik, Soziales) sind auch bei der Abfrage nach den letzten vier Wochen die am stärksten besetzten Bereiche (Tabelle 3-9 im Online-Anhang).

Tatsächlich lassen sich Engagementbereiche erkennen, die man als Wachstumsbereiche bezeichnen kann, in denen der Anteil freiwillig Engagierter in den vergangenen fünfzehn Jahren jeweils besonders deutlich zugelegt hat (siehe Profile gesellschaftlicher Engagementund Aktivitätsbereiche im Anhang): Schule und Kindergarten (von 5,9 Prozent auf 9,1 Prozent), Kultur und Musik (von 4,9 Prozent auf 9,0 Prozent), der soziale Bereich (von 4,1 Prozent auf 8,5 Prozent) sowie Jugendarbeit und Bildungsarbeit für Erwachsene (von 1,7 Prozent auf 4,0 Prozent). Offensichtlich zeigen sich hier aktuelle Schwerpunkte des freiwilligen Engagements wie Bildung und Soziales.

Wie unterscheiden sich die Bereiche hinsichtlich der in ihnen freiwillig engagierten und öffentlich gemeinschaftlich aktiven Bevölkerungsgruppen oder anders gefragt: Wer engagiert sich in welchem gesellschaftlichen Bereich beziehungsweise ist dort öffentlich aktiv? Dieser Frage wird im Folgenden überblicksartig nachgegangen. Eine differenzierte Betrachtung der verschiedenen Bereiche wird in den Bereichsprofilen im Anhang dieses Kapitels vorgenommen.

Frauen engagieren sich am häufigsten freiwillig im Bereich Sport und Bewegung, gefolgt vom Bereich Schule und Kindergarten und dem sozialen Bereich. An vierter Stelle folgt bei den Frauen der kirchliche oder religiöse Bereich. An fünfter Stelle steht der Bereich Kultur und Musik. Männer engagieren sich ebenfalls am häufigsten freiwillig im Bereich Sport und Bewegung. Bei ihnen steht bereits an zweiter Stelle Kultur und Musik, erst an dritter Stelle Schule oder Kindergarten, an vierter Stelle der soziale Bereich und an fünfter Stelle der Bereich Freizeit und Geselligkeit. $\mathrm{Zu}$ den Bereichen, in denen sich Frauen überdurchschnittlich häufig freiwillig engagieren, das heißt deutlich häufiger als Männer, ge- hören: Schule und Kindergarten, der kirchliche oder religiöse Bereich, der soziale Bereich und der Gesundheitsbereich. Männer engagieren sich hingegen häufiger freiwillig als Frauen in den Bereichen Sport und Bewegung und Freizeit und Geselligkeit, zudem im Bereich Politik und politische Interessenvertretung und berufliche Interessenvertretung. Am deutlichsten dominiert durch das freiwillige Engagement von Männern ist der Bereich Unfall- oder Rettungsdienst sowie Freiwillige Feuerwehr.

Je nach Tätigkeitsfeld sind manche der Engagementbereiche auch unterschiedlich attraktiv für verschiedene Altersgruppen: Für 14- bis 29-Jährige ist die bereichsspezifische Engagementquote überdurchschnittlich im Bereich Sport und Bewegung, im Bereich Unfall- oder Rettungsdienst und im Bereich Jugendarbeit oder Bildungsarbeit für Erwachsene. Auch die 30- bis 49-Jährigen engagieren sich zu größeren Anteilen in den Bereichen Sport und Bewegung, Schule oder Kindergarten und Unfall- oder Rettungsdienst als die älteren Altersgruppen. Der Bereich Schule oder Kindergarten ist somit in der Lebensphase wichtig, in der die meisten Menschen Familien gegründet haben und Kinder im schulpflichtigen Alter betreut werden. Die Personen im Alter von 50 bis 64 Jahren engagieren sich überdurchschnittlich häufig im sozialen Bereich und in den Bereichen Kultur und Musik, Freizeit und Geselligkeit sowie Politik und politische Interessenvertretung. Für Personen im Alter von 65 und mehr Jahren ist die bereichsspezifische Engagementquote lediglich in einem Bereich überdurchschnittlich ausgeprägt, nämlich im sozialen Bereich. Dieser Bereich scheint somit ein Spektrum von freiwilligen Aufgaben vorzusehen, von dem sich insbesondere Menschen im mittleren und höheren Erwachsenenalter angesprochen fühlen.

Die bereichsspezifischen Engagementquoten unterscheiden sich auch deutlich nach Bildungsgruppen, da die Wahrscheinlichkeit, sich freiwillig zu engagieren, stark von den individuell zur Verfügung stehenden Ressourcen abhängt. Allerdings sind die Unterschiede etwa zwi- 
schen der Gruppe der Personen mit niedrigem Schulabschluss und der Gruppe der Personen mit hohem Schulabschluss in den vierzehn gesellschaftlichen Bereichen unterschiedlich stark ausgeprägt. Wenn sich Personen mit niedriger Bildung freiwillig engagieren, dann tun sie das insbesondere in den Bereichen Sport und Bewegung, im sozialen Bereich sowie im Bereich Freizeit und Geselligkeit.

Personen mit hoher Bildung engagieren sich insgesamt wesentlich häufiger freiwillig, und am häufigsten zum Beispiel in den Bereichen Sport und Bewegung, Kultur und Musik und im Bereich Schule oder Kindergarten. Schülerinnen und Schüler engagieren sich ebenfalls am häufigsten in dem Bereich Sport und Bewegung, darüber hinaus sind für Personen, die noch zur Schule gehen, Tätigkeiten in den Bereichen Schule oder Kindergarten und Kirche oder Religion am häufigsten. Betrachtet man die Differenz in den bereichsspezifischen Engagementquoten jeweils für die Gruppe der Personen mit niedriger und mit hoher schulischer Bildung, zeigen sich diese Muster: Die Bildungsunterschiede sind am stärksten ausgeprägt in den Bereichen: Sport und Bewegung, Schule und Kindergarten, Kultur und Musik, Jugendarbeit und Bildungsarbeit für Erwachsene und Kirche oder Religion. In allen diesen Bereichen sind die bereichsspezifischen Engagementquoten für Personen mit hoher Bildung deutlich höher als diejenigen der Personen mit niedriger Bildung. Die Bildungsunterschiede sind am wenigstens ausgeprägt in den Bereichen, in denen sich niedriggebildete Personen ähnlich häufig engagieren wie hochgebildete Personen, zum Beispiel im Bereich Freizeit und Geselligkeit und im Bereich Unfall- oder Rettungsdienst und Freiwilliger Feuerwehr (siehe Bereichsprofile im Anhang dieses Kapitels).

\subsection{Diskussion}

Von der Wohnbevölkerung Deutschlands im Alter ab 14 Jahren sind 43,6 Prozent freiwillig engagiert, dies entspricht etwa 30,9 Millionen Menschen. Der Anteil freiwillig Engagierter hat in den letzten fünfzehn Jahren um 9,6 Prozentpunkte zugenommen. Während im Jahr 1999 noch 34,0 Prozent freiwillig engagiert waren, sind es im Jahr 2014 mit 43,6 Prozent deutlich mehr. Das freiwillige Engagement weist in Deutschland ein hohes und langfristig steigendes Niveau auf. Der Anstieg hat sich dynamisiert, da die Quote zwischen 2009 und 2014 stärker angestiegen ist als zuvor. Mehr als zwei Drittel der Wohnbevölkerung in Deutschland sind im Jahr 2014 öffentlich und gemeinschaftlich aktiv. Mit dem insgesamt starken Anstieg des Anteils freiwillig Engagierter ist jedoch lediglich ein leichter Zuwachs des Anteils Aktiver einhergegangen. Dieser Anteil öffentlich Aktiver ist in den letzten fünfzehn Jahren nur um 4,5 Prozentpunkte angestiegen.
Bevor wir den Anstieg der Engagementquote inhaltlich diskutieren, erörtern wir, welche Bedeutung methodische Entscheidungen für die Höhe (und Veränderung) der Engagementquoten haben könnten. Angesichts des starken Anstiegs der Engagementquote insbesondere zwischen 2009 und 2014 könnte man die Frage stellen, ob methodische Veränderungen, die den Freiwilligensurvey 2014 von den vorangegangenen Erhebungen unterscheiden, für diesen starken Anstieg verantwortlich sind. Im Folgenden erläutern wir, dass diese methodischen Aspekte, wenn überhaupt, nur einen geringen Einfluss auf die Engagementquote 2014 gehabt haben können (siehe Kapitel 2).

Veränderter Zugang: Im Jahr 2014 wurde das Stichprobendesign durch Einbezug von Mobilfunknummern erweitert. Die allgemeinen Engagementquoten der beiden Teilstichproben ,Festnetzanschluss' und ,Mobilfunk' sind sehr 
ähnlich. Der veränderte Zugang ist also nicht ursächlich für den Anstieg der Engagementquote.

Verstärkter Einbezug von Menschen mit Migrationshintergrund: Im Jahr 2014 wurde der Einbezug von Menschen mit Migrationshintergrund verbessert. Da der Anteil der freiwillig Engagierten bei Personen mit Migrationshintergrund geringer ist als bei deutschen Staatsangehörigen ohne Migrationshintergrund, kann dies nicht zu einem Anstieg der Engagementquote beigetragen haben.

Veränderungen in der Verzerrung der Stichprobe: Es gibt keine Hinweise, dass die Stichprobe des Freiwilligensurveys 2014 stärkere Verzerrungen (etwa nach Bildung) aufweist als die vorangegangenen Erhebungen. Ein Anstieg der Engagementquote kann hieraus nicht abgeleitet werden.

Gewichtung: Die Gewichtungsprozedur im Jahr 2014 orientierte sich an den Gewichtungsroutinen der vorherigen Wellen: Es wurden im Jahr 2014 dieselben Gewichtungsmerkmale herangezogen wie in früheren Wellen. Auf eine Hinzunahme weiterer Faktoren wurde aus Gründen der Vergleichbarkeit mit den bisherigen Erhebungen verzichtet. Die Einführung eines zusätzlichen Gewichtungsmerkmals würde Auswirkungen auf die Engagementquote in allen Erhebungswellen haben, da eine Neugewichtung in allen Erhebungswellen durchgeführt werden müsste. Gewichtet man nach Bildungsstand, so führt dies dazu, dass die Engagementquoten in allen Erhebungsjahren drei bis vier Prozentpunkte unter den ausgewiesenen Anteilen liegen; da dies alle Erhebungswellen in ähnlichem Ausmaß betrifft, wirkt sich dies jedoch nicht auf den beobachteten Anstieg der Engagementquote aus.

Veränderung der Interviewdauer: Nicht-engagierte Personen könnten aufgrund der längeren Interviewdauer (im Jahr 2014 durchschnittlich 30, zuvor nur 20 Minuten) weniger häufig bereit gewesen sein, am Interview teilzunehmen. Vergleiche zwischen der Stichprobe und Daten der amtlichen Statistik geben jedoch keine Hinweise auf erhöhte Teilnahmeselektivitäten durch die Verlängerung der Interviewdauer.

Ergänzung eines Zeitfensters: Im Jahr 2014 wurde nach dem ,Engagement in den letzten zwölf Monaten' gefragt (nicht wie bisher nach ,derzeitigem Engagement'). In einer Vorstudie zeigten sich keine Unterschiede zwischen den beiden Varianten. Darüber hinaus wurde das Zeitfenster auch für die öffentlichen gemeinschaftlichen Aktivitäten ergänzt; hier gab es jedoch keinen vergleichbaren Anstieg.

Wechsel des Erhebungsinstituts: Im Jahr 2014 hat ein Wechsel des Erhebungsinstituts stattgefunden. $\mathrm{Da}$ es sich um eine standardisierte Befragung handelt und beide Erhebungsinstitute nach anerkannten Standards arbeiten, gehen wir davon aus, dass sich der Wechsel des Erhebungsinstituts kaum auf die Engagementquote ausgewirkt haben kann.

Veränderung in der Überprüfung der Selbstangaben zum freiwilligen Engagement: Ein zunehmend größerer Anteil der Selbstangaben der Befragten, freiwillig engagiert $\mathrm{zu}$ sein, wurde zwischen 1999 und 2009 als Nicht-Engagement eingestuft. Durch den zunehmenden Anteil von Recodierungen in den Erhebungswellen 1999, 2004 und 2009 wurde der Anstieg der Engagementquote bislang nicht in vollem Umfang deutlich. Die seltenere Recodierung der Selbstangaben im Jahr 2014 trägt nur zu einem geringen Teil zu dem Anstieg der Engagementquote bei, denn auch bei Betrachtung der ungeprüften Quoten 1999 und 2014 zeigt sich ein vergleichbarer dynamisierter Anstieg.

Die Erörterung methodischer Aspekte lässt den Schluss zu, dass der Anstieg der Engagementquote als belastbarer Befund zu bewerten ist. Im folgenden Abschnitt diskutieren wir jene gesellschaftlichen Trends, die zu einem Anstieg des Anteils freiwillig engagierter Menschen in Deutschland - und zu der Dynamisierung dieses Trends in den letzten fünf Jahren - beigetragen haben können. 


\subsubsection{Der Anstieg der Engagement- quote vor dem Hintergrund gesellschaftlicher Trends}

Der Blick in Befunde anderer sozialwissenschaftlicher Studien zeigt, dass auch andere Surveys, wie beispielsweise der European Social Survey (ESS), der Deutsche Alterssurvey (DEAS) oder das Sozio-oekonomische Panel (SOEP) einen Trend zu mehr Engagement in den letzten Jahren belegen (Böhnke 2011; Eurostat 2010; Künemund \& Schupp 2008; Naumann \& Romeu Gordo 2010). Das Statistische Bundesamt (2015b) hat erste Ergebnisse zur Zeitverwendung in Deutschland 2012/2013 veröffentlicht und geht von einem Anteil freiwillig oder ehrenamtlich Engagierter von 40 Prozent an der Bevölkerung im Alter ab zehn Jahren aus. Obwohl dies im Vergleich zur Zeitbudgeterhebung 2001/2002 faktisch einen Rückgang um drei Prozentpunkte bedeutet, lässt sich auch hieraus auf einen nach wie vor hohen Anteil freiwillig Engagierter in Deutschland schließen (Kahle \& Schäfer 2005). Der Anstieg des freiwilligen Engagements seit 1999 kann auf verschiedene gesellschaftliche Trends zurückgeführt werden, die auch zu einer Dynamisierung des Anstiegs in den letzten fünf Jahren beigetragen haben können.

Thematisierung des freiwilligen Engagements in Politik und Öffentlichkeit: Das Themenfeld freiwilliges Engagement hat in den letzten Jahren deutlich an Aufmerksamkeit gewonnen. Freiwilliges Engagement wurde zunehmend als gesellschaftliche Ressource entdeckt. Gesetze, Initiativen oder Projekte zur Stärkung des freiwilligen Engagements wurden ins Leben gerufen (Klein, Olk \& Hartnuß 2010). Wir nehmen an, dass diese Veränderungen zu einer Erhöhung der Engagementbereitschaft in der Bevölkerung und zu einer erhöhten Engagementquote beigetragen haben. Vor dem Hintergrund der stärkeren Thematisierung von Engagement und Ehrenamt in der Öffentlichkeit und in politischen Diskursen ist zwar auch vorstellbar, dass Personen für das Thema nun stärker sensibilisiert sind und ihre Tätigkeiten jenseits der Erwerbsarbeit oder der
Familie eher als noch vor ein paar Jahren als freiwilliges oder ehrenamtliches Engagement einschätzen. Durch die zweistufige Abfrage zu Aktivitäten und Engagement im Freiwilligensurvey, in der die Begriffe Ehrenamt und Engagement bewusst vermieden werden, sollte dieser Effekt jedoch eher gering sein.

Zunehmende Anzahl von Vereinen und Einrichtungen für Engagement: Die Zahl der Vereine ist in den letzten Jahrzehnten deutlich gewachsen. In Deutschland existieren heute rund $600.000 \mathrm{zi}$ vilgesellschaftliche Organisationen, so viele wie nie zuvor (Krimmer \& Priemer 2013). Durch das Mitmachen in Vereinen ergeben sich nicht selten Anlässe beziehungsweise Gelegenheiten sich freiwillig zu engagieren. Auch wenn der Anstieg der Engagementquote stärker auf einen Zuwachs des individuell organisierten und projektförmigen Engagements zurückzuführen ist als auf vereinsgebundenes Engagement (siehe Kapitel 20), ist die Gesamtzahl derer, die sich in Vereinen oder Verbänden engagieren, ebenfalls gestiegen. Zudem wächst die Anzahl von Einrichtungen wie Freiwilligenagenturen, Mehrgenerationenhäuser, Kulturzentren oder Seniorenbüros, die Engagement fördern und unterstützen.

Bildungsexpansion: Der Anteil von Menschen mit höherer Bildung in der Bevölkerung hat sich in den letzten Jahrzehnten stetig erhöht (Statistisches Bundesamt 2015a). Da sich Menschen mit höherer Bildung zu größeren Anteilen freiwillig engagieren als Menschen mit niedrigerem Bildungsniveau, gehen wir davon aus, dass sich diese Bildungsexpansion steigernd auf die Engagementquote ausgewirkt hat.

Ansprache jüngerer Menschen: Für die Gruppe der Jüngeren und insbesondere für Schülerinnen und Schüler sind trotz des gestiegenen Leistungsdrucks auch Trends zu konstatieren, die eine bessere Hinführung an das freiwillige Engagement bedeuten können. Aufgrund des demografischen Wandels, der ja nicht nur mit einem höheren Anteil älterer Menschen, sondern auch mit einem geringeren Anteil Jüngerer einhergeht, ist es nachvollziehbar, dass sich zivilgesellschaftliche Akteure besondere Mühe geben, um die Jünge- 
ren als die freiwillig Engagierten der Zukunft zu werben. Dass junge Menschen durchaus bereit sind, sich zu engagieren, zeigt sich auch an der großen Beteiligung von jungen Erwachsenen in Freiwilligendiensten (siehe Kapitel 5).

Gestiegene Erwerbsbeteiligung: Die Erwerbsbeteiligung von Frauen (Brenke 2015; Simonson, Romeu Gordo \& Titova 2011) und von älteren Menschen (Naumann \& Romeu Gordo 2010) ist in den letzten Jahrzehnten deutlich gestiegen. Die Arbeitslosenquoten sind zudem zurückgegangen. Diese Entwicklungen können sich auch im Engagement niederschlagen, da sich über die Erwerbsarbeit zusätzliche Gelegenheiten für freiwilliges Engagement ergeben können. Tatsächlich sind die Anteile Engagierter unter erwerbstätigen Personen höher als unter Nicht-Erwerbstätigen (siehe Kapitel 16). Der Anstieg des Engagements kann also auch als ein Ausdruck gestiegener Gelegenheiten durch zunehmende Erwerbsbeteiligung gesehen werden.

Veränderungen von Familienstrukturen: Familien und Lebensformen sind vielfältiger geworden (Frick, Grabka, Rasner, Schmidt, Schuth \& Westermeier 2012). Die Wohnentfernungen zwischen den familialen Generationen werden durch zunehmende Mobilität größer. Menschen werden später im Lebenslauf (oder gar nicht) Eltern oder Großeltern. Das vorhandene Hilfepotenzial könnte sich daher auf andere Empfängerinnen und Empfänger verlagert haben, auch im Rahmen freiwilligen Engagements.

Veränderungen der Lebensphase Alter: Die heute Älteren haben durch die gestiegene Lebenserwartung nicht nur die Aussicht auf eine viele Jahre andauernde Phase des beruflichen Ruhestandes, die sie im Durchschnitt in relativer wirtschaftlicher Sicherheit und bei vergleichsweise noch guter Gesundheit verbringen können (Wurm, Schöllgen \& Tesch-Römer 2010), sondern sie können auch auf einen großen Erfahrungsschatz zurückgreifen, und diesen, wenn sie denn wollen, auch im freiwilligen Engagement einbringen (Naumann \& Romeu Gordo 2010). Die heute Älteren sind außerdem im Durchschnitt höher gebildet als die Älteren früherer
Geburtsjahrgänge. Hinzu kommt ein politischer Diskurs des aktiven Alterns, in dem Engagement gefördert wird (Bundesministerium für Familie, Senioren, Frauen und Jugend (BMFSFJ) 2005; 2010).

\subsubsection{Freiwilliges Engagement in verschiedenen Bevölkerungsgruppen}

Die Befunde des Freiwilligensurveys 2014 spiegeln einen beachtlichen Anstieg des freiwilligen Engagements seit 1999 wider. Allerdings ist zu berücksichtigen, dass nicht alle Bevölkerungsgruppen gleichermaßen am Anstieg des freiwilligen Engagements teilhaben und es große Unterschiede zwischen einzelnen Gruppen gibt. Im Folgenden werden die unterschiedlichen geschlechtsspezifischen Entwicklungen des Engagements beschrieben sowie das vielschichtige Bild des Engagements der jungen sowie der älteren Menschen zusammengefasst, wobei auch die unterschiedlichen Bildungsressourcen berücksichtigt werden, welche die Möglichkeiten der sozialen Teilhabe im Engagement strukturieren.

Obgleich das freiwillige Engagement der Frauen in den letzten fünfzehn Jahren insgesamt stärker gestiegen ist als das der Männer, ist die Engagementquote bei Frauen immer noch niedriger als die der Männer. Es zeigt sich auch, dass sich die Unterschiede im Engagement zwischen Frauen und Männern in den verschiedenen $\mathrm{Al}$ tersphasen verschieden darstellen. Während die Geschlechterdifferenz im freiwilligen Engagement bei den Älteren (65-Jährige und Ältere) am größten ist und sich in den letzten fünfzehn Jahren als relativ konstant erweist, ist vor allem bei jüngeren Altersgruppen eine starke Angleichung zwischen den Geschlechtern zu beobachten. Bei den Schülerinnen liegt die Engagementquote 2014 sogar über der der Schüler. Auffällig ist insbesondere bei den jungen Frauen und Männern, dass die Geschlechterunterschiede im freiwilligen Engagement auch sehr stark mit der Bildung zusammenhängen: Je höher die Bildung, umso geringer sind die geschlechtsspezifischen 
Unterschiede der Engagementquoten. Eine weitere Gruppe von Frauen, die (erstmals) 2014 eine höhere Engagementquote als die gleichaltrigen Männer aufweist, sind die 30- bis 45-jährigen Frauen, insbesondere dann, wenn Kinder unter 14 Jahren im Haushalt leben. Dies lässt darauf schließen, dass die Lebensphase mit minderjährigen Kindern das freiwillige Engagement von Frauen begünstigt.

Die Befunde zu den unterschiedlichen Bereichen, in denen sich Frauen und Männer freiwillig engagieren, verweisen allerdings darauf, dass sich die bestehende gesellschaftliche Arbeitsteilung der Geschlechter auch weiterhin im Engagement fortschreibt. Frauen sind auch 2014 stärker als Männer in klassischen familienbezogenen und sozialen Feldern wie Schule oder Kindergarten, im gesundheitlichen und sozialen Bereich oder in der Kirche und Religion freiwillig engagiert. Männer engagieren sich hingegen anteilig häufiger freiwillig im Sport, im politischen Bereich und im Unfall- oder Rettungsdienst beziehungsweise bei der Freiwilligen Feuerwehr. Auffällig ist dabei, dass das freiwillige Engagement der Frauen im Vergleich zu dem der Männer viel stärker durch die unterschiedlichen Lebensphasen geprägt zu sein scheint. Das umfangreiche Engagement der Frauen beispielsweise in Kindergarten und Schule ist insbesondere in der Familienphase mit kleineren Kindern zu beobachten und damit meist auch zeitlich begrenzt. Die Engagementquoten in männerdominierten Bereichen, wie beispielsweise im Unfall- oder Rettungsdienst oder im sportlichen Bereich, stellen sich über die Lebensphasen als relativ konstant dar und nehmen erst in den höheren Altersgruppen ab, nicht zuletzt, weil hier teilweise Höchstaltersgrenzen wirksam werden. Es zeigt sich, dass es trotz einer Annäherung der Engagementquoten zwischen Frauen und Männern immer noch große geschlechtsspezifische Unterschiede in der Ausgestaltung und in der lebensphasenspezifischen Verortung des freiwilligen Engagements gibt. Im Hinblick auf eine Chancengleichheit von Frauen und Männern im Engagement sind insbesondere neue Lebensentwürfe von Frauen und Männern $\mathrm{zu}$ unterstützen und die gleichberechtigte Arbeitsteilung zwischen Frauen und Männern sowohl in der Familien- und Sorgearbeit als auch in der Erwerbsarbeit zu fördern. Erst hierdurch können gleiche Chancen für Frauen und Männer eröffnet werden, sich in allen Phasen des Lebensverlaufs am kulturellen, politischen oder sozialen Leben zu beteiligen und schließlich können für beide Geschlechter neue Freiräume für ihr Engagement entstehen.

Das Engagement von jungen Menschen ist in den letzten fünfzehn Jahren besonders stark angestiegen. Die Gruppe der 14- bis 19-Jährigen weist im Vergleich mit anderen Altersgruppen die höchste Engagementquote auf, hier sind über die Hälfte freiwillig engagiert. Auch die 20- bis 24-Jährigen zeigen mit 48,4 Prozent eine vergleichsweise hohe Engagementquote. In den mittleren Altersgruppen liegt die Engagementquote jedoch niedriger und erreicht erst wieder bei Personen ab 35 Jahren ein ähnlich hohes Niveau. Auffällig und sozialpolitisch relevant ist die Entwicklung der Engagementquote der jungen Menschen mit niedriger Bildung. Hier sind es insbesondere die jungen Frauen mit niedriger Bildung, die eine sehr geringe Engagementquote aufweisen, die im Zeitvergleich auch noch gesunken ist. Gerade auf diese Gruppe von jungen Menschen sollten die Akteure der Zivilgesellschaft und der Engagementpolitik ihr Augenmerk stärker richten und die Möglichkeiten der gesellschaftlichen Teilhabe über freiwilliges Engagement verbessern, um soziale Ungleichheiten im freiwilligen Engagement abzubauen, die sich über den gesamten weiteren Lebensverlauf auswirken können. Im Vergleich mit anderen Altersgruppen sind junge Menschen überdurchschnittlich häufig im Bereich Sport und Bewegung engagiert, aber auch im kirchlichen und religiösen Bereich sind die Engagementquoten der Jugendlichen und jungen Erwachsenen vergleichsweise hoch. Eine überdurchschnittlich hohe Quote von jungen Frauen findet man darüber hinaus in der Jugendarbeit oder Bildungsarbeit für Erwachsene, bei den jungen Männern hingegen im Engagement beim 
Unfall- oder Rettungsdienst beziehungsweise bei der Feuerwehr. In allen im Freiwilligensurvey benannten Engagementbereichen haben sich die Engagementquoten der jungen Menschen erhöht. Die in der Vergangenheit gelegentlich genannte Befürchtung, dass das Engagement von Jugendlichen und jungen Erwachsenen aufgrund des schulischem Erfolgsdruck oder durch sich ändernde Freizeitaktivitäten, wie Computer- und Mediennutzung abnehme, kann also nicht bestätigt werden. Der Wert des freiwilligen Engagements scheint insbesondere bei den jüngeren Menschen anerkannt und auch in schulischen oder universitären Curricula fest verankert.

Obgleich das freiwillige Engagement der älteren Menschen (65-Jährige und Ältere) mit 34,0 Prozent im Vergleich zum Engagement anderer Altersgruppen am niedrigsten ausfällt, ist auch hier ein überdurchschnittlicher Anstieg der Engagementquote seit 1999 um elf Prozentpunkte zu verzeichnen. Betrachtet man die Anteile der Engagierten etwas differenzierter nach Altersgruppen so zeigt sich, dass das Engagement der jüngeren Älteren (65- bis 69-Jährigen) ähnlich hoch ist wie das der vorhergehenden Altersgruppen im erwerbsfähigen Alter, erst im Alter ab 70 Jahren und noch deutlicher ab 75 Jahren sind die Anteile der freiwillig Engagierten deutlich niedriger. Ein weiterer wichtiger Befund des
Freiwilligensurveys zeigt, dass insbesondere die Älteren regelmäßiger engagiert zu sein scheinen als Jüngere, so berichten vergleichsweise viele 65-Jährige und Ältere, dass sie sich nicht nur in den letzten zwölf Monaten sondern auch in den letzten vier Wochen engagiert haben. Die vier wichtigsten Engagementbereiche der älteren Menschen sind der soziale Bereich, Sport und Bewegung, Kultur und Musik sowie Kirche und Religion. Hier zeigen sich noch stärker als in jüngeren Altersgruppen traditionelle geschlechtsspezifische Unterschiede: Während im sozialen und kirchlichen Bereich die Engagementquoten der älteren Frauen höher sind, engagieren sich ältere Männer in steigendem Maße im Sport sowie im kulturellen Bereich. Aufgrund der demografischen Entwicklung wird es in Zukunft noch wichtiger sein, Engagement von älteren Menschen und insbesondere älteren Frauen zu fördern und es in vorhandene Strukturen einzubinden, aber auch Freiräume für neue Strukturen zu schaffen. So kann erreicht werden, dass allen Menschen gleichermaßen der Zugang zu freiwilligen Tätigkeiten in verschiedenen Engagementbereichen ermöglicht wird, und Menschen nicht durch strukturelle Gründe daran gehindert werden, sich zu engagieren, wenn sie sich engagieren möchten.

\subsection{Fazit}

Auch wenn sich nach wie vor sehr deutliche Unterschiede in der Engagementbeteiligung von Bevölkerungsgruppen zeigen, die auch auf unterschiedliche Chancen und Möglichkeiten, sich freiwillig zu engagieren, schließen lassen, kann dennoch insgesamt ein positives Fazit gezogen werden. Der Anstieg des Anteils freiwillig Engagierter über die letzten fünfzehn Jahre auf 43,6 Prozent kann als Ausdruck der zahlreichen Bemühungen verschiedener politischer und zivilgesellschaftlicher Akteure verstanden werden, die Rahmenbedingungen und die Infrastrukturen für freiwilliges Engagement in der Bundesrepublik nachhaltig zu verbessern. Neben den institutionellen Akteuren sind jedoch vor allem die Menschen selbst in den Blick zu rücken. Nicht zuletzt kann der Anstieg des freiwilligen Engagements auch als direktes Ergebnis des vielfältigen Engagements der Menschen betrachtet werden, die unsere Gesellschaft mitgestalten und dadurch prägen. 


\section{Literatur}

Böhnke, P. (2011). Ungleiche Verteilung politischer und zivilgesellschaftlicher Partizipation. Aus Politik und Zeitgeschichte, $61(1 / 2), 18-25$.

Brenke, K. (2015). Wachsende Bedeutung der Frauen auf dem Arbeitsmarkt. DIW Wochenbericht, 82(5), 75-86.

Bundesministerium für Familie, Senioren, Frauen und Jugend (BMFSFJ) (2010). Sechster Bericht zur Lage der älteren Generation in der Bundesrepublik Deutschland. Altersbilder in der Gesellschaft. Berlin: BMFSFJ.

Bundesministerium für Familie, Senioren, Frauen und Jugend (BMFSFJ) (2005). Fünfter Bericht zur Lage der älteren Generation in der Bundesrepublik Deutschland. Potenziale des Alters in Wirtschaft und Gesellschaft - ein Beitrag älterer Menschen zum Zusammenhalt der Generationen. Berlin: BMFSFJ.

Enquete-Kommission ,Zukunft des Bürgerschaftlichen Engagements' (2002). Bericht der Enquete-Kommission ,Zukunft des Bürgerschaftlichen Engagements'. Bürgerschaftliches Engagement: auf dem Weg in eine zukunftsfähige Bürgergesellschaft (Bundestagsdrucksache 14/8900). Berlin: Deutscher Bundestag.

Eurostat (2010). Social participation and social isolation. Luxembourg: European Commission.

Frick, J. R., Grabka, M. M., Rasner, A., Schmidt, M., Schuth, M., \& Westermeier, C. (2012). Familienbiographische Verläufe im Kohortenvergleich (SOEPpapers 439). Berlin: Deutsches Institut für Wirtschaftsforschung.

Gille, M. (2015). Sind junge Menschen heute vereinsmüde? Vereinsaktivitäten und Vereinsengagement von Jugendlichen und jungen Erwachsenen zwischen 2009 (AID:A I) und 2014/15 (AID:A II). In: S. Walper, W. Bien \& T. Rauschenbach (Hrsg.) Aufwachsen in Deutschland heute. Erste Befunde aus dem DJI-Survey AID:A 2015 (S. 46-50). München: Deutsches Jugendinstitut.

Hartnuß, B., Olk, T., \& Klein, A. (2011). Engagementpolitik. In: T. Olk \& B. Hartnuß (Hrsg.) Handbuch Bürgerschaftliches Engagement (S. 761-776). Weinheim: Beltz Juventa.

Hille, A., Arnold, A., \& Schupp, J. (2013). Freizeitverhalten Jugendlicher: Bildungsorientierte Aktivitäten spielen eine immer größere Rolle. DIW-Wochenbericht 80(40), 15-25.

International Labour Organization (ILO) (2011). Manual on the Measurement of Volunteer Work. Genf: ILO.

Kahle, I., \& Schäfer, D. (2005). Ehrenamt und bürgerschaftliches Engagement: Ergebnisse der Zeitbudgeterhebung 2001/2002. Wirtschaft und Statistik, 2005(4), 311-317.

Karakayali, S., \& Kleist, J. O. (2015). EFA-Studie. Strukturen und Motive der ehrenamtlichen Flüchtlingsarbeit (EFA) in Deutschland. Ergebnisse einer explorativen Umfrage vom November/Dezember 2014. Berlin: Berliner Institut für empirische Integrations- und Migrationsforschung der Humboldt-Universität zu Berlin (BIM).

Klein, A., Olk, T., \& Hartnuß, B. (2010). Engagementpolitik als Politikfeld: Entwicklungserfordernisse und Perspektiven. In: T. Olk, A. Klein \& B. Hartnuß (Hrsg.) Engagementpolitik. Die Entwicklung der Zivilgesellschaft als politische Aufgabe (S. 24-59). Wiesbaden: VS Verlag für Sozialwissenschaften.

Krimmer, H., \& Priemer, J. (2013). ZIVIZ-Survey 2012. Zivilgesellschaft verstehen. Berlin: Stifterverband für die Deutsche Wissenschaft.

Künemund, H., \& Schupp, J. (2008). Konjunkturen des Ehrenamts - Diskurse und Empirie. In: M. Erlinghagen \& K. Hank (Hrsg.) Produktives Altern und informelle Arbeit in modernen Gesellschaften (S. 145-163). Wiesbaden: VS Verlag für Sozialwissenschaften.

Leven, I. \& Schneekloth, U. (2015). Freizeit und Internet: Zwischen klassischem „Offline“ und neuem Sozialraum. In: Shell Deutschland Holding (Hrsg.) Jugend 2015. Eine pragmatische Generation im Aufbruch (S. 111-151). Frankfurt am Main: Fischer.

Mutz, G., Costa-Schott, R., Hammer, I., Layritz, G., Lexhaller, C., Mayer, M., Poryadina, T., Ragus, S., \& Wolff, L. (2015). Engagement für Flüchtlinge in München. Ergebnisse eines Forschungsprojekts an der Hochschule München in Kooperation mit dem Münchner Forschungsinstitut miss. München: Hochschule für anwandte Wissenschaften München. Online: https://w3-mediapool.hm.edu/mediapool/media/dachmarke/dm_lokal/presse/pm/2015_4/Abschlussbericht_final_30092015.pdf (zuletzt abgerufen 2.3.2016).

Naumann, D., \& Romeu Gordo, L. (2010). Gesellschaftliche Partizipation: Erwerbstätigkeit, Ehrenamt und Bildung. In: A. Motel-Klingebiel, S. Wurm \& C. Tesch-Römer (Hrsg.) Altern im Wandel. Befunde des Deutschen Alterssurveys (DEAS) (S. 118-141). Stuttgart: Kohlhammer. 
Rosenbladt, B. von (Hrsg.) (2001). Freiwilliges Engagement in Deutschland. Freiwilligensurvey 1999. Ergebnisse der Repräsentativerhebung zu Ehrenamt, Freiwilligenarbeit und bürgerschaftlichem Engagement. Band 1: Gesamtbericht. Stuttgart: Kohlhammer.

Schneekloth, U. (2015). Jugend und Politik: Zwischen positivem Gesellschaftsbild und anhaltender Politikverdrossenheit. In: Shell Deutschland Holding (Hrsg.) Jugend 2015. Eine pragmatische Generation im Aufbruch (S. 153-200). Frankfurt: Fischer.

Simonson, J., Romeu Gordo, L., \& Titova, N. (2011). Changing employment patterns of women in Germany: How do baby boomers differ from older cohorts? A comparison using sequence analysis. Advances in Life Course Research, 16(2), 6582.

Statistisches Bundesamt (2015a). Bildungsstand der Bevölkerung. Wiesbaden: Statistisches Bundesamt.

Statistisches Bundesamt (2015b). Wie die Zeit vergeht. Ergebnisse zur Zeitverwendung in Deutschland 2012/2013. Wiesbaden: Statistisches Bundesamt.

Wurm, S., Schöllgen, I., \& Tesch-Römer, C. (2010). Gesundheit. In: A. Motel-Klingebiel, S. Wurm \& C. Tesch-Römer (Hrsg.) Altern im Wandel. Befunde des Deutschen Alterssurveys (DEAS) (S. 90-117). Stuttgart: Kohlhammer. 


\subsection{Anhang: Profile gesellschaftlicher Engagement- und Aktivitätsbereiche}

Im Folgenden werden die vierzehn gesellschaftlichen Engagement- und Aktivitätsbereiche einzeln vorgestellt. Hierfür werden jeweils typische Tätigkeiten in den verschiedenen Bereichen benannt sowie ein Überblick über die Quoten des freiwilligen Engagements und der öffentlichen gemeinschaftlichen Aktivitäten gegeben. Für jeden einzelnen Bereich ist es somit möglich, eine Vorstellung über die konkreten Tätigkeiten der freiwillig Engagierten zu bekommen und sich ein Bild über die Aktivitäten in diesen Bereichen zu verschaffen: Wie hoch ist der Anteil der Engagierten, engagieren sich mehr Männer oder Frauen, wie alt sind die Engagierten oder gibt es besonders deutliche Bildungsgruppenunterschiede in spezifischen Bereichen? Und haben das Engagement und die Aktivität in den letzten fünfzehn Jahren in diesen Bereichen zu- oder abgenommen?

Im Deutschen Freiwilligensurvey 2014 liegen von den Befragten 25.530 Tätigkeitsangaben vor, die über Inhalte und die organisatorische Anbindung der freiwilligen Tätigkeiten Aufschluss geben. Diese Angaben ermöglichen einen Einund Überblick über die vielfältigen Tätigkeitsfelder und -inhalte der freiwillig Engagierten in Deutschland. Im Rahmen der Datenaufbereitung wurden diese Angaben darüber hinaus dafür genutzt, die Angaben zum Engagement anhand eines Kriterienkatalogs auf ihre Gültigkeit zu prüfen (siehe Kapitel 2).

Auch innerhalb der vierzehn gesellschaftlichen Bereiche können die konkreten Tätigkeiten sowie der organisatorische Kontext des Engagements sehr unterschiedlich sein. In den folgenden beispielhaften Auflistungen ist die Auswahl von uns so getroffen, dass ein breites Spektrum von Tätigkeiten abgebildet wird. Auffällig ist dabei, dass ähnliche Tätigkeiten auch in verschiedenen Bereichen vorkommen, so wird das Organisieren von Veranstaltungen von Engagierten in fast allen gesellschaftlichen Bereichen genannt.

Die Bereichsprofile weisen die Anteile öffentlich aktiver Personen und freiwillig engagierter Personen im entsprechenden Bereich für 2014 aus, neben den Gesamtanteilen werden die Anteile von Frauen und Männern, sowie die Anteile in den Alters- und den Bildungsgruppen dargestellt. Zudem werden die Anteile aktiver und engagierter Personen im Zeitvergleich der Jahre 1999 und 2014 ausgewiesen. Darüber hinaus enthalten die Abbildungen jeweils Informationen darüber, wie sich der Anteil Engagierter mit Leitungsfunktion und der Anteil Engagierter ohne Leitungsfunktion an der Wohnbevölkerung im Alter ab 14 Jahren zwischen 1999 und 2014 entwickelt haben. 


\section{SPORT UND BEWEGUNG}

Abbildung 3-B1: Anteile aktiver und engagierter Personen im Bereich Sport und Bewegung

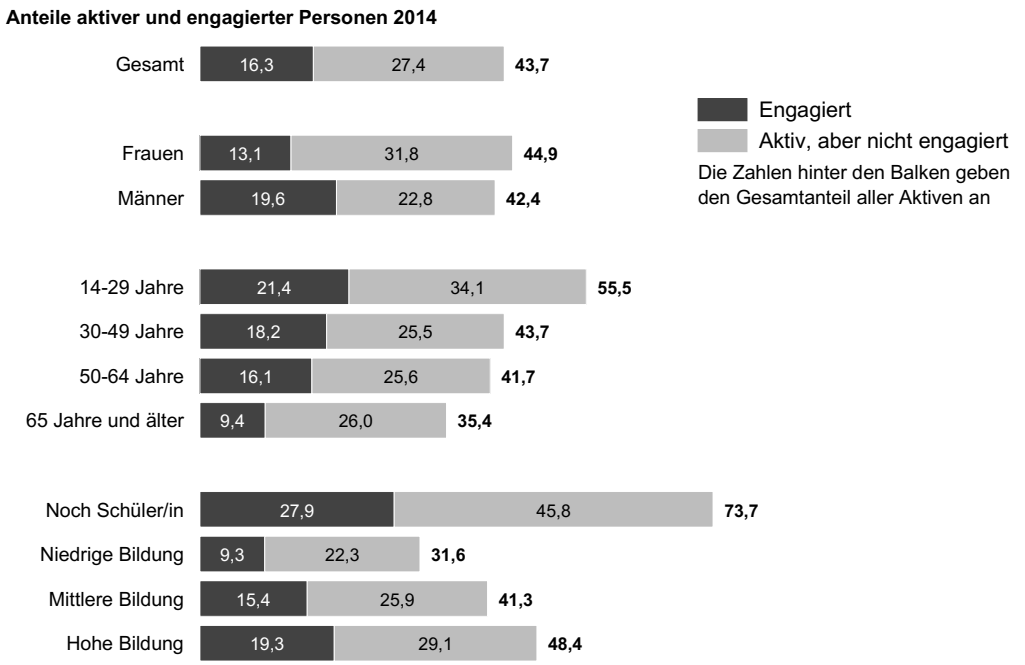

Im Zeitvergleich

\begin{tabular}{r|r|r|r}
1999 & 11,2 & 25,4 & 36,6 \\
\hline 2014 & 16,3 & 27,4 & 43,7
\end{tabular}

Anteile Engagierter nach Leitungsfunktion im Zeitvergleich

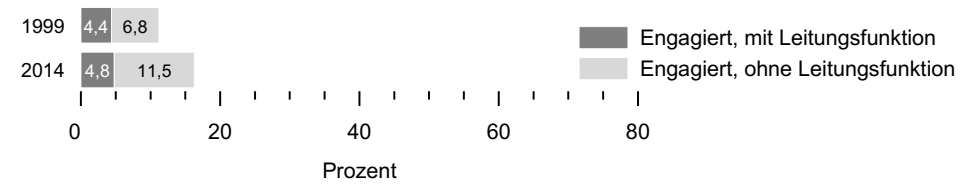

Quelle: FWS, gewichtet, eigene Berechnungen (DZA). Basis: Alle Befragten. FWS 1999 ( $n=14.922$ ), FWS 2014 $(n=28.689)$. 
Sport ist auch 2014 mit Abstand der Bereich, in dem die meisten Menschen in Deutschland aktiv mitmachen oder engagiert sind. Wie die offenen Angaben zeigen, ist der organisatorische Rahmen für freiwilliges Engagement im Sportbereich ganz überwiegend der Verein. Neben Trainertätigkeiten werden häufig auch andere Tätigkeiten, wie beispielsweise die Organisation von Veranstaltungen oder koordinierende Aufgaben genannt. Auffällig ist, dass sich hier mehr Männer als Frauen engagieren, und dass insbesondere die jüngeren Altersgruppen, darunter viele
Schülerinnen und Schüler in diesem Bereich aktiv sind und sich engagieren. Insgesamt sind zudem Höhergebildete häufiger sportlich aktiv oder engagiert als Niedriggebildete. Trotz einer zunehmenden Konkurrenz privater, kommerziell betriebener Sportangebote, wie beispielsweise im Fitnessbereich oder bei den Trendsportarten, hat das freiwillige Engagement im Sportbereich in den letzten fünfzehn Jahren zugenommen, insbesondere der Anteil der Engagierten ohne Leitungsfunktion ist stark gestiegen.

\section{Beispiele für Tätigkeiten der Engagierten im Bereich Sport und Bewegung}

- Sportclub: Übungsleiter

- Fußballverein: Trainer

- Triathlonverein: Kinder sportlich anleiten

- Reitverein: Trainer, voltigieren

- Sportgruppe: Turnierleitung, Schiedsgericht, Kuchen backen

- Tanzgruppe privat: Aufwärmübungen/Leitung

- Erwachsenenbildung und adipöse Jugendliche: Körper- und Entspannungsarbeit

- Gruppe in einem Pflegeheim: Koordinationsbewegungen

- Tennisverein: Organisation von Festen, Veranstaltungen, Motivationskampagne in Schulen und Ferienlagern für Jugendliche
- Regionsvolleyballverband: Koordination von schulübergreifenden Wettkämpfen

- Fußballverein für Erwachsene: Aktiver Spieler im Tor

- Motorradgruppe: Touren organisieren

- Sportverein: schreibe Protokolle, Briefe und Einladungen

- Handballverein: Kassenwart

- Wandergruppe: Geschäftsführer und Kassenwart, Schriftführer

- Betriebssportgemeinschaft: Rechtsfragen

- Tischtennisverein: Jugendliche zum Spiel fahren 


\section{SCHULE ODER KINDERGARTEN}

Abbildung 3-B2: Anteile aktiver und engagierter Personen im Bereich Schule und Kindergarten

Anteile aktiver und engagierter Personen 2014

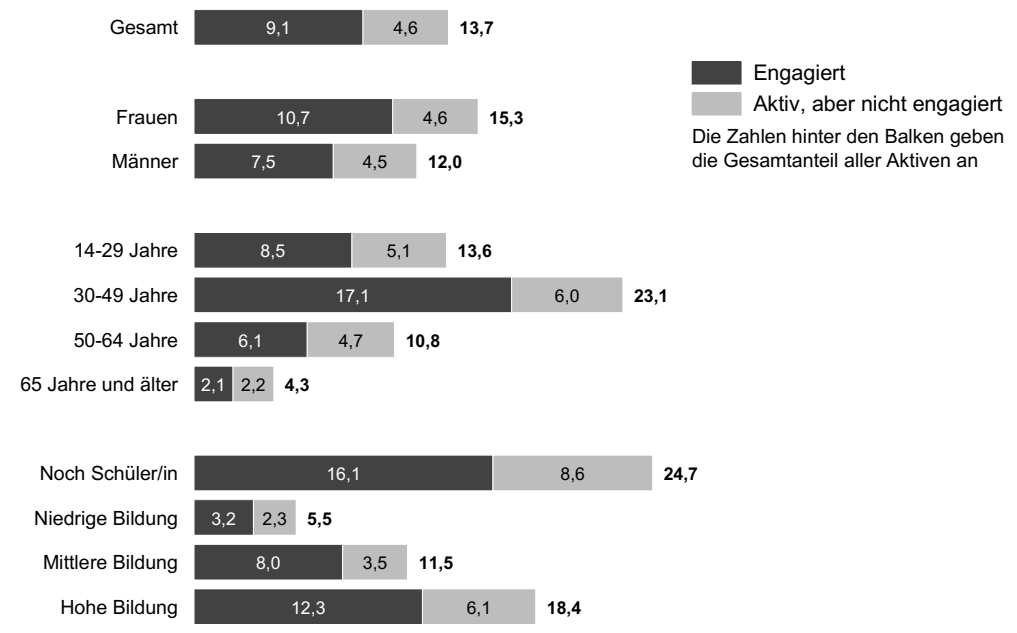

Im Zeitvergleich

\begin{tabular}{|r|r|r|r|r}
1999 & 5,9 & 4,9 & \multicolumn{2}{|c|}{$\mathbf{1 0 , 8}$} \\
\hline 2014 & 9,1 & 4,6 & $\mathbf{1 3 , 7}$
\end{tabular}

Anteile Engagierter nach Leitungsfunktion im Zeitvergleich

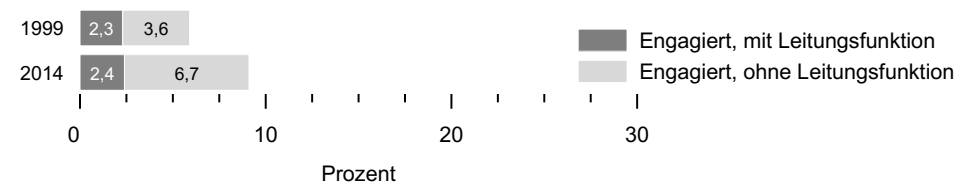

Quelle: FWS, gewichtet, eigene Berechnungen (DZA). Basis: Alle Befragten. FWS $1999(n=14.922)$, FWS 2014 $(n=28.689)$. 
Der Bereich Schule und Kindergarten ist auch einer der großen Engagementbereiche. Im Vergleich zu anderen Bereichen sind hier überdurchschnittlich viele Frauen und Männer, nämlich zwei Drittel, die in diesem Bereich 2014 aktiv sind, auch gleichzeitig freiwillig engagiert. Die Aktivitäten und das Engagement sind sowohl bei Schülerinnen und Schülern als auch bei 30 - bis 49-jährigen Frauen und Männern - darunter viele Eltern - besonders ausgeprägt. Die Schülerinnen und Schüler sind als Schülervertreter, im Schulcafé oder in Arbeitsgemeinschaften (AGs) engagiert, die Eltern häufig als Elternvertrete- rinnen oder Elternvertreter, in Fördervereinen oder anderen Elterninitiativen. Die Bildungsunterschiede sind in diesem Bereich ähnlich stark wie im Bereich Kultur und Musik ausgeprägt: Personen mit höherer Bildung sind im Vergleich zu Personen mit niedriger Bildung wesentlich häufiger engagiert. Es handelt sich um einen Bereich, in dem Frauen häufiger als Männer aktiv sind und/oder sich engagieren. Im Zeitvergleich zeigt sich, dass insbesondere der Anteil der Engagierten ohne Leitungsfunktion in den letzten fünfzehn Jahren gestiegen ist.

\section{Beispiele für Tätigkeiten der Engagierten im Bereich Schule oder Kindergarten}

- Kindergarten: Elternvertretung, Organisation von Ausflügen

- Kindergarten-Förderverein: Veranstaltungsorganisation

- Förderverein Hauptschule: Erste Vorsitzende

- Gymnasium: Arbeit im Förderverein

- Elternstammtisch: Beratung von Eltern

- Elterninitiative Mittagsbetreuung für Schüler: Vorsitzender

- Mitglied im Schulausschuss: Organisation der Schulfeste und des Abiturballs, Stufensprecher

- Schülervertretung: Vermittlung zwischen Lehrern und Schülern

- Kreisschülerrat: Beteiligung an Projekten

- Schach-AG: Schachunterricht

- Gesamtschule: Spieleausgabe
- Schülercafé: Betreuung und Überwachung

- Nachhilfegruppe: Nachhilfe in Englisch und Chemie

- Väterverein: Kassenprüfer

- Caritas Lernhilfe: Hausaufgabenbetreuung für sozial schwache Kinder

- Katholische Öffentliche Bücherei: vorlesen, Erklärung der Bücherei, Betreuung

- Industrie- und Handelskammer: Prüfungen abnehmen

- Schule: Pausenpate (Schulhofaufsicht mit Betreuung)

- Förderverein der Moschee: Nachhilfelehrer

- Verein Deutscher Ingenieure: Durchführung von Experimenten und Vorführungen 


\section{KULTUR UND MUSIK}

Abbildung 3-B3: Anteile aktiver und engagierter Personen im Bereich Kultur und Musik

Anteile aktiver und engagierter Personen 2014

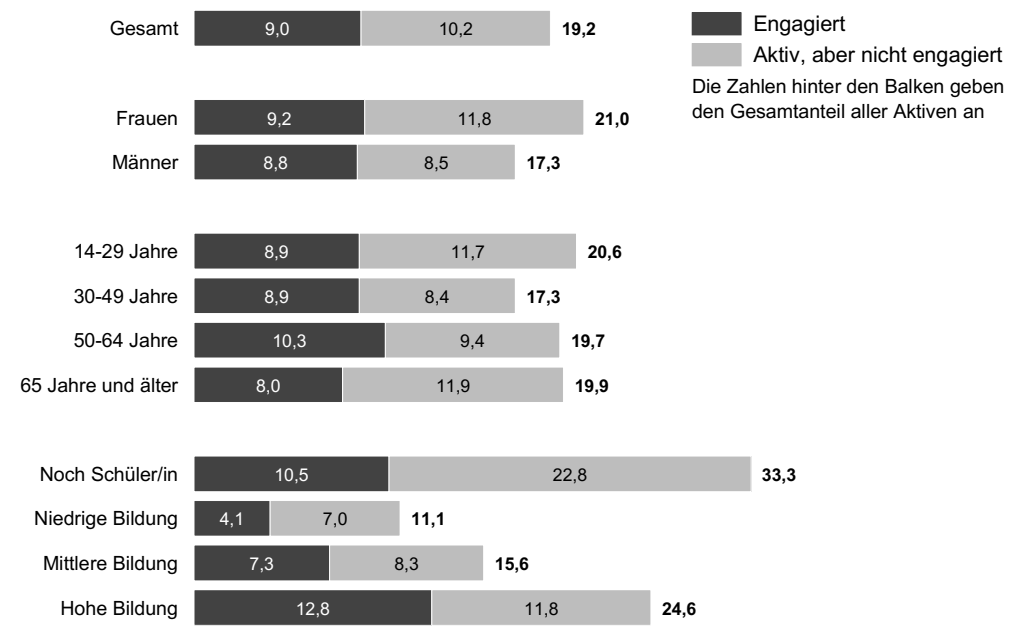

Im Zeitvergleich

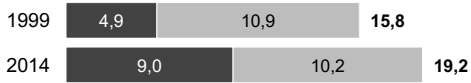

Anteile Engagierter mit Leitungsfunktion

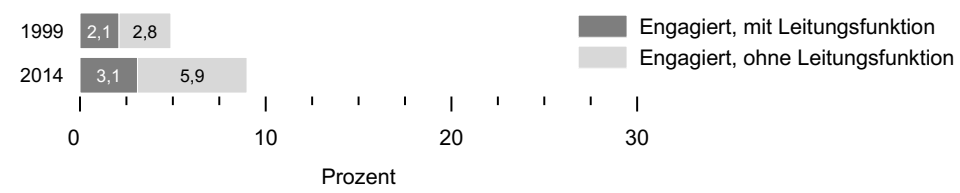

Quelle: FWS, gewichtet, eigene Berechnungen (DZA). Basis: Alle Befragten. FWS $1999(n=14.922)$, FWS 2014 $(n=28.689)$. 
Der zweitgrößte Aktivitäts- beziehungsweise der drittgrößte Engagementbereich ist der Kulturund Musikbereich. Die Angaben der Befragten zeigen wie vielfältig und unterschiedlich das Engagement in diesem Bereich ist. Es reicht von Aufgaben in der Gemeinde oder im Museum bis hin zu Tätigkeiten im Chor oder im Rahmen von Musikvereinen, Theater- oder Tanzgruppen. Der Unterschied zwischen den Bildungsgruppen ist in diesem Bereich - ähnlich wie beim Engagement im Bereich Schule - besonders hoch: Die
Höhergebildeten sind im Vergleich zu den Personen mit niedriger Bildung besonders häufig engagiert. Zudem zeigen die Ergebnisse, dass sich anteilig etwas mehr Frauen als Männer im Kultur- und Musikbereich freiwillig engagieren. Während der Anteil der Personen, die nur aktiv sind, vergleichsweise stabil geblieben ist, hat sich der Anteil der Engagierten, die zusätzliche Aufgaben oder Arbeiten übernommen haben, in den letzten fünfzehn Jahren deutlich erhöht.

\section{Beispiele für Tätigkeiten der Engagierten im Bereich Kultur und Musik}

- Museum: Museumspädagogische Aufgaben

- Heimatforschung für die Gemeinde: Archivbesuche, Verwaltung, Vervollständigung der Ortsgeschichte

- Städtepartnerschaftsverein: Kassenwart

- Bürgerinitiative: Unterstützung durch Beratung

- Gemeinde: bei Organisation und Veranstaltungen helfen

- Trachtenverein: Leitung der Tanzgruppen und Vortänzer

- Programm für ausländische Studierende: Behördengänge, erste Schritte in Deutschland begleiten

- Seniorenclub: Beteiligung an Wanderungen und Chor
- Vorlesekreis des Familienzentrums: vorlesen bei unterschiedlichen Gastgebern

- Musikschule: Unterstützung der Events

- Musikgruppe, kleines Orchester: Orchesterleitung

- Radio- und Klangkunstmacher: Organisation von Hörabenden

- Chor: Konzertvorbereitung, Pressearbeit

- Chor: Leitung

- Musikverein: Schriftführung

- Spielmannszug: Organisation und Ausbildung des Nachwuchses

- Theatergruppe: Technik

- Freie Theatergruppe: Regie

- Tanzgruppe: Kostüme nähen

- Musicalprojekt für benachteiligte Jugendliche: Tanzgruppe betreuen 


\section{SOZIALER BEREICH}

Abbildung 3-B4: Anteile aktiver und engagierter Personen im sozialen Bereich

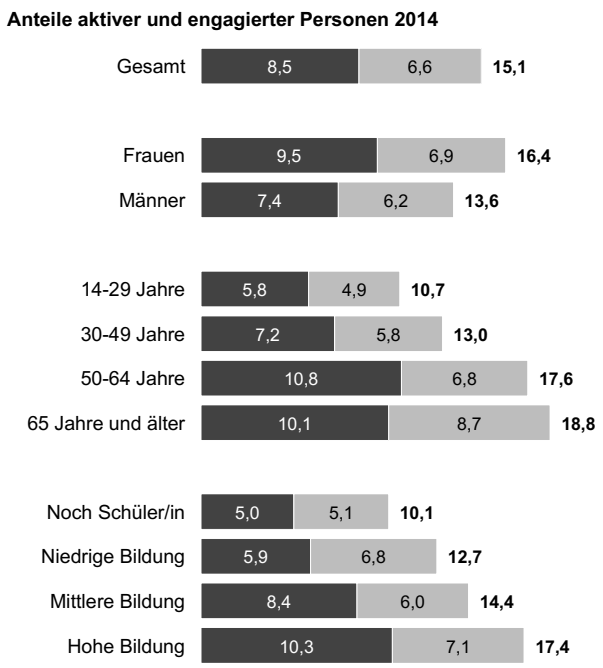$$
\text { Gesamt }
$$$$
8,5
$$$$
\text { Frauen }
$$

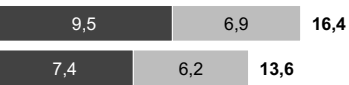

Männer

14-29 Jahre

30-49 Jahre

50-64 Jahre

65 Jahre und älter

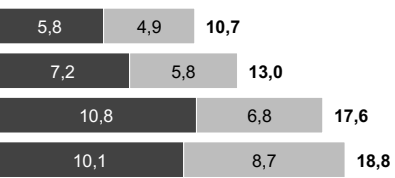

\section{Noch Schüler/in \\ Niedrige Bildung}

Mittlere Bildung

Hohe Bildung

\begin{tabular}{|c|c|c|c|}
\hline 5,0 & 5,1 & 10,1 & \\
\hline 5,9 & 6,8 & & 12,7 \\
\hline 8,4 & & 6,0 & 14,4 \\
\hline 10,3 & & & 7,1 \\
\hline
\end{tabular}

Im Zeitvergleich

\begin{tabular}{|c|c|c|c|}
\hline 1999 & 4,1 & 6,7 & 10,8 \\
\hline 2014 & & & 6,6 \\
\hline
\end{tabular}

Anteile Engagierter nach Leitungsfunktion im Zeitvergleich

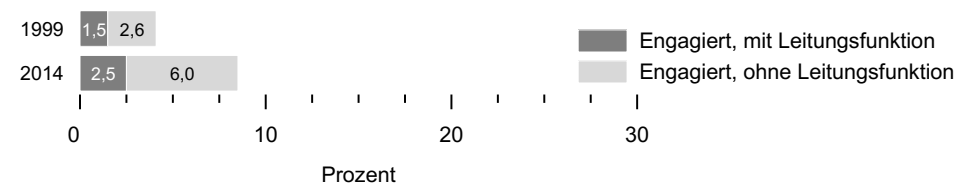

Quelle: FWS, gewichtet, eigene Berechnungen (DZA). Basis: Alle Befragten. FWS 1999 ( $n=14.922$ ), FWS 2014 $(n=28.689)$. 
Der soziale Bereich gehört auch zu den größeren gesellschaftlichen Bereichen, in denen sich Frauen und Männer in Deutschland engagieren oder aktiv mitmachen. Das Engagement ist recht vielfältig und umfasst sehr unterschiedliche Tätigkeiten sowie Zielgruppen - wie die offenen Tätigkeitsangaben zeigen. Gut die Hälfte der Personen, die in diesem Bereich aktiv sind, engagiert sich auch, das heißt, sie haben zusätzliche Aufgaben oder Arbeiten übernommen; dieser
Anteil ist im Vergleich zu anderen Bereichen relativ hoch. Sehr ausgeprägt sind die Unterschiede der Anteile nach Geschlecht und Alter: Im sozialen Bereich engagieren sich vor allem Ältere und Frauen. Wie auch in den anderen Bereichen ist im sozialen Bereich ein Bildungsunterschied zugunsten der Höhergebildeten zu beobachten. Auch ist hier insbesondere das Engagement im Vergleich zu anderen Bereichen zwischen 1999 und 2014 stark angestiegen.

\section{Beispiele für Tätigkeiten der Engagierten im sozialen Bereich}

- Förderverein Kindergarten: backe Kuchen und verkaufe bei Solidaritätsbasar

- Hort: Außenbereich neu gestalten, Verbesserung des Kindergartens

- Kindergruppe: Organisatorische Aufgaben

- Jungschar: Kinder betreuen

- Altenheim: Gespräche mit Alten führen

- Selbsthilfegruppe für Alkoholprobleme: als Zuhörer, Berater

- Katastrophenhilfe: schaufeln, suchen, Aufbauarbeit, Zuhörarbeit, psychologische Hilfestellung

- Krankenpflege: betreuen von älteren pflegebedürftigen Menschen

- Obdachlosenbetreuung: Abendbrot für Obdachlose bereitstellen

- Sozialausschuss im Ort: Planung und Organisation von gemeindlichen Aufgaben
- Selbsthilfegruppe Krebspatienten: Beratung

- Nachbarschaftshilfe/Selbsthilfegruppe: kümmert sich um Flüchtlinge/Eingliederung in die Gesellschaft

- Volkssolidarität: Blutspende betreuen

- Offene Behindertenarbeit: Freizeitgestaltung

- Hospizgruppe: Ausbildung von Hospizbegleitern

- Deutsche Rheuma-Liga: Patientenschulungen

- Kinderpatenschaft: betreue Kinder aus sozial schwachen Familien

- Arbeitsloseninitiative: Organisation von Ausflügen, Betriebsbesichtigungen

- Alpenverein: Kinderbetreuung

- Stadt: Grünanlagen pflegen, sauber halten

- Ärzte ohne Grenzen: Medizinische Betreuung der Bevölkerung im Ausland 


\section{KIRCHLICHER ODER RELIGIÖSER BEREICH}

Abbildung 3-B5: Anteile aktiver und engagierter Personen im kirchlichen oder religiösen Bereich

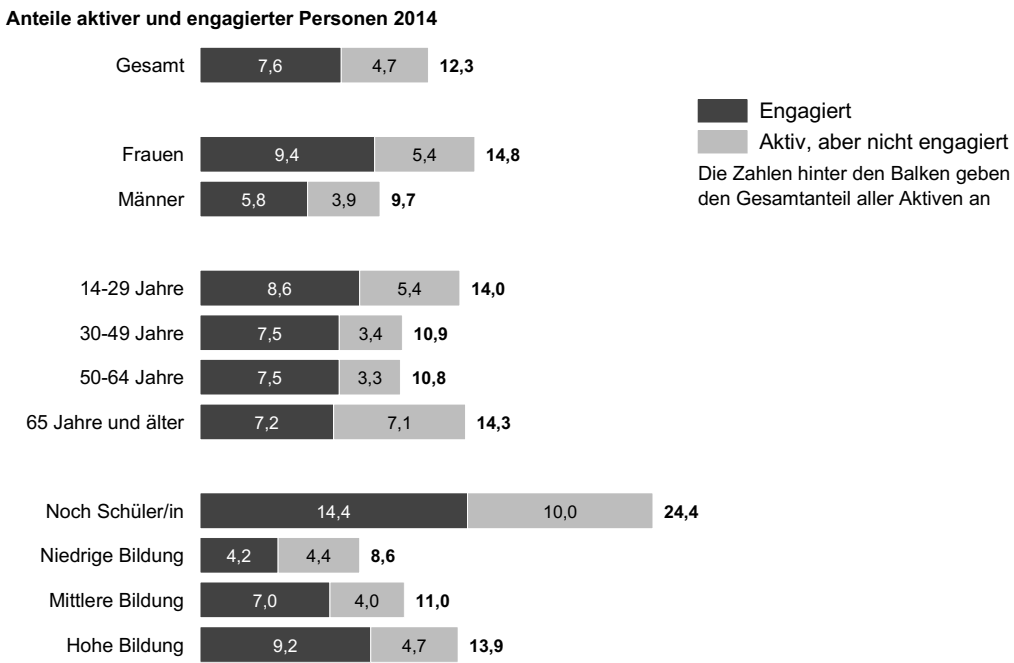

\begin{tabular}{l|c|c|c|}
1999 & 5,3 & 4,7 & \multicolumn{2}{|c|}{$\mathbf{1 0 , 0}$} \\
\hline 2014 & 7,6 & 4,7 & 12,3
\end{tabular}

Anteile Engagierter nach Leitungsfunktion im Zeitvergleich

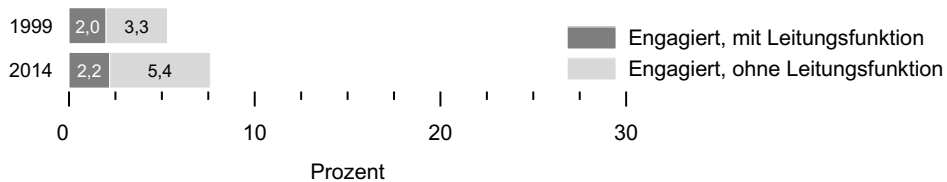

Quelle: FWS, gewichtet, eigene Berechnungen (DZA). Basis: Alle Befragten. FWS 1999 ( $n=14.922)$, FWS 2014 $(n=28.689)$. 
Das freiwillige Engagement im Kontext von Kirche und Religion gehört ebenfalls $\mathrm{zu}$ den großen Engagementbereichen in Deutschland. Auffällig ist der überdurchschnittlich hohe Anteil von Frauen. Altersdifferenzen gibt es nur vergleichsweise geringe: In allen hier ausgewiesenen Altersgruppen ist der Anteil der Aktiven und Engagierten recht hoch, lediglich bei den Jüngeren sowie bei den Älteren sind das Engagement beziehungsweise die Aktivität etwas stärker ausgeprägt. Ähnlich wie beispielsweise im Bereich Sport und Bewegung oder Kultur und $\mathrm{Mu}$ sik gibt es einen hohen Anteil von Schülerinnen und Schüler, die im Bereich Kirche und Religion aktiv oder engagiert sind. Trotz sinkender Mitgliederzahlen der Kirchen hat das Engagement in Kirche und Religion zwischen 1999 und 2014 in Deutschland zugenommen; im Vergleich zu anderen Engagementbereichen fällt der Anstieg jedoch eher moderat aus.

\section{Beispiele für Tätigkeiten der Engagierten im kirchlichen oder religiösen Bereich}

- Kirchengemeinde, Ortsausschuss: Organisation/Leitung

- Kirche: Chormitglied

- Verwaltungsrat, Pfarrgemeinderat: Teilnahme an Sitzungen, Ausschussvorsitzender, Organisation

- Evangelische Kirchgemeinde: Bauausschuss

- Katholische Kirchengemeinde: Begleitung kranker und hilfsbedürftiger Menschen

- Offene Kirche: austragen der Kirchenzeitung

- Kirche: Suppenküche, Obdachlosenhilfe

- Dom Förderverein: Erhalt des Doms

- Afrikanische Kirche: Essen vorbereiten

- Moschee: Spenden sammeln

- Quäker: Schatzmeister
- Jugendfreizeit: Organisation, Familiengottesdienste

- Konfirmanden: Kinder betreuen

- Notfallseelsorge: Sterbehilfe, Betreuung einsamer Menschen

- Beförderungsdienst der Kirche: Fahrdienst zum Gottesdienst für gehbehinderte Menschen

- Bahnhofsmission: Umsteigehilfe, Betreuung

- Bischöfliches Gericht: Vernehmungsrichter im Offizialat

- Redaktion Gemeindebrief: Organisation der Verteilung

- Mormonen: Musikbeauftragter

- Buddhistische Meditationsgruppe: Reiselehrer 


\section{FREIZEIT UND GESELLIGKEIT}

Abbildung 3-B6: Anteile aktiver und engagierter Personen im Bereich Freizeit und Geselligkeit

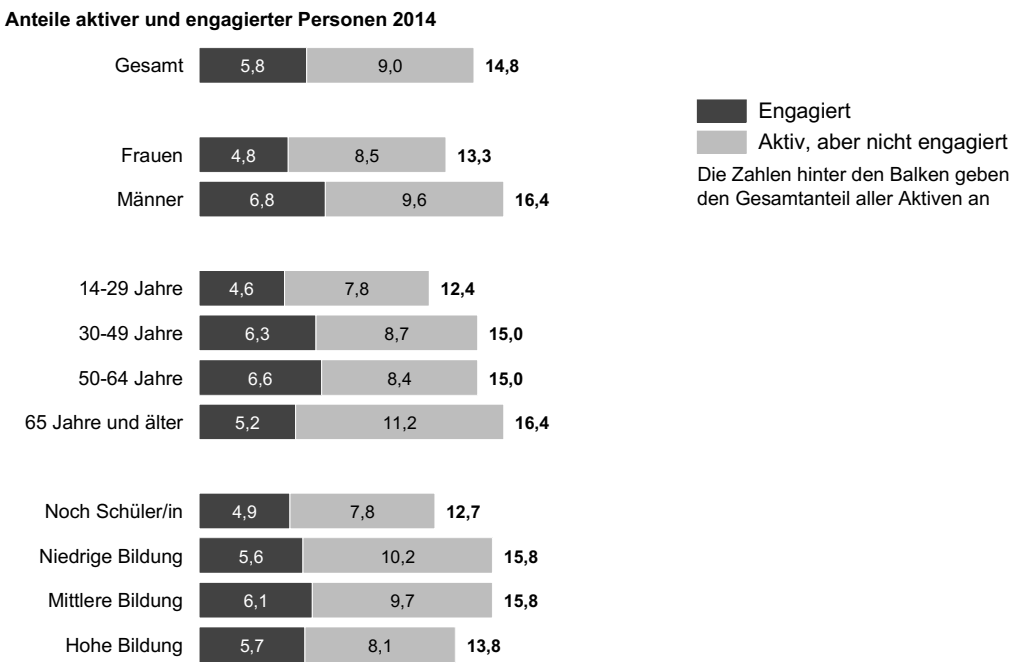

Im Zeitvergleich

\begin{tabular}{|c|c|c|c|}
\hline 1999 & 5,6 & & 9,5 \\
\hline 2014 & 5,8 & 9,0 & 14,8 \\
\hline
\end{tabular}

Anteile Engagierter nach Leitungsfunktion im Zeitvergleich

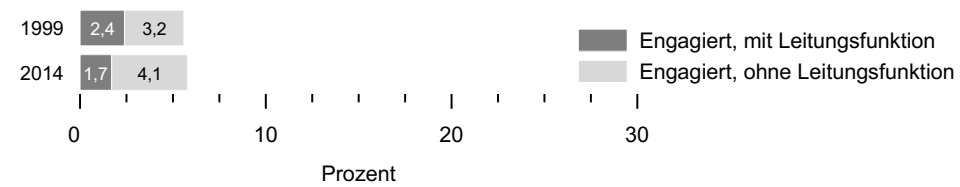

Quelle: FWS, gewichtet, eigene Berechnungen (DZA). Basis: Alle Befragten. FWS 1999 ( $n=14.922$ ), FWS 2014 ( $n=28.689)$. 
Im Bereich Freizeit und Geselligkeit sind auch vergleichsweise viele Personen aktiv und engagiert. Der Bereich sticht allerdings heraus, weil hier in den letzten fünfzehn Jahren der Anteil der Aktiven stark zurückgegangen ist und der Anteil der Engagierten nicht zugenommen hat, sondern zwischen 1999 und 2014 auf ähnlichem Niveau blieb. Während in vielen Bereichen die Jünge- ren unter den Engagierten dominieren, sind im Bereich Freizeit und Geselligkeit die Altersunterschiede gering; bei den Aktiven ist der Anteil der Älteren sogar etwas höher als der Anteil der Jüngeren. Es fällt auf, dass es bei den Engagierten kaum Bildungsunterschiede gibt, eine ähnliche Gleichverteilung nach Bildung gibt es nur noch im Bereich des Unfall- oder Rettungsdienstes.

\section{Beispiele für Tätigkeiten der Engagierten im Bereich Freizeit und Geselligkeit}

- Skatverein: Jahresfeiern, Versammlungen und Turniere organisieren

- Kleingartenverein: Wegedienste im Kleingarten

- Angelverein: Vereinsvorsitzender, der alles organisiert

- Wandergruppe: Tourenplanung

- Schützenverein: Vorbereitung und Nachbereitung des jährlichen Schützenfestes

- Kegelclub: Kassenwart

- Altersheim: vorlesen von Geschichten und musizieren

- Arbeiterwohlfahrt: Essensausgabe für ältere Menschen, Kartenspielen mit diesen und Betreuung

- Reservisten: Schriftführer

- Motorsportclub: Nachwuchsarbeit, führt Jugendliche an den Motorsport heran
- Singlestammtisch Ü50: Organisation von Ausflügen und Treffen

- Bürgerverband: Organisation eines internationalen Festes

- Nachbarschaftsverein: Kassenwart und Hilfe bei Festen

- Polnischer Kulturverein: Werbung neuer Mitglieder, Betreuung der Bibliothek

- Deutscher Landfrauenverein: Organisation von Dorffesten

- Karnevalsverein: Büttenreden, Jugendzeltlager betreuen

- Kulturstammtisch: Organisation von Veranstaltungen

- Imkerverein: Tag der offenen Tür organisieren

- Frauengruppe: Leitung, Organisation von Treffen 


\section{AUSSERSCHULISCHE JUGENDARBEIT ODER BILDUNGSARBEIT FÜR ERWACHSENE}

Abbildung 3-B7: Anteile aktiver und engagierter Personen im Bereich außerschulische Jugendarbeit oder Bildungsarbeit für Erwachsene

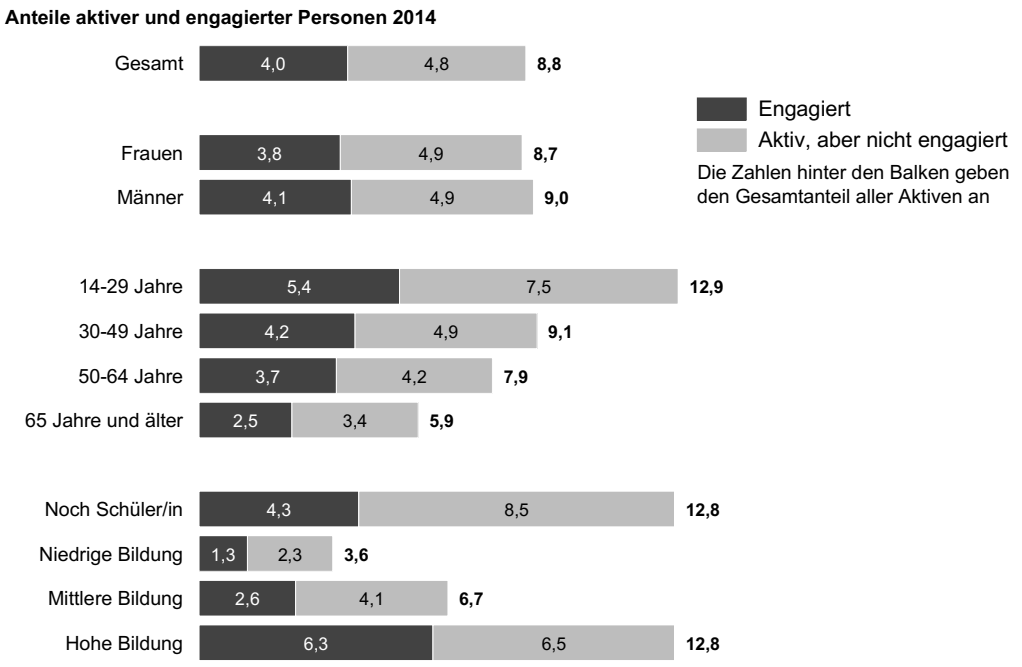

Im Zeitvergleich

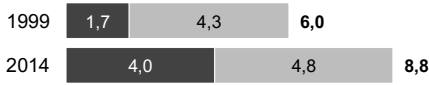

Anteile Engagierter nach Leitungsfunktion im Zeitvergleich

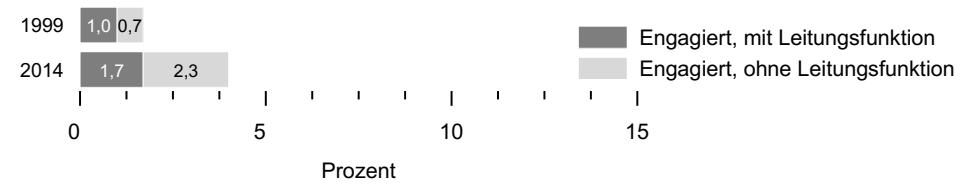

Quelle: FWS, gewichtet, eigene Berechnungen (DZA). Basis: Alle Befragten. FWS $1999(n=14.922)$, FWS 2014 $(n=28.689)$. 
Der Bereich Jugendarbeit und Bildungsarbeit für Erwachsene gehört zu den vergleichsweise kleinen Engagementbereichen. Er umfasst sowohl die Arbeit mit Jugendlichen (wie die Betreuung im Jugendtreff oder Zeltlager) als auch Bildungsangebote für Erwachsene (wie beispielsweise im Rahmen einer Arbeitsloseninitiative, einer Seniorenakademie oder der Volkshochschule). Der Anteil der Engagierten mit Leitungsfunktion in diesem Bereich ist vergleichsweise hoch. Im Bereich Jugendarbeit und Bildungsarbeit für Erwachsene ist der Anteil der jüngeren Menschen, die hier aktiv oder engagiert sind, höher als jener der älteren Menschen. Geschlechterun- terschiede gibt es im Gegensatz zu vielen anderen Bereichen kaum: Nahezu ein gleich großer Anteil von Frauen und Männern engagieren sich in der Jugendarbeit und Bildungsarbeit für Erwachsene beziehungsweise sind hier aktiv. Die Bildungsunterschiede sind in diesem Bereich ähnlich stark wie im Bereich Kultur und Musik oder im Bereich Schule und Kindergarten: Die Personen mit höherer Bildung sind im Vergleich zu denen mit niedriger Bildung besonders häufig engagiert. Der Anstieg des Engagements in diesem Bereich ist in den letzten fünfzehn Jahren im Vergleich mit anderen Bereichen besonders stark ausgefallen.

\section{Beispiele für Tätigkeiten der Engagierten im Bereich der außerschulischen Jugendarbeit oder der Bildungsarbeit für Erwachsene}

- Jugendrotkreuz: Begleitung im Zeltlager

- Verein für Geflüchtete: Vorstandsmitglied, Deutschkurse, politische und allgemeine Bildung

- Schule: Fortbildungen für Lehrer im Bereich Prävention sexueller Missbrauch

- Schule: Kriminalprävention, Vorträge halten

- Jugendtreff: Betreuung von Kindern

- Jugendgruppe: Gruppenleiter, Jugendsprecher

- Eine Welt- und Arbeitsloseninitiative: Vorstandsmitglied, Informationsarbeit

- Nachhilfe: Nachhilfe in Mathe, Englisch, Latein, Französisch

- Wissenschaftliche Gesellschaft: Vorträge halten

- Pfadfindergruppe der Gemeinde: Mitarbeit im Sanitätsdienst

- Fortbildungsveranstaltung für Pflegekräfte: Referentenauswahl, Schulungen, Moderation
- Volkshochschule: Sprachkurse geben

- Bürgerakademie: Organisation von Ausstellungen und Vorträgen

- Trainingslager: Betreuung von Kindern Spiel-Spaß-Sport

- Landfrauenarbeit: Vorsitzende

- Seniorenakademie: Vortragstätigkeit

- Kinder- und Jugendvereinigung der Stadt: Initiative- und Projektarbeit, Freizeitgestaltung

- Organisation für anonyme Hilfeleistungen: Jugendliche unterstützen, ein drogenfreies Leben zu führen

- Deutschkurs für Senioren: Sprachtraining

- Politische Bildung für Erwachsene: Referate, Versammlungen, Leitung

- Sozialeinrichtung: Sozialbetreuer für Jugendliche, die Sozialstunden ableisten müssen 


\section{POLITIK UND POLITISCHE INTERESSENVERTRETUNG}

Abbildung 3-B8: Anteile aktiver und engagierter Personen im Bereich Politik und politische Interessenvertretung

Anteile aktiver und engagierter Personen 2014

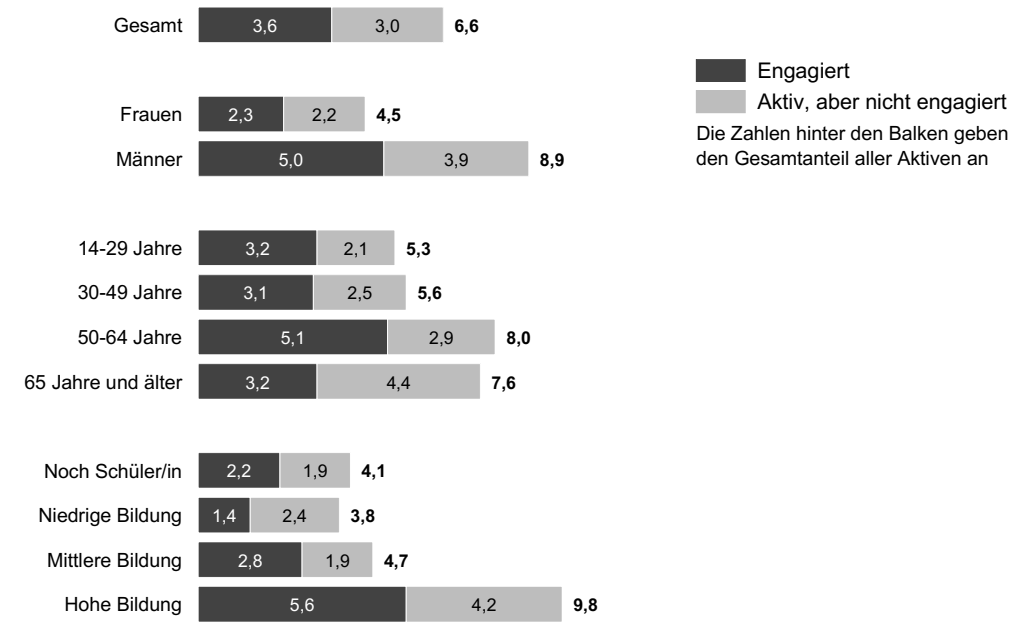

Im Zeitvergleich

\begin{tabular}{r|r|r|r}
1999 & \multicolumn{1}{|c|}{2,6} & 3,7 & $\mathbf{6 , 3}$ \\
\hline 2014 & 3,6 & 3,0 & $\mathbf{6 , 6}$
\end{tabular}

Anteile Engagierter nach Leitungsfunktion im Zeitvergleich

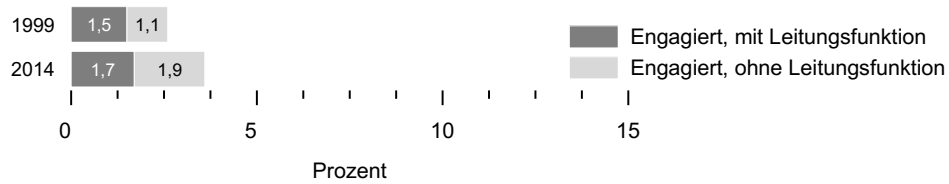

Quelle: FWS, gewichtet, eigene Berechnungen (DZA). Basis: Alle Befragten. FWS 1999 ( $n=14.922$ ), FWS 2014 $(n=28.689)$. 
Der vergleichsweise kleine Bereich Politik und politische Interessenvertretung ist einer der Bereiche, in dem mehr als die Hälfte der Personen, die hier aktiv sind, sich auch gleichzeitig engagieren, das heißt freiwillig und unentgeltlich Aufgaben übernehmen. Die politischen Tätigkeiten finden häufig in Parteien, auf Gemeindeebene oder in Bürgerinitiativen statt. Der Anteil der Leitungsfunktionen im Rahmen des Engagements ist vergleichsweise hoch. Es handelt sich um einen Bereich - ähnlich wie der Bereich der beruflichen Interessenvertretung - in dem wesentlich mehr Männer als Frauen und in einem besonderen Maße die Altersgruppe der 50- bis 64-Jährigen aktiv oder engagiert sind. Die Bildungsunterschiede fallen auch hier vergleichsweise groß aus: Personen mit hoher Bildung engagieren sich politisch wesentlich häufiger als Personen mit niedriger Bildung. Der Anstieg der politischen Aktivitäten und des Engagements in diesem Bereich fallen von 1999 bis 2014 im Vergleich $\mathrm{zu}$ anderen Bereichen gering aus.

\section{Beispiele für Tätigkeiten der Engagierten im Bereich Politik und politische Interessenvertretung}

- Partei: Vorstand

- Stadtrat bei der Stadt: Stadträtin, Mitglied

- Stadtverordnetenversammlung: Ausschuss Soziales, Bürgergespräche

- Kreistag im Landkreistag: Arbeiten im Ausschuss, Initiativen bewerten, Vorlagen bewerten

- Blog im Internet: Informationen über allgemeine Themen bereitstellen

- Partei: Stadtrat und Ausschüsse beraten und Abstimmung über Verwaltungsakte

- Partei: Rechnungsprüfer

- Lesegruppe: Verschiedene politische Themen diskutieren

- Bürgerinitiative: Unterschriften sammeln

- Gewerkschaft: Vertretung der Frauen, Gleichberechtigung und gegen sexuelle Gewalt
- Selbstorganisierte politische Bildung: Organisieren und Veranstaltungen durchführen

- Gemeinde: Wahlhelfer

- Initiative: Betreuung von Asylbewerbern, helfen und wertschätzen

- Jugendgemeinderat: Finanzminister

- Nachbarschaftsinitiative: recherchieren, Veröffentlichung einer Broschüre, Veranstaltungen

- Bürgerverein: Ausrichtung einer Wahlveranstaltung

- Kommunalstadtverordneter und Ortsbeirat: Reden halten, Anträge stellen, Vorschläge machen, um die Belange der Bevölkerung kümmern

- Frauenbund: Unterschriftensammlungen 


\section{UMWELT, NATURSCHUTZ ODER TIERSCHUTZ}

Abbildung 3-B9: Anteile aktiver und engagierter Personen im Bereich Umwelt, Naturschutz oder Tierschutz

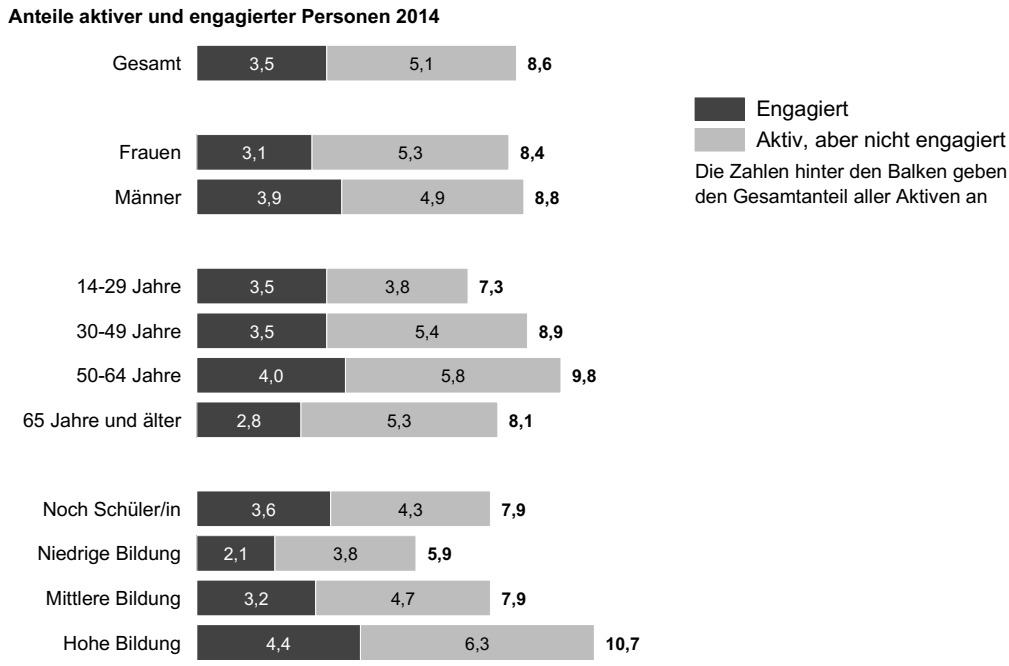

Im Zeitvergleich

\begin{tabular}{r|r|r|r}
1999 & 1,8 & \multicolumn{3}{|c|}{6,6} & $\mathbf{8 , 4}$ \\
2014 & 3,5 & 5,1 & $\mathbf{8 , 6}$
\end{tabular}

Anteile Engagierter nach Leitungsfunktion im Zeitvergleich

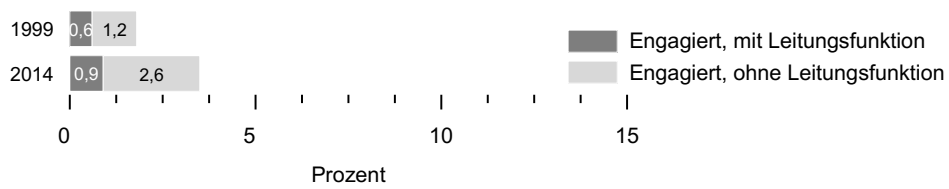

Quelle: FWS, gewichtet, eigene Berechnungen (DZA). Basis: Alle Befragten. FWS 1999 ( $n=14.922$ ), FWS 2014 ( $n=28.689$ ). 
Der Bereich Umwelt, Naturschutz oder Tierschutz ist ebenfalls ein vergleichsweise kleiner Bereich, in dem Menschen in Deutschland aktiv sind oder sich engagieren. Die Tätigkeiten der Engagierten finden häufig in Verbänden oder Vereinen statt, wobei das Engagement aber vergleichsweise selten mit einer Leitungsfunktion verbunden ist. Die Geschlechterdifferenzen sowie die Altersunterschiede fallen in diesem Bereich eher gering aus. Es sind geringfügig mehr
Männer als Frauen engagiert und das Engagement der jüngeren und der mittleren Altersgruppe ist lediglich etwas höher als das der Älteren. Bildungsunterschiede zugunsten der Höhergebildeten gibt es zwar, aber auch diese fallen im Vergleich zu anderen Bereichen eher gering aus. Die Zunahme des Engagements in den letzten fünfzehn Jahren fällt in diesem Bereich - zwar auf niedrigem Niveau - jedoch vergleichsweise hoch aus.

\section{Beispiele für Tätigkeiten der Engagierten im Bereich Umwelt, Naturschutz oder Tierschutz}

- Tierschutzverein: Organisation von Veranstaltungen

- Jagdgruppe: Revierarbeiten

- Gruppe für Tieradoptionen: Gutachter, Vermitteln und Nachkontrolle

- Tierschutzverein: Katzen einfangen, füttern und versorgen

- Rettungshundestaffel: Helfer Ausbildung

- Tierheim: zuständig für Grafik und Illustration

- Gnadenhof: Versorgung von Tieren, Stall sauber halten

- Naturfreunde: Müll sammeln in Parks und im Wald

- Umweltschutzorganisationen: (Online-)

Petitionen, Unterschriftensammlung
- Umweltgruppe: Veranstaltungen zur Information zu Natur- und Umweltschutz

- Angelverein: Umweltschutzaufgaben, Müllbeseitigung, Gewässererhaltung

- Vegan Body: Beratung über veganes Essen

- Bürgerinitiative gegen Windkraft: Organisation von Versammlungen, Demonstrationen

- Imkerverein: Organisation von Veranstaltungen

- Landschaftspflegeverband: beisitzende Tätigkeit

- Bürgerinitiative Lärmschutz: Sprecher der Gruppe

- Albverein: Ausschilderung von Wanderwegen 


\section{UNFALL- ODER RETTUNGSDIENST, FREIWILLIGE FEUERWEHR}

Abbildung 3-B10: Anteile aktiver und engagierter Personen im Bereich Unfall- oder Rettungsdienst, Freiwillige Feuerwehr

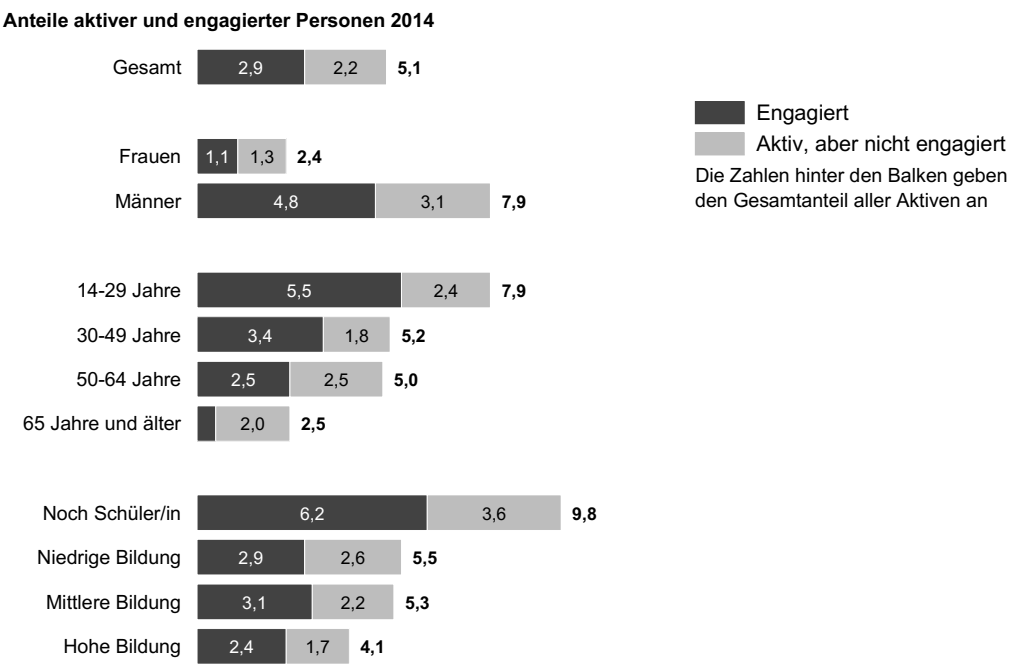

\begin{tabular}{|c|c|c|c|}
\hline 14-29 Jahre & \multicolumn{2}{|c|}{5,5} & 2,4 \\
\hline 30-49 Jahre & 3,4 & 1,8 & 5,2 \\
\hline 50-64 Jahre & 2,5 & 2,5 & 5,0 \\
\hline ahre und älter & 2,0 & & \\
\hline
\end{tabular}

\begin{tabular}{|c|c|c|c|c|}
\hline Noch Schüler/in & \multicolumn{2}{|c|}{6,2} & & 3,6 \\
\hline Niedrige Bildung & 2,9 & 2,6 & 5,5 & \\
\hline Mittlere Bildung & 3,1 & 2,2 & 5,3 & \\
\hline Hohe Bildung & 2,4 & & & \\
\hline
\end{tabular}

Im Zeitvergleich

\begin{tabular}{l|l|l|r|}
1999 & 2,5 & 2,3 & $\mathbf{4 , 8}$ \\
\hline 2014 & 2,9 & 2,2 & $\mathbf{5 , 1}$
\end{tabular}

Anteile Engagierter nach Leitungsfunktion im Zeitvergleich

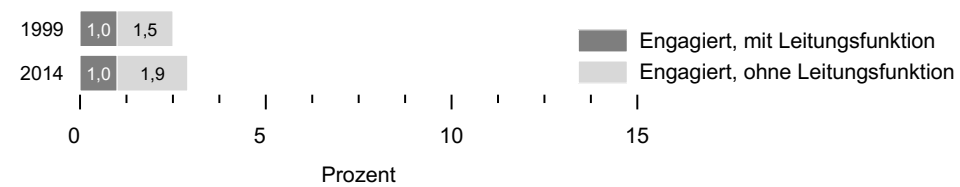

Quelle: FWS, gewichtet, eigene Berechnungen (DZA). Basis: Alle Befragten. FWS 1999 ( $n=14.922$ ), FWS 2014 $(n=28.689)$. 
Obgleich die freiwillig Engagierten im Unfalloder Rettungsdienst und bei der Feuerwehr einen Grundstock des Rettungswesens in Deutschland darstellen, ist dieser Engagementbereich vergleichsweise klein. In diesem Bereich sind die Gruppenunterschiede besonders deutlich: Der Frauenanteil ist sehr gering und die jüngeren Altersgruppen dominieren. In die freiwillige
Feuerwehr erfolgt ein Einstieg häufig bereits in jungen Jahren über die Jugendfeuerwehr, dies spiegelt sich auch in dem vergleichsweise hohen Anteil von Schülerinnen und Schülern in diesem Bereich wider. Der Anstieg des Anteils der freiwillig Engagierten in diesem Bereich ist in den letzten fünfzehn Jahren allerdings nur sehr gering ausgefallen.

\section{Beispiele für Tätigkeiten der Engagierten im Unfall- oder Rettungsdienst oder in der Freiwilligen Feuerwehr}

- Deutsche Lebensrettungs-Gesellschaft: Wasserrettung

- Feuerwehr: für Kindergärten neue Sandkisten, Schaukeln und Rutschen bauen

- Freiwillige Feuerwehr: Löscharbeiten

- Freiwillige Feuerwehr: retten, bergen, schützen

- Jugendfeuerwehr: Betreuer

- Deutsche Lebensrettungsgesellschaft: Schulungen
- Sanitätsdienst: Erste-Hilfe leisten und Kurse anleiten

- Deutsches Rotes Kreuz: Rettungssanitäter

- Technisches Hilfswerk: Leitende Position, Führung und Kommunikation

- Katastrophenschutz: Deich gegen Hochwasser schützen

- Erste Hilfe: Krankenpfleger

- Rotes Kreuz: Betreuung älterer Menschen 


\section{BERUFLICHE INTERESSENVERTRETUNG AUSSERHALB DES BETRIEBS}

Abbildung 3-B11: Anteile aktiver und engagierter Personen im Bereich berufliche Interessenvertretung außerhalb des Betriebs

Anteile aktiver und engagierter Personen 2014

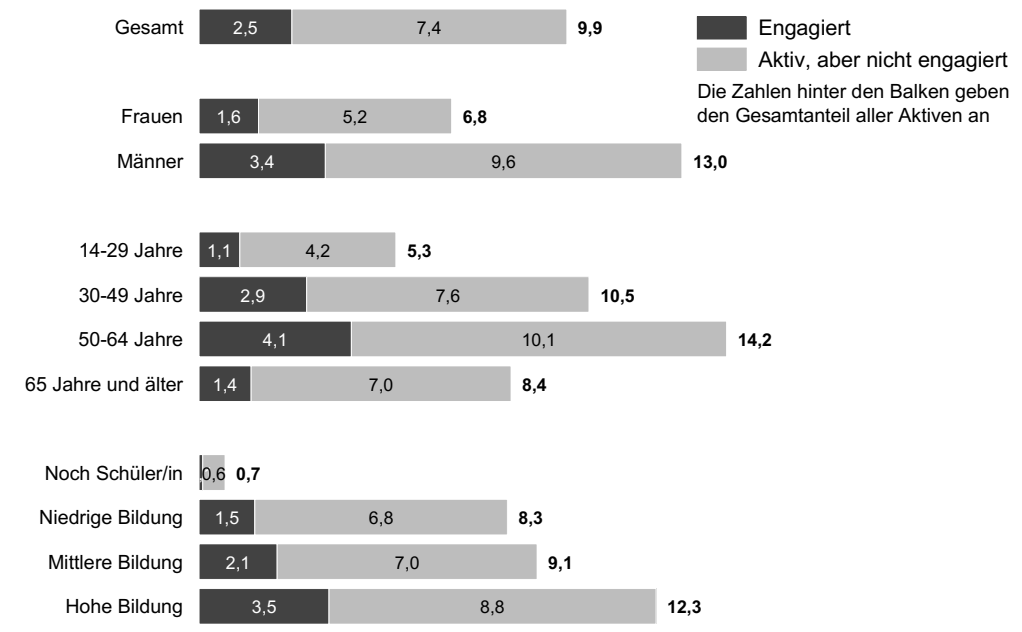

Im Zeitvergleich

\begin{tabular}{r|r|r|r}
1999 & 2,3 & 6,7 & 9,0 \\
\hline 2014 & 2,5 & 7,4 & 9,9
\end{tabular}

Anteile Engagierter nach Leitungsfunktion im Zeitvergleich

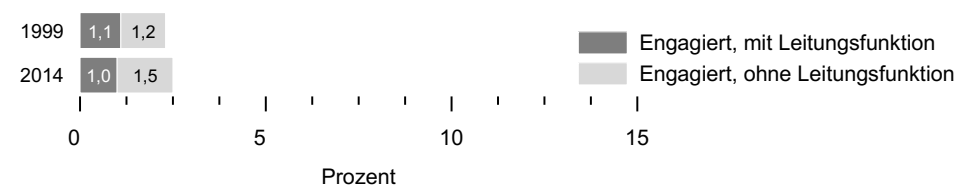

Quelle: FWS, gewichtet, eigene Berechnungen (DZA). Basis: Alle Befragten. FWS 1999 ( $n=14.922$ ), FWS 2014 $(n=28.689)$. 
Während insgesamt so gut wie jede zehnte Person in Deutschland im Rahmen einer beruflichen Interessenvertretung aktiv mitmacht, ist der Anteil der freiwillig Engagierten in diesem Bereich vergleichsweise gering. Ähnlich wie im Bereich Politik und politische Interessenvertretung sind hier wesentlich mehr Männer als Frauen aktiv oder engagiert. Die freiwilligen Tätigkeiten in diesem Bereich finden häufig im Rahmen der Arbeit der Gewerkschaften oder der Berufsver- bände statt. Demnach ist der Anteil der Aktiven und Engagierten auch insbesondere in den mittleren Altersgruppen (30- bis 49-Jährige und 50- bis 64-Jährige) - also bei jenen Personen, die dem Arbeitsmarkt vornehmlich zur Verfügung stehen - besonders hoch. Ins Auge springt, dass es einer der wenigen Bereiche ist, in dem sich die Anteile der Personen, die sich engagieren beziehungsweise sich aktiv beteiligen, in den letzten fünfzehn Jahren kaum verändert haben.

\section{Beispiele für Tätigkeiten der Engagierten im Bereich der beruflichen Interessenvertretung außer- halb des Betriebs}

- Interessenvertretung der Landwirte: Organisation von berufsspezifischen Fachvorträgen, Veranstaltungen

- Gewerkschaft: Unterstützung bei Streiks, Information Tarifpolitik

- Gewerkschaft: Vertrauensfrau, Beratung und Betreuung

- Hausarztkreis: Kassenwart

- Berufsverbände: Mithilfe bei der Erarbeitung einer Richtlinie

- Berufsverband Ärztegemeinschaft: Referentin für Fachthemen

- Philologenverband: Vertrauenslehrer

- Verein der Deutschen Ingenieure: Kassenprüfer im Bezirksverein
- Seniorenarbeitskreis Verdi: Seminare organisieren, Informationsstand organisieren

- Seniorengruppe der Gewerkschaft: Mithilfe bei Veranstaltungen, Platzwart, Schriftführer

- Frauennetzwerk von Selbstständigen: Forenleiterin, Moderation bei Veranstaltungen

- Industrie- und Handelskammer: Prüfer

- Handwerkskammer: Abnahme von Abschlussprüfungen

- Prüfungsausschuss für Facharbeiter und Meister: Prüfer, Vorsitzender

- Hochschule: Seminare für Berufseinsteiger

- Fleischer-Innung: Wurstprüfer

- Arbeitsamt: Existenzgründerberater

- Berufsgenossenschaft: Erste-Hilfe-Kurse 


\section{GESUNDHEITSBEREICH}

Abbildung 3-B12: Anteile aktiver und engagierter Personen im Gesundheitsbereich

Anteile aktiver und engagierter Personen 2014

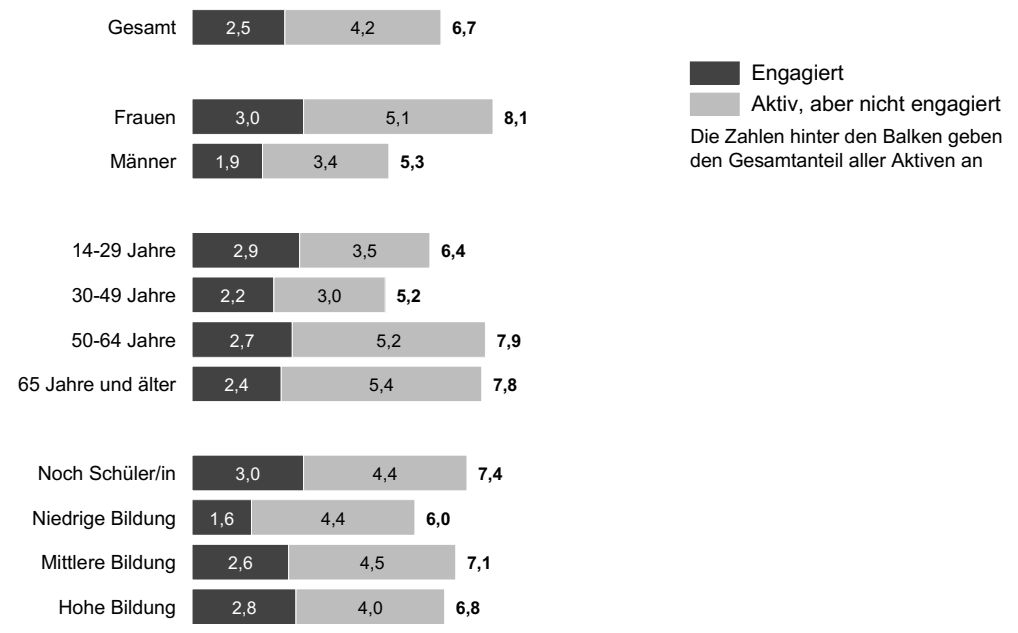

Im Zeitvergleich

\begin{tabular}{r|r|r|r|r}
1999 & 1,2 & 3,5 & \multicolumn{2}{|c}{$\mathbf{4 , 7}$} \\
\\
2014 & 2,5 & & 4,2 & $\mathbf{6 , 7}$
\end{tabular}

Anteile Engagierter nach Leitungsfunktion im Zeitvergleich

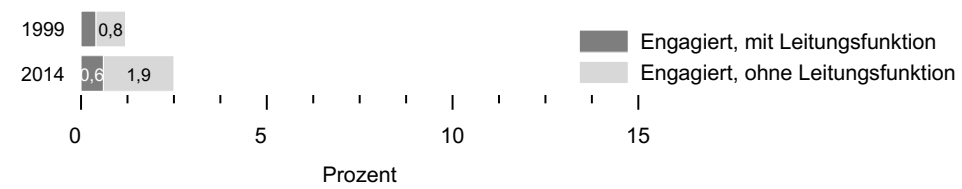

Quelle: FWS, gewichtet, eigene Berechnungen (DZA). Basis: Alle Befragten. FWS $1999(n=14.922)$, FWS 2014 $(n=28.689)$. 
Der Gesundheitsbereich gehört ebenfalls zu den eher kleinen Bereichen, in denen sich Frauen und Männer in Deutschland engagieren und aktiv sind. Der organisatorische Rahmen sowie die Zielgruppen des Engagements sind recht vielfältig: Die Engagierten sind sowohl in bestehenden Einrichtungen wie Krankenhäusern, Pflegeheimen oder in Hospizen als auch im Rahmen von Nachbarschaftshilfe oder Selbsthilfegruppen aktiv. Das Engagement kommt Kindern, älteren Menschen, Behinderten, kranken oder benachteiligten Menschen zugute. Der Gesundheitsbereich gehört zu den Bereichen, in denen Frauen im Vergleich zu Männern wesentlich häufiger aktiv sind und sich engagieren. Der Anteil von Leitungsfunktionen ist im Vergleich zu anderen Bereichen am geringsten. Altersunterschiede gibt es im Rahmen des Engagements kaum, die aktive Teilnahme im Gesundheitsbereich ist jedoch bei den älteren Menschen etwas weiter verbreitet als bei den Jüngeren. Auch die Bildungsunterschiede fallen sehr moderat aus. Der Gesundheitsbereich ist einer von den Bereichen, in denen das Engagement in den letzten fünfzehn Jahren vergleichsweise stark zugenommen hat.

\section{Beispiele für Tätigkeiten der Engagierten im Gesundheitsbereich}

- Seniorenbetreuung: Einkaufshilfe, spazieren gehen mit Patienten

- Krankenhaus: Besuche, kleinere Besorgungen, Gespräche mit Patienten

- Kinderfürsorge: Mütter beraten

- Private Nachbarschaftshilfe: Unterstützung von Demenzkranken, z. B. spazieren gehen, Gespräche führen

- Pflegeheim: Spaziergänge, vorlesen, kochen, helfen

- Kinderhospiz: Verpflegungsunterstützung

- Medinetz: Vermittlung von Menschen ohne Papiere an Ärzte, Sprechstunden

- Hilfe bei Blutspendenaktion: Aushilfstätigkeit

- Aidshilfe: Öffentlichkeitsarbeit

- Selbsthilfegruppe psychisch kranker Frauen: Koordination und Anleitung
- Betreuung einer Schule: Kinder unterrichten in Sachen Gesundheit

- Deutsches Rotes Kreuz: Erste-Hilfe-Ausbilder

- Interessenorganisation von Sozialberatern: Arbeitskreisleitung

- Sanitätsdienst: Versorgung Verletzter am Unfallort, schnelle Einsatzgruppe

- Sozialstation: Vorstandsarbeit

- Technischer Katastrophenschutz: Helfer in der Technikeinheit

- Arche: Essen verteilen an Obdachlose

- Verbandsgemeinde: Beratung von Behinderten

- Babyklappen: ärztliche Erstuntersuchung von abgegebenen Neugeborenen

- Ethikkomitee: Organisation, Gespräche führen, beraten 


\section{JUSTIZ ODER KRIMINALITÄTSPROBLEME}

Abbildung 3-B13: Anteile aktiver und engagierter Personen im Bereich Justiz oder Kriminalitätsprobleme Anteile aktiver und engagierter Personen 2014

\begin{tabular}{|c|c|c|c|c|c|}
\hline Gesamt & 0,7 & 0,5 & 1,2 & & \\
\hline Frauen & 0,6 & $0,3 \mathbf{0 ,}$ & & & \\
\hline Männer & 0,8 & 0 & & 1,5 & \\
\hline 14-29 Jahre & $, 20,3 \quad 0$ &, 5 & & & \\
\hline 30-49 Jahre & 0,6 & 0,4 & 0 & & \\
\hline 50-64 Jahre & & 1,5 & & 0,6 & 2,1 \\
\hline 65 Jahre und älter & 0,5 & 0,7 & 1,2 & & \\
\hline Noch Schüler/in & 0,2 & & & & \\
\hline Niedrige Bildung & $0,4 \quad 0,3$ & 0,7 & & & \\
\hline Mittlere Bildung & $0,4 \quad 0,4$ & 0,8 & & & \\
\hline Hohe Bildung & 1,2 & & 0,7 & & 1,9 \\
\hline
\end{tabular}

Im Zeitvergleich

\begin{tabular}{l|l|l|l}
1999 & 0,7 & 0,6 & $\mathbf{1 , 3}$ \\
\hline 2014 & 0,7 & 0,5 & $\mathbf{1 , 2}$
\end{tabular}

Anteile Engagierter nach Leitungsfunktion im Zeitvergleich

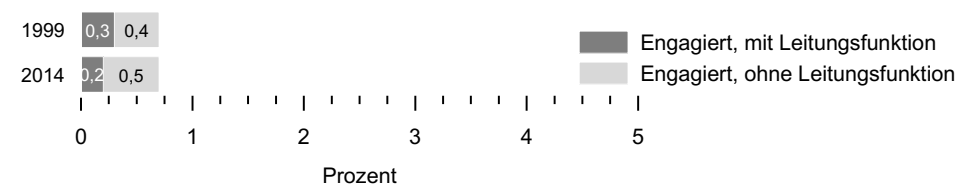

Quelle: FWS, gewichtet, eigene Berechnungen (DZA). Basis: Alle Befragten. FWS $1999(n=14.922)$, FWS 2014 $(n=28.689)$. 
Der Bereich Justiz und Kriminalitätsprobleme ist der kleinste hier vertretene Engagementbereich. Mehr als die Hälfte der in diesem Feld Aktiven ist gleichzeitig freiwillig engagiert. Die Engagierten sind häufig als Schöffin oder Schöffe, aber auch in der Straffälligenarbeit oder in der Opferberatung tätig. Der Anteil der aktiven und engagierten Männer ist hier größer als jener der Frauen. Darüber hinaus fällt auf, dass innerhalb der Altersgruppe der 50- bis 64-Jährigen das Engagement besonders hoch ist. Die Bildungsunterschiede fallen im Bereich Justiz und Kriminalität besonders stark aus: Es sind insbesondere Personen mit hoher Bildung, die aktiv oder engagiert sind. Das Engagement in diesem Bereich hat zwischen 1999 und 2014 nicht zugenommen, sondern es stagniert.

\section{Beispiele für Tätigkeiten der Engagierten im Bereich der Justiz und der Kriminalitätsprobleme}

- Jugendgericht: Schöffe

- Amtsgericht: Schöffe

- Kreisgericht: Ehrenrichterin

- Handelsrichter: Richter

- Gefängnis: Besuche von einem Gefangenen, Seelsorge auf der persönlichen Ebene

- Einrichtung für Kriminalitätsopfer: Schulung und Training für ehrenamtliche Opferberater

- Straffälligenarbeit: Vorstandsarbeit

- Opferberatung: Opfer von rechtsextremer Gewalt beraten

- Schiedsamt: Streitschlichtung

- Gremium gegen sexuellen Kindesmissbrauch: Vorträge halten, Netzwerke organisieren
- Jugendclub: organisiert Möglichkeiten zum Abarbeiten von Strafstunden für straffällige Jugendliche

- Besuchsdienste für Häftlinge: Wiedereingliederung in das Leben, Kontakte knüpfen

- Weißer Ring: Opferbetreuung

- Justizvollzugsanstalt: Anleitung der Ausbildungsküche

- Gefangenenbetreuung: Freizeitgestaltung, z. B. Organisation von Spielen

- Justiz Bewährungshelfer: Betreuung von Intensiv-Straftätern

- Verein: Wiedereingliederung, Forensiker

Open Access Dieses Kapitel wird unter der Creative Commons Namensnennung 4.0 International Lizenz (http://creativecommons.org/licenses/by/4.0/deed.de) veröffentlicht, welche die Nutzung, Vervielfältigung, Bearbeitung, Verbreitung und Wiedergabe in jeglichem Medium und Format erlaubt, sofern Sie den/die ursprünglichen Autor(en) und die Quelle ordnungsgemäß nennen, einen Link zur Creative Commons Lizenz beifügen und angeben, ob Änderungen vorgenommen wurden.

Die in diesem Kapitel enthaltenen Bilder und sonstiges Drittmaterial unterliegen ebenfalls der genannten Creative Commons Lizenz, sofern sich aus der Abbildungslegende nichts anderes ergibt. Sofern das betreffende Material nicht unter der genannten Creative Commons Lizenz steht und die betreffende Handlung nicht nach gesetzlichen Vorschriften erlaubt ist, ist für die oben aufgeführten Weiterverwendungen des Materials die Einwilligung des jeweiligen Rechteinhabers einzuholen. 